\title{
BNREL
}

\section{The Cost of Floating Offshore Wind Energy in California Between 2019 and 2032}

Philipp Beiter, Walt Musial, Patrick Duffy, Aubryn Cooperman, Matt Shields, Donna Heimiller, and Mike Optis

National Renewable Energy Laboratory

Cost and Performance Results Data

NREL is a national laboratory of the U.S. Department of Energy

Office of Energy Efficiency \& Renewable Energy

Operated by the Alliance for Sustainable Energy, LLC

This report is available at no cost from the National Renewable Energy Laboratory (NREL) at www.nrel.gov/publications.

\section{Technical Report}

NREL/TP-5000-77384

Revised November 2020 


\section{GNREL}

The Cost of Floating Offshore Wind Energy in California Between 2019 and 2032

Philipp Beiter, Walt Musial, Patrick Duffy, Aubryn Cooperman, Matt Shields, Donna Heimiller, and Mike Optis

National Renewable Energy Laboratory

This report is available from the Bureau of Ocean Energy Management by referencing OCS Study BOEM 2020-048.

\section{Suggested Citation}

Beiter, Philipp, Walter Musial, Patrick Duffy, Aubryn Cooperman, Matt Shields, Donna Heimiller, and Mike Optis. 2020. The Cost of Floating Offshore Wind Energy in California Between 2019 and 2032. Golden, CO: National Renewable Energy Laboratory. NREL/TP-5000-77384. https://www.nrel.gov/docs/fy21osti/77384.pdf.

NREL is a national laboratory of the U.S. Department of Energy Office of Energy Efficiency \& Renewable Energy Operated by the Alliance for Sustainable Energy, LLC

This report is available at no cost from the National Renewable Energy Laboratory (NREL) at www.nrel.gov/publications.

Contract No. DE-AC36-08GO28308
Technical Report

NREL/TP-5000-77384

Revised November 2020

National Renewable Energy Laboratory 15013 Denver West Parkway Golden, CO 80401

303-275-3000 • www.nrel.gov 


\section{NOTICE}

This work was authored by the National Renewable Energy Laboratory, operated by Alliance for Sustainable Energy, LLC, for the U.S. Department of Energy (DOE) under Contract No. DE-AC36-08GO28308. Funding provided by the U.S. Department of Interior (DOI), Bureau of Ocean Energy Management (BOEM), Pacific Region Office, under Agreement No IAG-19-2123. The views expressed herein do not necessarily represent the views of the DOE or the U.S. Government.

This report is available at no cost from the National Renewable Energy Laboratory (NREL) at www.nrel.gov/publications.

U.S. Department of Energy (DOE) reports produced after 1991 and a growing number of pre-1991 documents are available free via www.OSTI.gov.

Cover photo by Senu Sirnivas, NREL 27604

NREL prints on paper that contains recycled content. 


\section{Errata}

Table ES-2 and Table 18, which compare the cost and performance results of this study to the 2019-2020 Integrated Resource Planning, were updated in November 2020 following the report's original October 2020 publication. The capital expenditures (CapEx) in the column titled “2019-2020 IRP” were incorrectly denoted in \$2016 instead of \$2019 because of a transcription error from the modeling results. 


\section{Acknowledgments}

This study was funded by the U.S. Department of the Interior, Bureau of Ocean Energy Management (BOEM), Pacific Regional Office, through interagency agreement number M19PG00025 with the U.S. Department of Energy's National Renewable Energy Laboratory (NREL). The authors would like to thank the many people who contributed to the content of this report including BOEM staff: Sara Guiltinan, Necy Sumait, Doug Boren, Joan Barminski, Darryl Francois, Whitney Hauer, and Jean Thurston-Keller, as well as other bureau team members for their thoughtful reviews, comments, and suggestions. Peer reviewers for this report include Danielle Mills (American Wind Energy Association), Chris Potter (California Ocean Protection Council), Alla Weinstein (Castle Wind), Patrick Gilman (U.S. Department of Energy), Tyler Studds (EDPR), Michael Olsen (Equinor), Jeff Kehne (Magellan Wind), Paula Major (Mainstream Renewable Power), Maren Wenzel (Pacific Gas and Electric Company), Aaron Smith, Amisha Patel, Mathijs van den Burg, and Luisa Amorim (Principle Power, Inc.), Ruth Perry (Shell), Maurice Ahyow (Southern California Edison), Jennifer Mattox (California State Lands Commission Executive Office), Mikael Jacobson (Cierco), Liz Burdock, Brandon Burke (Business Network for Offshore Wind), Hans Petter Ovrevik, Fraser Brown, and Kamil Siddiqi (Aker Solutions).

We also want to thank the NREL contributors and reviewers, including Eric Lantz, Paul Veers and Brian Smith, as well as Tiffany Byrne, who coordinated the project schedule and deliverables. Technical editing was provided by Deanna Cook and Sheri Anstedt. Any errors or omissions are the sole responsibility of the authors.

In addition, the authors would especially like to recognize a working group committee between the California Public Utilities Commission (CPUC), BOEM, and NREL. These working group members also provided extensive support in the peer review of this document. Members of the working group include the co-authors of this report, the BOEM contributors listed earlier, as well as:

- Neil Raffan-CPUC

- Donald Brooks - CPUC

- David Miller-CPUC

- Karolina Maslanka-CPUC

- Ali Eshraghi-CPUC

- Cheryl Cox-CPUC

- Femi Sawyerr - Consultant to the CPUC (Energy and Environmental Economics, Inc.)

- Aaron Burdick - Consultant to the CPUC (Energy and Environmental Economics, Inc.)

- Gregory Brinkman-NREL

- Galen Maclaurin-NREL.

For an informal consultation meeting about the California transmission system as it relates to offshore wind, we thank Delphine Hou and Jeffrey Billinton from the California Independent System Operator. 


\section{List of Acronyms}

$\begin{array}{ll}\text { AEP } & \text { annual energy production } \\ \text { ATB } & \text { Annual Technology Baseline } \\ \text { BOEM } & \text { Bureau of Ocean Energy Management } \\ \text { CAISO } & \text { California Independent System Operator } \\ \text { CapEx } & \text { capital expenditures } \\ \text { COD } & \text { commercial operation date } \\ \text { CPUC } & \text { California Public Utilities Commission } \\ \text { GCF } & \text { gross capacity factor } \\ \text { GW } & \text { gigawatt } \\ \text { FLORIS } & \text { FLOw Redirection and Induction in Steady State } \\ \text { IEA } & \text { International Energy Agency } \\ \text { IRP } & \text { Integrated Resource Planning } \\ \text { km } & \text { kilometer } \\ \text { kV } & \text { kilovolt } \\ \text { kW } & \text { kilowatt } \\ \text { LCOE } & \text { levelized cost of energy } \\ \text { m } & \text { meter } \\ \text { m/s } & \text { meters per second } \\ \text { MW } & \text { megawatt } \\ \text { MWh } & \text { megawatt-hour } \\ \text { nm } & \text { nautical miles } \\ \text { NCF } & \text { net capacity factor } \\ \text { NOAA } & \text { National Oceanic and Atmospheric Administration } \\ \text { NREL } & \text { National Renewable Energy Laboratory } \\ \text { OCS } & \text { Outer Continental Shelf } \\ \text { O\&M } & \text { operation and maintenance } \\ \text { OpEx } & \text { operational expenditures } \\ \text { ORBIT } & \text { Offshore Renewable Balance-of-system Installation Tool } \\ \text { ORCA } & \text { Offshore Regional Cost Analyzer } \\ \text { SB } & \text { Senate Bill } \\ \text { W } & \text { Watts } \\ & \end{array}$




\section{Executive Summary}

California's energy planning is centered around meeting the emissions reduction and renewable energy requirements of Senate Bill $350^{1}$ by 2030 . However, state power system planning is expected to eventually address California's requirement to achieve $100 \%$ of total retail electricity sales from renewable energy and zero-carbon resources by 2045 , as mandated by Senate Bill $100 .^{2}$ To comply with these directives, California needs to investigate the further development of energy efficiency, storage, and a diverse range of renewable energy, zero-carbon emission, and transmission resources, including offshore wind. Wind resources off the coast of California have the potential to generate a significant portion of the state's electric energy as it moves toward a zero-carbon economy and can help diversify its energy mix. Floating offshore wind technology, which is suitable for the deep waters along the California coast, is currently in a precommercial phase, with approximately 84 megawatts (MW) installed worldwide at the end of 2019. Globally there are over 7,000 MW in planning and permitting phases of development, with the first commercial-scale projects expected to be operational in 2024 (Musial et al. 2020b).

This study provides site-specific cost and performance data for floating offshore wind to inform California's long-term energy planning. The identification of new resources to meet California's policy goals at least cost is part of the Integrated Resource Planning (IRP) process, which is coordinated by the California Public Utilities Commission (CPUC). In 2019-2020 IRP modeling, offshore wind was included for the first time as a candidate resource in some sensitivity cases (CPUC 2019a). The data and information presented in this report can be used to update offshore wind inputs in future IRP cycles.

The authors conducted a geospatial cost analysis over portions of the offshore wind resource area of California. The analyzed spatial domain includes sites with a mean wind speed of at least 7 meters per second and water depths between 40 meters $(\mathrm{m})$ and 1,300 $\mathrm{m}$. Costs and energy production vary across this analysis domain. We calculated these parameters on a grid layout with over 750 sites, with each site representing a 1,000-MW commercial offshore wind power plant. Levelized cost of energy (LCOE) was calculated at each site over the analysis domain. The resulting variation in LCOE across the analysis domain is illustrated through heat maps in this report. Five study areas were selected within the analysis domain where more detailed cost analysis was conducted and cost parameters, ${ }^{3}$ such as annual energy production, capital cost expenditures (CapEx), operational cost expenditures (OpEx), and net capacity factors are reported. These five study areas include (Figure ES-1):

- Morro Bay (Call Area)

- Diablo Canyon (Call Area)

- Humboldt (Call Area)

- Cape Mendocino

- Del Norte.

\footnotetext{
${ }^{1}$ Senate Bill 350, The Clean Energy and Pollution Reduction Act of 2015 (http://leginfo.legislature.ca.gov/faces/billTextClient.xhtml?bill_id=201520160SB350).

${ }^{2}$ Senate Bill 100 is known as the 100 Percent Clean Energy Act of 2018. For more information, see: https://leginfo.legislature.ca.gov/faces/billTextClient.xhtml?bill id=201720180SB100.

${ }^{3}$ All cost estimates in this report are in 2019 dollars, unless indicated otherwise.
} 
The first three study areas are Bureau of Ocean Energy Management (BOEM) Call Areas, ${ }^{4}$ and the latter two are additional study areas identified by Collier et al. (2019). These five study areas are geographically dispersed along the central and northern coast on the Outer Continental Shelf off California where commercial-scale offshore wind projects are under consideration. We selected the study areas for the purpose of estimating costs and performance only. This study is not a stakeholder engagement or a marine spatial planning effort to create wind energy areas under BOEM's leasing process, and the study areas have not been vetted by ocean user communities as part of this analysis. Environmental resources or related laws are not considered in this analysis. We also acknowledge that the degree of stakeholder engagement can influence these costs. In this assessment, the associated development costs are fixed.

Cost modeling is based on an assessment of current offshore wind technology and technology projections developed at the National Renewable Energy Laboratory (NREL). We assume that the accompanying port and grid infrastructure would be ready at the time of commercial deployment of the modeled projects. We estimate LCOE between 2019 and 2032 at commercial project scale. ${ }^{5}$ The year 2019 was chosen as the baseline for this analysis so that inferences can be made from current data and performance characteristics of floating offshore wind systems. Key modeling assumptions include turbine upsizing from $8 \mathrm{MW}$ (2019) to $15 \mathrm{MW}$ (2032), and the use of a semisubmersible floating substructure. This substructure type is currently the most common among all the planned and deployed projects in the floating wind industry (Musial et al. 2020b). Modeling of installation and operations costs assume that each site would be served by the closest port among a set of five ports identified as being suitable in principle for assembly of floating offshore wind systems (Porter and Phillips 2016). Humboldt Bay is modeled as the construction and operations port for Humboldt, Del Norte, and Cape Mendocino, with Port Hueneme serving Morro Bay and Diablo Canyon. Electrical system costs include an export cable that follows the shortest straight-line distance from the study area to shore and a uniform assumption for the onshore spur line length of 5 kilometers. Any other interconnection costs (e.g., for a land-based substation or bulk transmission system upgrades) are not part of this study, which is a limitation of this analysis. These additional interconnection costs might need to be supplemented to properly model offshore wind in capacity expansion models, such as the IRP capacity expansion model, RESOLVE.

The costs of grid connection and bulk power upgrades are also a major source of uncertainty for offshore wind development in California. Through a review of publicly available transmission data and stakeholder consultation, we identified significant deficiencies in the bulk transmission system's ability to carry gigawatt-scale offshore wind power to load centers at some study areas, especially on the northern coast. While not a focus of this study, we concluded that major bulk transmission system expansion and substation upgrades will likely be necessary, depending on the location, to interconnect commercial-scale offshore wind with the California Independent System Operator (CAISO) market. The cost allocation for these investments to accommodate offshore wind has not yet been decided among developers, state policymakers, utilities, or private investors. Further, assessing the costs of major bulk transmission expansion is

\footnotetext{
${ }^{4}$ Three Call Areas offshore California were identified by BOEM in 2018 as potentially suitable for offshore wind energy leasing: Humboldt Call Area, Morro Bay Call Area, and Diablo Canyon Call Area. These three Call Areas were under consideration for offshore wind energy as of the publication date of this report.

${ }^{5}$ These years are intended to represent the commercial operation date of a floating offshore wind farm.
} 
challenging because of a lack of data and the need to accurately capture development and permitting timelines and their impact on project expenses. As such, the cost of bulk power system upgrades is not included in the LCOE or CapEx values reported in this study. We recommend future research to determine the costs associated with offshore wind interconnection and transmission expansion.

Continued technology advancement, deployment, and economies of size (as it relates to the plant and manufacturing) of the floating offshore wind industry are assumed, which contribute significantly to the modeled LCOE reductions. Table ES-1 shows the turbine technology assumptions for the expected available commercial technology in four reference years: 2019, 2022, 2027, and 2032 (all years represent the commercial operation date [COD]). ${ }^{6}$

Table ES-1. Technology Assumptions

\begin{tabular}{|c|c|c|c|c|c|}
\hline & \multirow[t]{2}{*}{ Unit } & \multicolumn{4}{|c|}{ COD Year } \\
\hline & & 2019 & 2022 & 2027 & 2032 \\
\hline Turbine Rated Power & MW & 8 & 10 & 12 & 15 \\
\hline Turbine Rotor Diameter & $\mathrm{m}$ & 175 & 196 & 215 & 240 \\
\hline Turbine Hub Height & $\mathrm{m}$ & 118 & 128 & 138 & 150 \\
\hline Turbine Specific Power & watts $/ \mathrm{m}^{2}$ & 332 & 332 & 332 & 332 \\
\hline Blade Waterline Clearance & $\mathrm{m}$ & 30 & 30 & 30 & 30 \\
\hline Substructure Type & Name & \multicolumn{4}{|c|}{ Semisubmersible } \\
\hline Minimum Water Depth & $\mathrm{m}$ & \multicolumn{4}{|c|}{40} \\
\hline Maximum Water Depth & $\mathrm{m}$ & \multicolumn{4}{|c|}{1,300} \\
\hline Wind Plant Rating & MW & \multicolumn{4}{|c|}{1,000} \\
\hline Turbine Spacing & $\begin{array}{l}\text { rotor diameter } \\
\text { (D) }\end{array}$ & \multicolumn{4}{|c|}{ 7D by 7D } \\
\hline
\end{tabular}

We estimated turbine growth from literature research and by tracking industry progress over time. The turbine technology specified is assumed available to global markets 2 years prior to the COD reference year, at financial close of the offshore wind project. For instance, we assume 15MW turbines are available by 2030 for a project that is commissioned in 2032 . We consider this turbine technology trajectory achievable both with respect to the scale of the rotor diameters (capture area) and the nameplate capacities. Industry consultation suggests that this trajectory might be a conservative assumption.

We used industry cost data for pilot-scale projects operating in 2019 to model the costs of an upscaled 1,000-MW facility using a conceptual NREL-designed 8-MW wind turbine. ${ }^{7}$ The 1,300-m maximum water depth was selected as an outer boundary, which was increased from

\footnotetext{
${ }^{6} \mathrm{COD}$ is the year commercial operation for the offshore wind power plant commences.

${ }^{7} \mathrm{~A}$ wind power plant size of 1,000 MW was assumed to represent a commercial-scale project. Note that although some U.S. projects are planned for smaller project sizes (e.g., U.S. Wind [248 MW] and Skipjack [120 MW]), several recent projects planned for commercial operation in the mid-2020s exceed a project size of $600 \mathrm{MW}$ (e.g., Vineyard Wind [800 MW] and Ocean Wind [1,100 MW]) (Musial et al. 2020). For early floating projects in 2019 and 2022, 1000-MW may overestimate plant size but in 2030, this plant size is considered appropriate. Note, we found the CapEx of a 600-MW wind farm to be approximately $\%$ higher than a 1,000-MW wind plant.
} 
$1,000 \mathrm{~m}$ in previous studies. This water depth does not represent a hard technology limit but provides a useful boundary for offshore wind cost and resource studies (Optis et al. 2020).

For a commercial-scale floating offshore wind project in the analysis domain with a COD in 2019 , the estimated LCOE ranges from $\$ 83 /$ megawatt-hour (MWh) to $\$ 180 / \mathrm{MWh}$ (shown in Figure ES-1). ${ }^{8}$ Among the five study areas of specific interest, we estimate the lowest LCOE for Cape Mendocino (\$95/MWh), followed by Del Norte (\$99/MWh), Humboldt (\$101/MWh), Morro Bay (\$112/MWh), and Diablo Canyon (\$114/MWh). The variation in LCOE among California study sites can be attributed primarily to differences in average wind speed (i.e., the net capacity factor) and the distance from site centroid to the nearest point from shore (i.e., the export cable costs). Additional cost differences are a result of distances to port facilities and variations in water depth. The northern study areas are among the sites with the lowest LCOE across the entire cost analysis domain offshore California. However, this study does not include costs associated with upgrades to bulk transmission, which might be higher in Northern California. Other locations within the California analysis domain with relatively low LCOE are located north of the San Francisco Bay and stretching toward the Cape Mendocino study area and north of the Channel Islands.
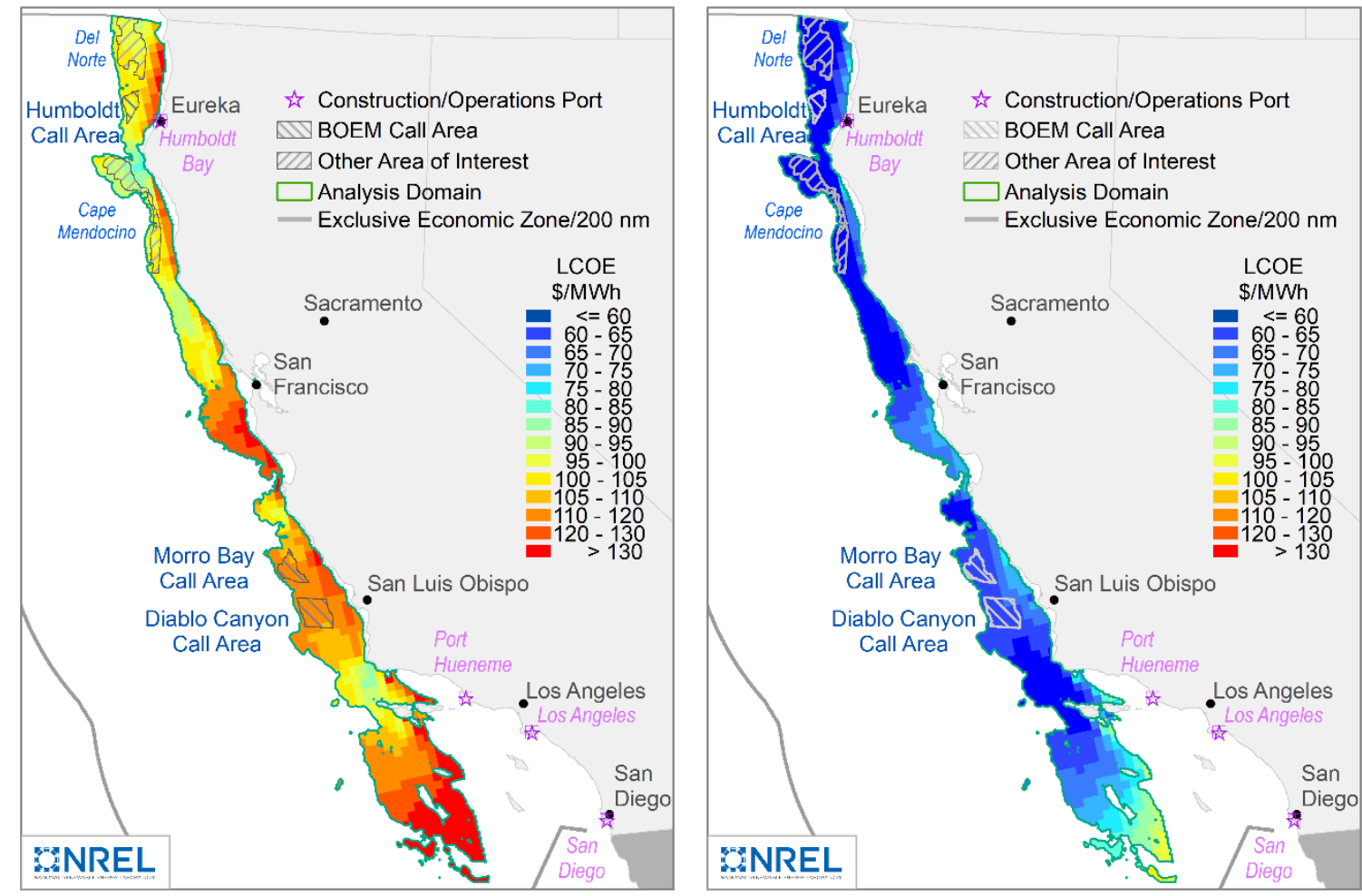

Figure ES-1. LCOE estimates (mid-case CapEx scenario) for the analysis domain offshore California estimated for a 2019 COD (left) and 2032 COD (right)

\footnotetext{
${ }^{8}$ All cost estimates in this report are denoted in 2019 dollars, unless indicated otherwise. The cost estimates presented in the Executive Summary are all for the CapEx mid-case scenario (see further details in the following sections).
} 
Between 2019 and 2032 (COD), the LCOE of the five study areas is estimated to decline by 44\% on average, reaching levels of \$53-\$64/MWh by 2032) (Figure ES-2).

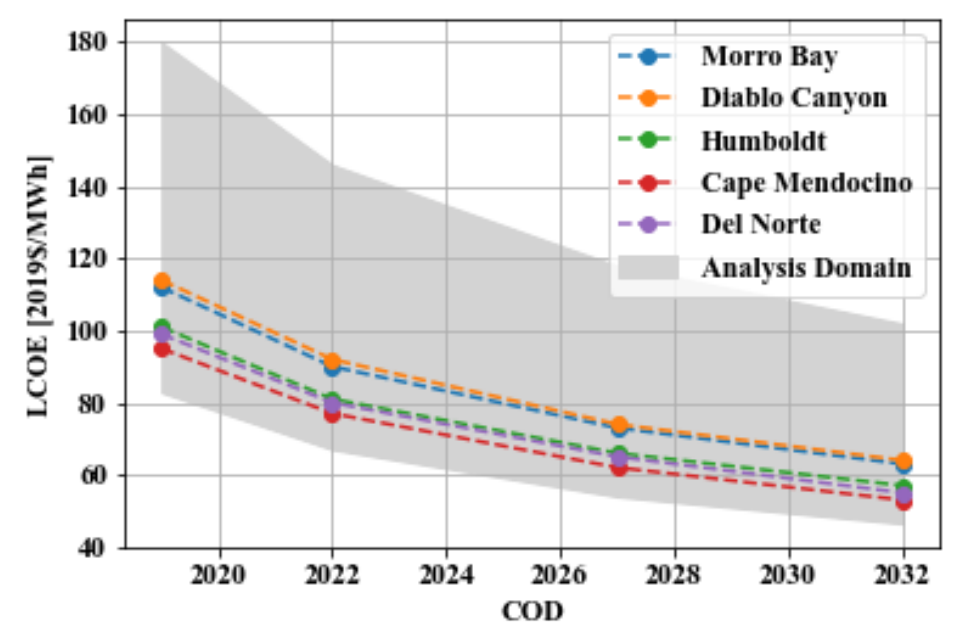

Figure ES-2. Estimated LCOE trajectory between 2019 and 2032 (COD)

Note: Light grey band represents the range between the minimum and maximum values across the entire analysis domain.

This cost trend is induced by the combined impact from turbine upsizing and learning effects in the supply chain and manufacturing, as well as technology innovation. Turbine upsizing results in lower per-unit costs (in terms of $\$ /$ kilowatt $[\mathrm{kW}]$ or $\$ / \mathrm{kW}$-year $[\mathrm{yr}]$ ), as fewer turbines are installed and maintained for a given power production. Learning effects in the supply chain allow for more efficient production and economies of scale (i.e., less capital input for a given manufacturing output). Technology innovation can reduce material use, improve performance, optimize (logistical) strategies, and lead to operational synergies. The wind power plant rating is held constant at 1,000 MW over the entire period from 2019 through 2032. To quantify the impact on CapEx from anticipated learning and improved efficiencies in the supply chain between 2019-2032, we estimate a learning rate of $7.5 \%$ from hindcast fixed-bottom offshore wind project data. This rate captures the decrease in CapEx for every doubling of globally installed floating capacity within this period. We assume a globally installed floating capacity of $8 \mathrm{GW}$ by 2032 to represent a CapEx mid deployment scenario. A low and a high deployment scenario are associated with global floating deployments of $4 \mathrm{GW}$ (low deployment scenario) and 13 GW (high deployment scenario), respectively. We included these CapEx scenarios to represent the uncertainty of future floating offshore wind deployment (and the associated cost reductions) and because three CapEx scenarios are required as inputs to the RESOLVE model.

This analysis builds on an earlier study assessing the costs of floating offshore wind in California (Musial et al. 2016a). In the 2019-2020 IRP process, floating cost estimates from a separate analysis were used, NREL's 2018 Annual Technology Baseline (NREL 2019a). These two earlier assessments reflect (at least somewhat) different sets of assumptions and modeling approaches than implemented in this study. Table ES-2 provides a comparison between the values used to represent offshore wind in the 2019-2020 IRP process and the values found in this 
study. We estimate the LCOE to be lower in this study because of technological and commercial advances of the offshore wind industry realized over the past few years. In year 2030, the estimated CapEx in this study is approximately 20\% lower on average across the study areas than the estimates used in the 2019-2020 IRP process. This is in part because of a higher turbine rating and larger plant size assumed in this study. With the exception of Morro Bay, net capacity factors are higher because the current study uses a state-of-the-art wind resource data set covering a 20-year period off the coast of California (Optis et al. 2020), which finds higher wind speeds than in previous resource assessments.

Table ES-2. Comparison Between the 2019-2020 IRP and NREL Cost and Performance Values

\begin{tabular}{|c|c|c|c|c|c|c|c|c|}
\hline & \multicolumn{2}{|c|}{$\begin{array}{l}\text { Net Capacity Factor } \\
(\%)\end{array}$} & \multicolumn{2}{|c|}{ CapEx (\$/kW) } & \multicolumn{2}{|c|}{ OpEx (\$/kW-yr) } & \multicolumn{2}{|c|}{ LCOE (\$/MWh) } \\
\hline & $\begin{array}{l}2019- \\
2020 \text { IRP }\end{array}$ & $\begin{array}{l}\text { NREL } \\
2020\end{array}$ & $\begin{array}{l}2019- \\
2020 \text { IRP }\end{array}$ & $\begin{array}{l}\text { NREL } \\
2020\end{array}$ & $\begin{array}{l}2019- \\
2020 \text { IRP }\end{array}$ & $\begin{array}{l}\text { NREL } \\
2020\end{array}$ & $\begin{array}{l}2019- \\
2020 \text { IRP }\end{array}$ & $\begin{array}{l}\text { NREL } \\
2020\end{array}$ \\
\hline COD & \multicolumn{8}{|c|}{2030} \\
\hline Morro Bay & 55 & 49 & 3,791 & 3,139 & 71 & 64 & 76 & 67 \\
\hline $\begin{array}{l}\text { Diablo } \\
\text { Canyon }\end{array}$ & 46 & 48 & 4,042 & 3,128 & 71 & 63 & 96 & 68 \\
\hline Humboldt & 52 & 53 & 3,791 & 3,064 & 71 & 62 & 81 & 61 \\
\hline $\begin{array}{l}\text { Cape } \\
\text { Mendocino }\end{array}$ & 53 & 55 & 3,791 & 2,976 & 71 & 64 & 79 & 57 \\
\hline Del Norte & 52 & 55 & 3,791 & 3,076 & 71 & 64 & 81 & 59 \\
\hline
\end{tabular}

Beyond general uncertainties associated with the availability of cost data, the timing of expected innovation (and associated cost reduction) trajectories, and macroeconomic factors (e.g., commodity prices, and exchange rates), there are some important caveats specific to this assessment of floating offshore wind costs in California:

- Bulk transmission expansion and land-based substation upgrades (and their costs) are not considered.

- We model a commercial-scale, 1,000-MW floating offshore wind power plant for projects with a COD between 2019 and 2032. Today, there are only pilot-scale floating offshore wind projects with up to $30 \mathrm{MW}$ of capacity (Musial et al. 2020b). Continued turbine and plant upscaling, as well as an expansion of the supply chain, are needed to obtain the costs modeled in this analysis.

- Local supply and logistical solutions along the Pacific Coast (e.g., port upgrades and vessel capabilities) are assumed to be available. This may include importing components from Asia where feasible. The costs associated with incentivizing and developing a local supply chain are not reflected in the LCOE estimated in this study. 
- This analysis is based on semisubmersible substructures, but other floating offshore wind substructure technology types could be applicable over the analyzed time frame.

As more data become available for the evolving global and U.S. floating wind industries, costs will need to be continuously refined. Further, a comprehensive evaluation of the competitiveness of offshore wind as a new electricity-generating resource in California will need to consider the costs and the complementarity of the technology's production profiles with the California Independent System Operator's future power system. 


\section{Table of Contents}

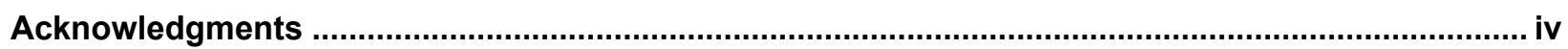

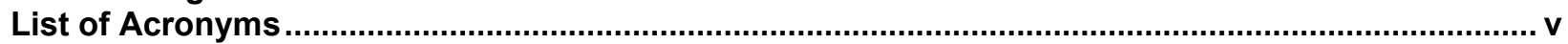

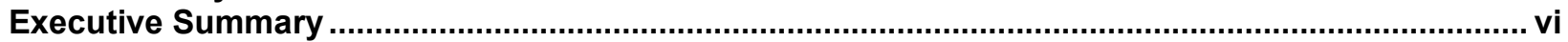

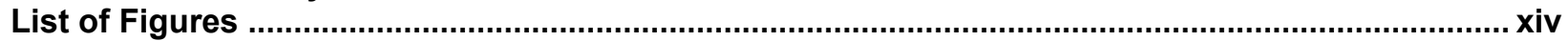

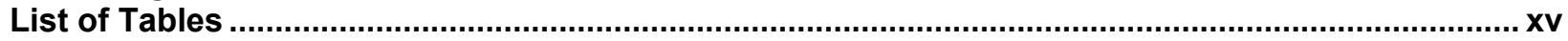

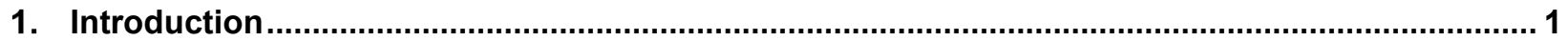

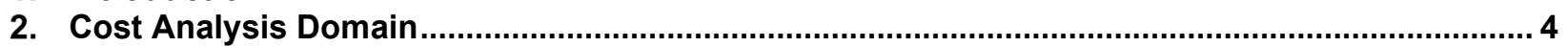

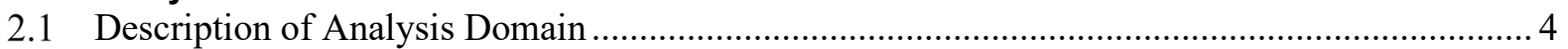

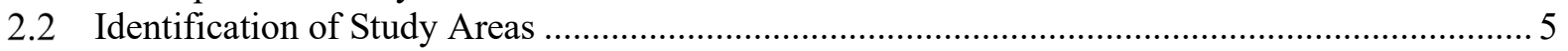

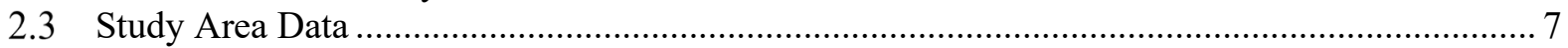

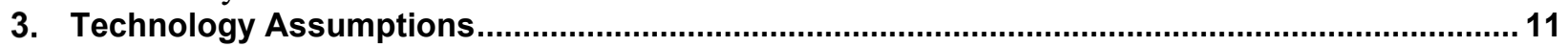

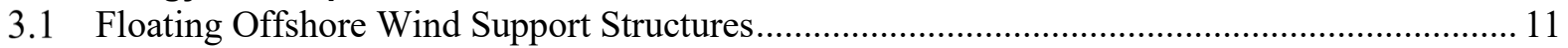

3.2 Turbine Technology Assumptions ................................................................................... 13

4. Annual Energy Production Calculation Methodology and Results......................................... 19

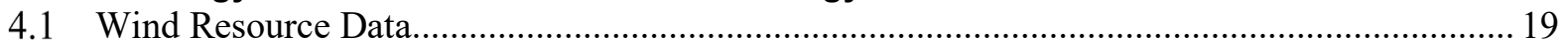

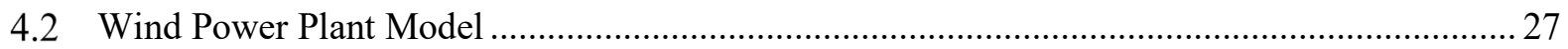

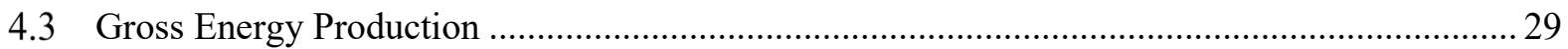

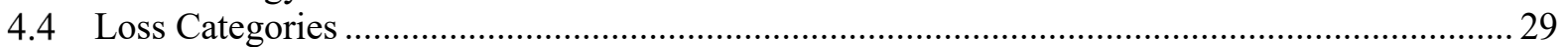

4.5 Net Energy Production Results ................................................................................... 32

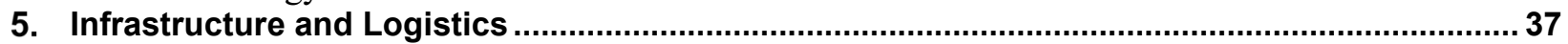

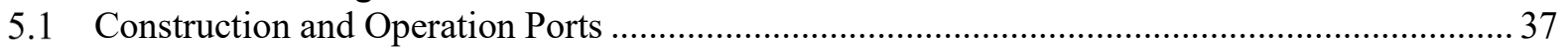

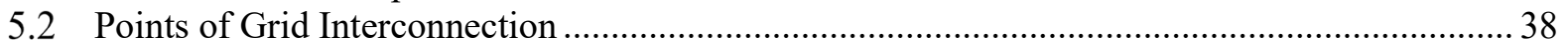

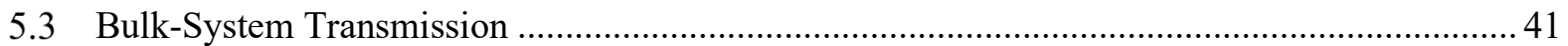

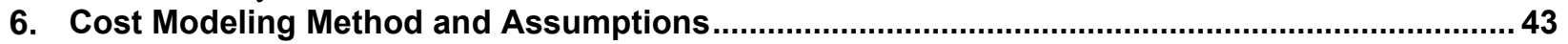

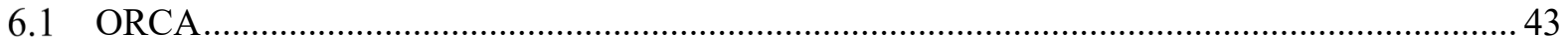

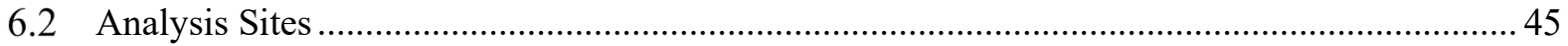

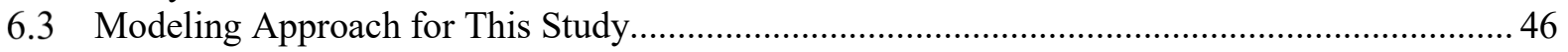

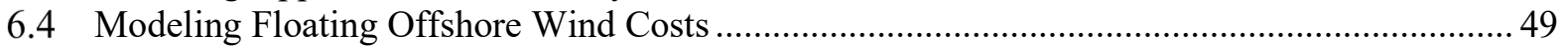

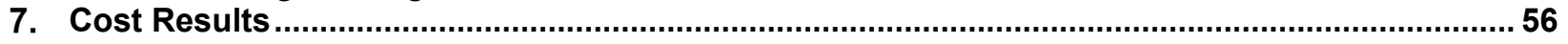

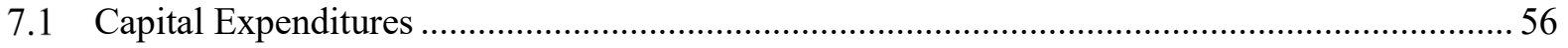

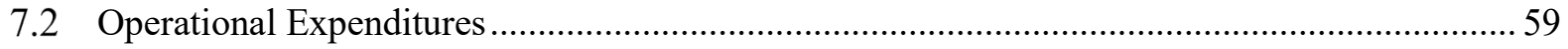

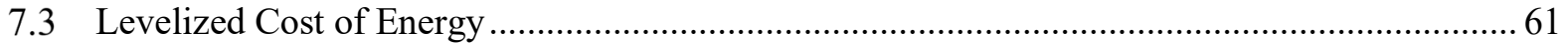

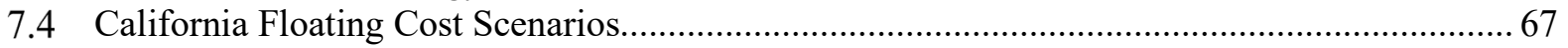

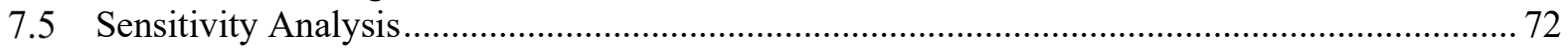

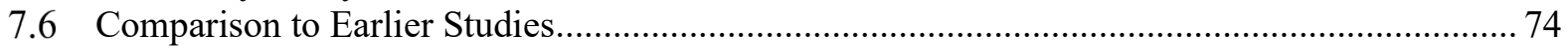

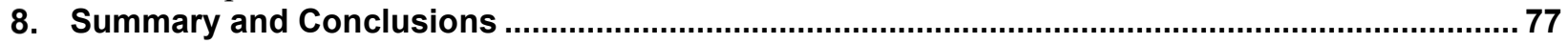

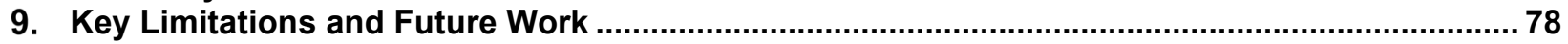

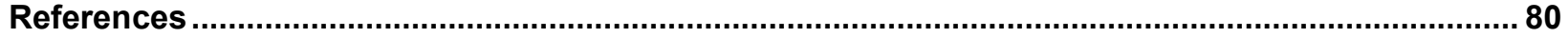

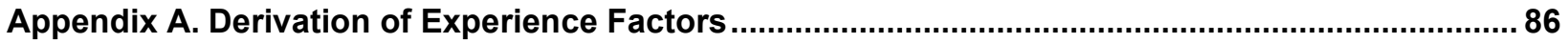

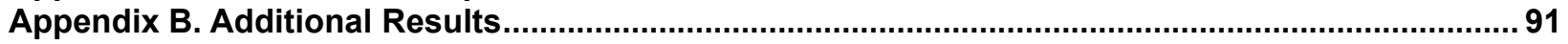

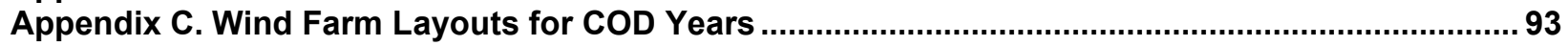




\section{List of Figures}

Figure ES-1. LCOE estimates (mid-case CapEx scenario) for the analysis domain offshore California estimated for a 2019 COD (left) and 2032 COD (right) ............................................... ix

Figure ES-2. Estimated LCOE trajectory between 2019 and 2032 (COD) ...................................... $x$

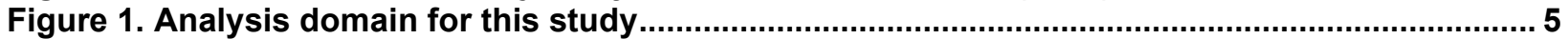

Figure 2. The five study areas within the California analysis domain........................................... 6

Figure 3. Ocean bathymetry map of California including the five study areas ................................ 9

Figure 4. Substructure archetypes for floating offshore wind systems including the spar buoy, semisubmersible, and tension leg platform ........................................................................... 12

Figure 5. Power and thrust coefficient curves for the 15-MW reference wind turbine from Gaertner

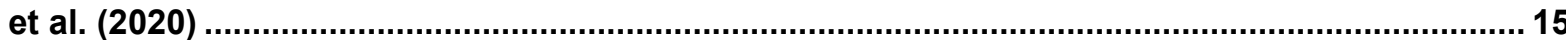

Figure 6. Offshore wind turbine power curves corresponding to 2019, 2022, 2027, and $2032 \ldots \ldots . .17$

Figure 7. Mean annual wind speed for the California OCS based on the new CA20 data set.......... 20

Figure 8. Comparing the mean annual 100-m wind speeds from the new data set CA20 (left) and the WIND Toolkit (WTK, center). The difference between the maps is shown on the right........ 21

Figure 9. (a) A 150-m histogram of wind speed distribution and (b) wind rose at Site 1: Morro Bay. Cut-in, rated, and cut-out wind speeds indicated in (a).

Figure 10. (a) A 150-m histogram of wind speed distribution and (b) wind rose at Site 2: Diablo Canyon. Cut-in, rated, and cut-out wind speeds indicated in (a)................................................ 23

Figure 11. (a) A 150-m histogram of wind speed distribution and (b) wind rose at Site 3: Humboldt. Cut-in, rated, and cut-out wind speeds indicated in (a). ................................................................ 24

Figure 12. (a) A 150-m histogram of wind speed distribution and (b) wind rose at Site 4: Cape Mendocino. Cut-in, rated, and cut-out wind speeds indicated in (a). ..................................... 25

Figure 13. (a) A 150-m histogram of wind speed distribution and (b) wind rose at Site 5: Del Norte. Cut-in, rated, and cut-out wind speeds indicated. .................................................................... 26

Figure 14. 20-year mean wind profiles at the study site centroids. Assumed hub heights of $118 \mathrm{~m}$, $128 \mathrm{~m}, 138 \mathrm{~m}$, and $150 \mathrm{~m}$ are noted for the COD years investigated. .......................................... 27

Figure 15. Plant layout for the 2022 (10-MW wind turbines). The dot radius represents one rotor diameter.....

Figure 16. Loss breakdown by site and for the analysis domain for COD 2019. Losses are in \% of gross production. ................................................................................................................... 34

Figure 17. Net capacity factor estimates for the analysis domain offshore California (2019 COD). 35

Figure 18. (a) Estimated capacity factor trajectory of the five California study areas between 2019 and 2032 and (b) a histogram showing distribution of NCF values across the analysis domain sites in 2019

Figure 19. Map of candidate points of interconnection for wind power plant sites on the OCS offshore California.

Figure 20. Transmission options for a 1,836-MW offshore wind power plant in the Humboldt Call Area

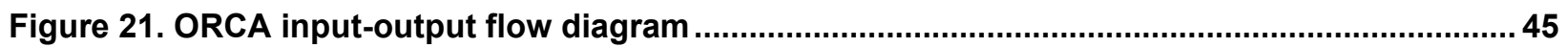

Figure 22. The five study areas within the California analysis domain ........................................... 46

Figure 23. Global LCOE estimates of floating offshore wind technology........................................ 49

Figure 24. Adjusted strike and contract prices from global offshore wind procurement .................50

Figure 25. Commercial offshore wind turbine size...........................................................................51

Figure 26. CapEx cost reductions from turbine upsizing and experiential learning attributed to

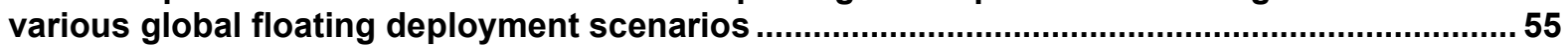

Figure 27. Histogram showing 2019 CapEx distribution across the 759 modeled analysis sites in the analysis domain offshore California

Figure 28. CapEx breakdown of the five study areas in the baseline year (2019)......................... 57

Figure 29. CapEx trajectory of the five California study areas between 2019 and 2032 ................ 58

Figure 30. CapEx estimates for the analysis domain offshore California in the baseline year (2019)

Figure 31. Histogram showing distribution of OpEx costs for the 759 analysis domain sites in 2019

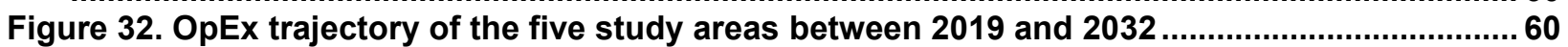


Figure 33. OpEx estimates for the analysis domain offshore California in the baseline year (2019)

Figure 34. (a) LCOE (mid) trajectories of the five study areas between 2019 and 2032 and (b) a histogram highlighting the distribution of LCOE values calculated in 2019 for the $\mathbf{7 5 9}$ sites in the analysis domain

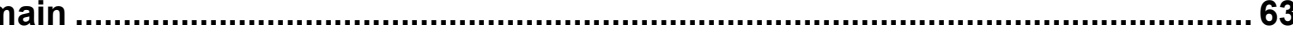

Figure 35. LCOE estimates (mid case) for the analysis domain offshore California (2019 COD) .... 64

Figure 36. LCOE estimates (mid case) for the analysis domain offshore California (2022 COD) .... 65

Figure 37. LCOE estimates (mid case) for the analysis domain offshore California (2027 COD) ....66

Figure 38. LCOE estimates (mid case) for the analysis domain offshore California (2032 COD) .... 67

Figure 39 (a)-(e). CapEx scenario trajectories for the five study sites ............................................. 70

Note that "Low" refers to the low deployment scenario not low cost. ............................................. 70

Figure 40. (a)-(e) Cost scenario trajectories for the five study sites ................................................ 72

Figure 41. Results of LCOE sensitivity analysis case (2019 baseline) .......................................... 73

Note: WACC, CapEx, OpEx and distance parameters were varied $+/-10 \%$ of their baseline values. NCF was varied $+/-1 \%$ of the baseline value. LCOE for the increased input value is shown in red; reduced input values are shown in blue.

Figure 42. CapEx estimated in this analysis in comparison to two prior California floating offshore wind studies illustrated for the Diablo Canyon study area .......................................................... 75

Figure 43. OpEx estimated in this analysis in comparison to two prior California floating offshore wind studies illustrated for the Diablo Canyon study area ....................................................... 76

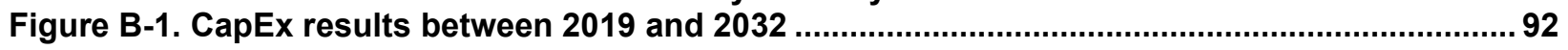

\section{List of Tables}

Table ES-1. Technology Assumptions .......................................................................................... viii

Table 1. Locational Data for the California Offshore Wind Study Areas ..........................................

Table 2. Technology Assumptions for the California Offshore Floating Wind Cost Analysis.......... 16

Table 3. IEC Loss Categories for Wind Farms ......................................................................... 30

Table 4. Gross Capacity Factors, Losses, and Net Capacity Factors for California Study Areas.... 33

Table 5. Losses for California Study Areas for 2019 COD................................................................... 34

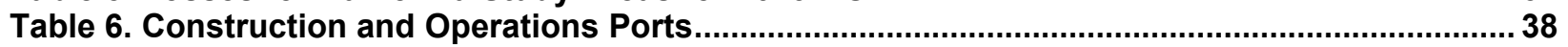

Table 7. Potential Points of Interconnection for the Five California Study Areas............................. 40

Table 8. Bottom-Up Engineering Tools that Inform the Spatial Relationships in ORCA.................. 44

Table 9. Definition of Key Cost and Performance Terms Used..................................................... 47

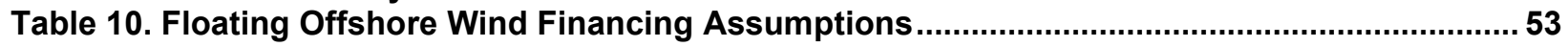

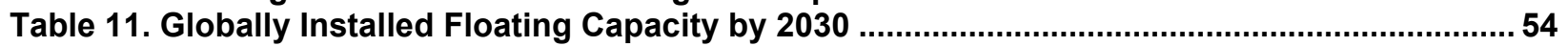

Table 12. CapEx for the Five Study Areas During the Baseline Year (COD 2019)............................56

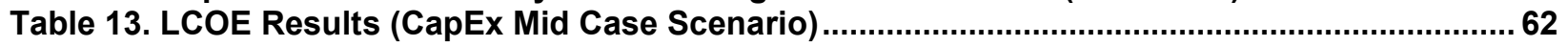

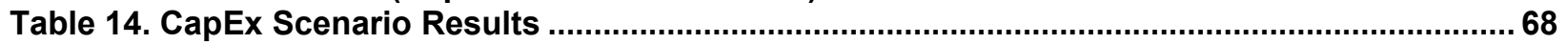

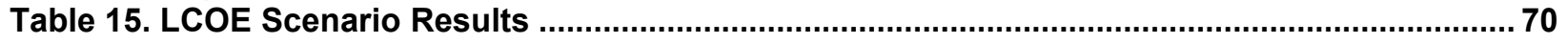

Table 16. LCOE Sensitivity Parameters and Results ....................................................................... 73

Table 17. Key Modeling Assumptions of This Study Compared to Two Prior NREL Assessments 74

Table A-2. Examples of Technological Innovations That Can Contribute to Capital Expenditure and Opertaional Expenditure (OpEx) Cost Reductions. Adapted from Valpy et al. (2017) and Valpy and English (2014).

Table B-1. Detailed Capital Expenditure Breakdown for the Five Study Areas (2019) ......................91

Table B-2. Detailed OpEx Breakdown for the Five Study Areas (2019) ........................................... 92

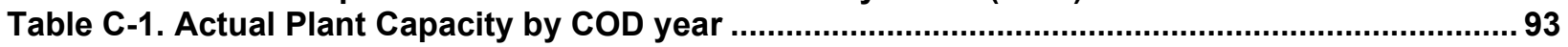

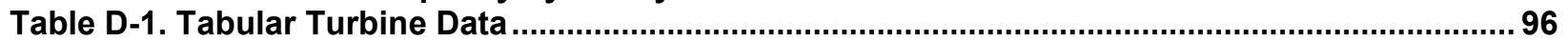




\section{Introduction}

California's energy planning is centered around meeting the emissions reduction and renewable energy requirements of Senate Bill (SB) $350^{9}$ by 2030 . Power sector planning is also expected to address the state's requirement to achieve $100 \%$ of total retail electricity sales from renewable energy and zero-carbon resources by 2045 , as mandated by SB $100 .{ }^{10}$ To comply with these directives, California needs to investigate the further development of energy efficiency, storage, and a diverse range of renewable energy, zero-carbon emission, and transmission resources, including offshore wind. Wind resources off the coast of California have the potential to generate a significant portion of the state's electric energy as part of a zero-carbon economy and help diversify its energy mix. The offshore wind technical resource ${ }^{11}$ was reassessed by the National Renewable Energy Laboratory (NREL) in early 2020 and was found to be more than 200 gigawatts (GW) (Optis et al. 2020). In a 2016 cost study conducted by NREL (Musial et al. 2016a), offshore wind deployment scenarios were considered that suggest a build-out of offshore wind of up to $15 \mathrm{GW}$ would be technically feasible in California after expected floating technology advancements are realized, but the study did not consider other factors related to environmental or conflicting use.

To advance the understanding of floating offshore wind cost in the United States, NREL recently conducted two studies that this current study builds upon. One study, published in October 2019, assessed the cost of floating offshore wind at five hypothetical sites in Oregon by incorporating multiple recent industry developments and cost modeling upgrades (Musial et al. 2019a). Another report was published in January 2020 and estimated the commercial cost of floating offshore wind in the state of Maine where the first pilot-scale plant comprising a single turbine up to 12 megawatts (MW) is scheduled for deployment in 2023 by the University of Maine (Musial et al. 2020a). We conducted industry consultations and collected data as part of these two studies that have informed the NREL cost models and assumptions used in this analysis. Compared to the earlier California floating offshore wind cost study conducted by NREL (Musial et al. 2016a) several key advancements and upgrades were added, which include:

- Consideration of European auction price data, which suggest declines of $65 \%$ between 2017 and 2025 (commercial operation date [COD]) (Beiter et al. 2019)

- Integration of a new wind speed resource data set covering a 20-year period off the coast of California

- Lower fixed charge rates to reflect recent industry reporting for commercial-scale (fixedbottom) offshore wind

\footnotetext{
${ }^{9}$ Senate Bill 350, The Clean Energy and Pollution Reduction Act of 2015 (http://leginfo.legislature.ca.gov/faces/billTextClient.xhtml?bill id=201520160SB350).

${ }^{10}$ Senate Bill 100 is known as the 100 Percent Clean Energy Act of 2018. For more information, see: https://leginfo.legislature.ca.gov/faces/billTextClient.xhtml?bill_id=201720180SB100.

11 "Technical resource" is defined as the subset of total resource potential that can be considered recoverable under available technological and turbine performance conditions and after exclusion of land-use and environmental siting constraints (Musial et al. 2016a). It does not include areas where the wind speeds are lower than 7 meters per second or deeper than 1,300 meters.
} 
- Cost projections that extend to 2032 COD in the model; in the Musial et al. (2016a) study, cost projections extended through 2030 COD

- Turbine size increases to $12 \mathrm{MW}$ for market availability in 2027, and 15-MW turbines for market availability by 2032; Musial et al. (2016a) assumed a maximum turbine size of 10 MW

- Turbine capital cost $(\$ /$ kilowatt $[\mathrm{kW}])$ declines to reflect recent market price data

- Lower semisubmersible floating platform costs and platform architectures that provide broader systemwide benefits

- Changes to the methodology for projecting costs including a decomposition of cost reductions into learning and increased efficiencies in the supply chain, turbine upsizing, and technological innovations effects.

The integration of a new resource data set and the newly introduced cost projection methodology are the primary changes in comparison to the earlier Oregon cost assessment (Musial et al. 2019a). The primary purpose of this study is to provide updated information for long-term energy planning in the state of California. Floating offshore wind technology, which is required for the deep waters along the California coast, is currently in a precommercial phase, with approximately $84 \mathrm{MW}$ installed worldwide at the end of 2019. In Europe there are more than 292 MW of new pilot projects scheduled to be operating by the end of 2022, and the first large-scale commercial projects are already in the permitting phase in Asia and scheduled for operation in 2024. This pace of floating wind technology advancements and commercial development indicates that commercial floating arrays may be technically feasible in California's market as early as the mid-2020s. A goal of this study is to provide cost and performance data that can help state energy analysts evaluate how offshore wind can become part of California's future energy mix, from a reliability, greenhouse-gas emissions, and economic perspective. A necessary step in that evaluation is for offshore wind to be represented in the Integrated Resource Planning (IRP) process coordinated by the California Public Utilities Commission (CPUC) and other state agencies (CPUC 2020). As part of the IRP process, each resource is represented in an electric grid capacity expansion model (referred to as the "RESOLVE model"), and various scenarios are run to inform how SB 350 and SB 100 objectives can be met. The IRP process analyzes transmission requirements via its interface with the California Independent System Operator's (CAISO's) Transmission Planning Process. This is relevant for offshore wind energy because transmission capacity extension and major upgrades might be required to interconnect this resource with major load centers (see Section 5). The CPUC will begin updating modeling inputs and assumptions for the next cycle of IRP, and data provided by this study can be used to inform that process (CPUC 2019b).

The analysis is conducted for projects commencing commercial operations between 2019 and 2032 using the latest version of the NREL Offshore Regional Cost Analyzer (ORCA) model. We chose the year 2019 as the baseline for this analysis so that inferences can be made from current data and performance characteristics of floating offshore wind systems. Local supply and logistical solutions along the Pacific Coast (e.g., port upgrades and vessel capabilities) are assumed to be available. Any costs associated with developing local port, manufacturing, and logistical infrastructure are not considered as part of project levelized cost of energy (LCOE). 
Because the LCOE of offshore wind energy is highly sensitive to spatial parameters (Beiter et al. 2016) we estimate capital expenditures (CapEx), operation and maintenance (O\&M), net capacity factor (NCF), and LCOE for a broad part of the California wind resource area (Section 2). The IRP process (as specified by the CPUC) also makes it necessary to evaluate the costs and performance of (floating) offshore wind for specific locations. Therefore, the primary geographic focus for this cost assessment is the three Call Areas in California ${ }^{12}$ (Bureau of Ocean Energy Management [BOEM] 2020a) and two additional study areas on the north coast that were added to provide higher spatial resolution across the analyzed spatial domain (see Section 2 for a detailed description). The remainder of this report provides the details on how we determined these cost parameters over the specified geographic domains and over time.

\footnotetext{
12 Three Call Areas offshore California were identified by BOEM in 2018 as potentially suitable for offshore wind energy leasing: Humboldt Call Area, Morro Bay Call Area, and Diablo Canyon Call Area. These three Call Areas were under consideration for offshore wind energy as of the publication date of this report.
} 


\section{Cost Analysis Domain}

We conducted a cost analysis over a broad range of the OCS offshore California, which is described in Section 2.1. To integrate these data into the IRP process, it was necessary to define specific locations that allow for a discrete set of input data to the IRP RESOLVE model. ${ }^{13}$ These data reflect typical cost and performance characteristics of near- to medium-term offshore wind development in California. The specific locations for our cost assessment are described in Section 2.2 and 2.3. The selection of these specific locations did not include stakeholder engagement or marine spatial planning, and moreover these locations do not imply that any part of BOEM's leasing process has preceded their selection or that the sites have been vetted by the many communities of ocean users. Any actual wind energy siting on the OCS would require comprehensive stakeholder engagement and analysis.

\subsection{Description of Analysis Domain}

The analysis domain within the OCS offshore California (Figure 1) is bounded by the following:

- Wind speeds greater than 7 meters per second $(\mathrm{m} / \mathrm{s})$

- Water depth between 40 and 1,300 meters (m)

- Any location that is south of the California border with Oregon (see horizontal line labeled "State Offshore Boundary") and north of the confines of the wind resource data set (see horizontal line labeled "wind resource data extent" in Figure 1).

The $7 \mathrm{~m} / \mathrm{s}$ wind speed cutoff is the typical limit that has been used in past offshore wind cost studies, below which the wind speed is considered too low to support an economical project (Musial et al. 2016a). Most of California's resource area is above this limit but in the southern region this limit eliminates most of the area south of the Channel Islands (Optis et al. 2020).

The upper value of the water depth limit was increased from $1,000 \mathrm{~m}$ used in previous studies to 1,300 $\mathrm{m}$ in this study (Musial et al. 2016a). This increase in the water depth limit was implemented after consulting with industry and BOEM and reflects recent advances in floating mooring line and submarine cable technology. This greater depth limit effectively increased the resource area on the outer margins farther from shore. The lower depth limit for the analysis domain was set at $40 \mathrm{~m}$, below which fixed-bottom substructures are often considered the optimal choice from a cost perspective. Areas in California with water depths less than $40 \mathrm{~m}$ are also too close to shore to be considered viable from a siting standpoint. The analysis domain corresponds approximately to the boundaries of the technical offshore wind resource area in California (Optis et al. 2020) except for the 40-m depth cutoff, which eliminates the nearshore sites.

\footnotetext{
${ }^{13}$ RESOLVE is the capacity expansion model that is used in the IRP process.
} 


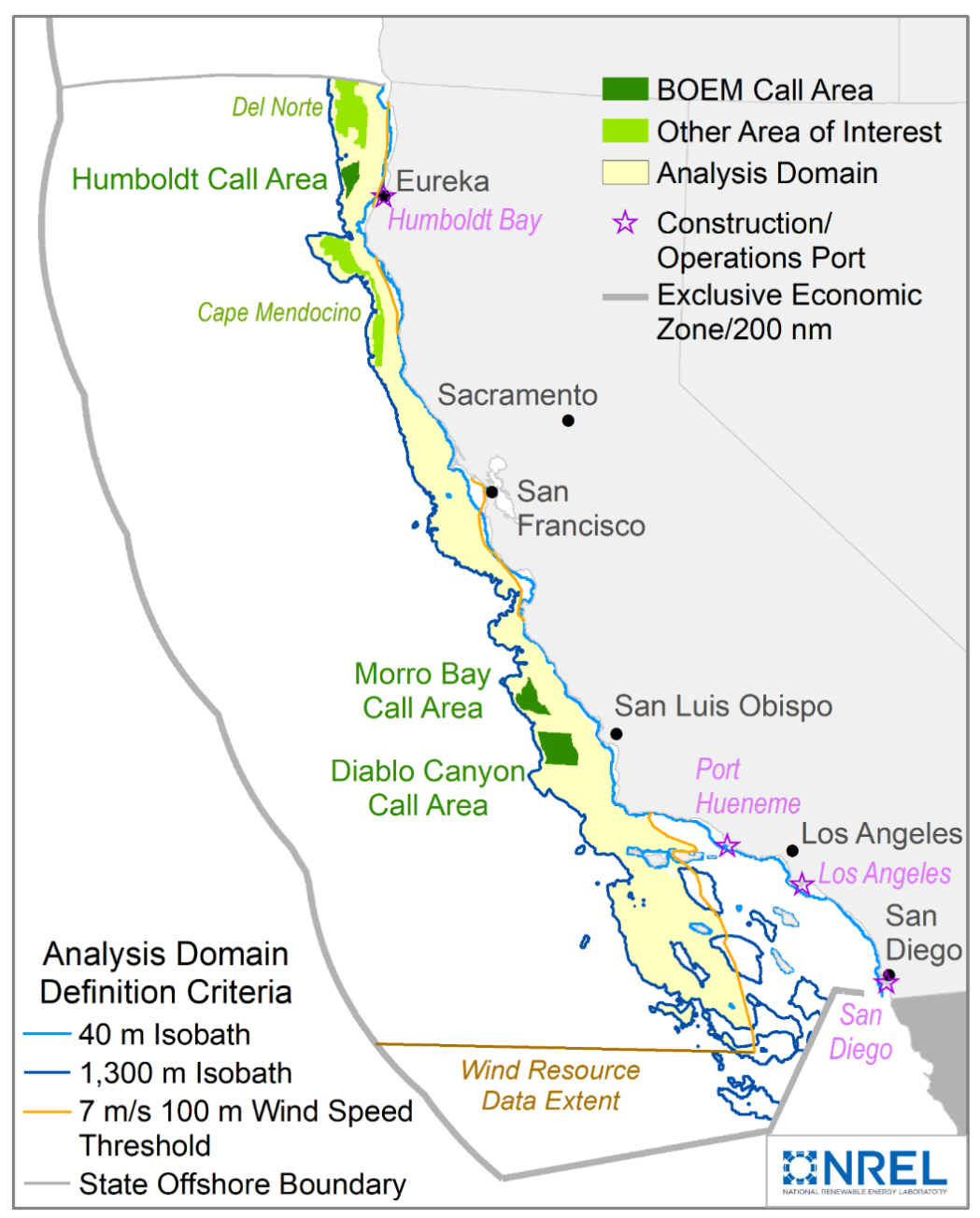

Figure 1. Analysis domain for this study

The "State Offshore Boundary" designates the analysis boundary between California and Oregon.

\subsection{Identification of Study Areas}

For cost analysis purposes, we represented individual offshore wind farms in a grid layout within the analysis domain (Figure 2). Each of these wind farms can support 1,000 MW of capacity. We selected five study areas (in pink) within the analysis domain. These study areas were used as reference locations for the 2019-2020 IRP inputs to assess and compare the typical cost and performance characteristics of floating offshore wind development in California. RESOLVE, the capacity expansion model used in the IRP process, requires such discrete inputs of a limited set of sites. Each study area is at a location where floating offshore wind development is presumed to be technically feasible, but they have not been vetted under any type of BOEM wind energy regulatory process.

The five study areas shown in Figure 2 are:

- Morro Bay (central coast)

- Diablo Canyon (central coast)

- Humboldt (northern coast) 
- Cape Mendocino (northern coast)

- Del Norte (northern coast).

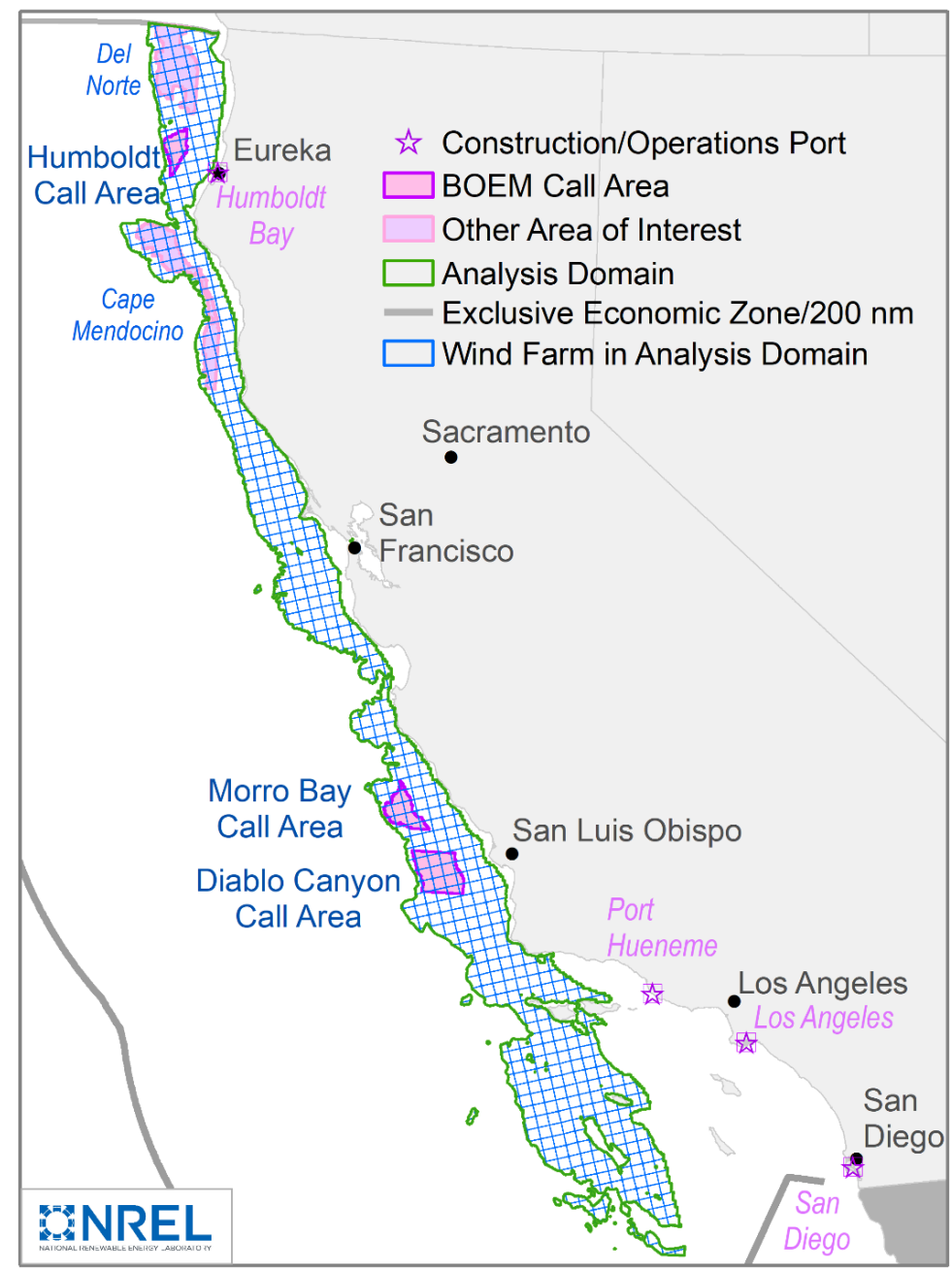

Figure 2. The five study areas within the California analysis domain

Modeled wind farm sites are indicated by blue boundary lines.

Morro Bay, Diablo Canyon, and Humboldt are the current BOEM Call Areas. On October 19, 2018, BOEM published a Call for Information and Nominations identifying these three geographically distinct Call Areas located in the OCS offshore California (BOEM 2018). The Call Areas, with a total area of 687,823 acres, were identified as potentially suitable for offshore wind leasing. In response to the Call for Information and Nominations, BOEM received 14 nominations from developers who expressed interest in specific portions of the Call Areas for possible commercial development (BOEM 2020b).

Del Norte and Cape Mendocino are additional areas of interest that were adopted from a recent University of California Berkeley study assessing the workforce impacts and grid integration of offshore wind in California (Collier et al. 2019). These sites were derived by Collier from an earlier NREL study (Musial et al. 2016a). This study defined site-selection criteria (e.g., for wind speed, water depth, use conflicts, access to transmission, suitable ports, and distance from shore) 
and identified sites that met these criteria to sustain a commercial offshore wind project. Neither Collier (2019) nor Musial (2019a) vetted these areas for offshore wind development among stakeholders, but they are identified as potential future deployment sites because they meet the technical requirements for floating offshore wind technology. These sites provide additional geographic diversity for this cost study, but they should not be confused with the actual BOEM Call Areas. Neither Del Norte nor Cape Mendocino have been designated by BOEM to move forward under any formal regulatory framework.

\subsection{Study Area Data}

The five geographically distinct study areas comprise an area totaling approximately 7,057 square kilometers $\left(\mathrm{km}^{2}\right)$, which is nearly $11 \%$ of the California technical offshore wind resource area extending to 1,300 m water depth (Musial et al. 2016b). As illustrated in Table 1, Humboldt and Morro Bay are the smallest areas, followed by Diablo Canyon, Cape Mendocino, and Del Norte with larger footprints.

Table 1. Locational Data for the California Offshore Wind Study Areas

\begin{tabular}{|c|c|c|c|c|c|c|}
\hline Item & Unit & $\begin{array}{l}\text { Site 1: } \\
\text { Morro Bay }\end{array}$ & $\begin{array}{l}\text { Site 2: } \\
\text { Diablo } \\
\text { Canyon }\end{array}$ & $\begin{array}{l}\text { Site 3: } \\
\text { Humboldt }\end{array}$ & $\begin{array}{c}\text { Site 4: } \\
\text { Cape } \\
\text { Mendocino }\end{array}$ & $\begin{array}{l}\text { Site 5: } \\
\text { Del Norte }\end{array}$ \\
\hline BOEM designation & $\mathrm{N} / \mathrm{A}$ & Call Area & Call Area & Call Area & $\mathrm{N} / \mathrm{A}$ & $\mathrm{N} / \mathrm{A}$ \\
\hline \multirow{4}{*}{$\begin{array}{c}\text { Size } \\
\text { and } \\
\text { nameplate } \\
\text { capacity } \\
\text { potential }\end{array}$} & $\mathrm{mi}^{2}$ & 311 & 557 & 207 & 800 & 850 \\
\hline & $\mathrm{km}^{2}$ & 806 & 1,441 & 536 & 2,072 & 2,202 \\
\hline & $\mathrm{MW} / \mathrm{km}^{2}$ & 3 & 3 & 3 & 3 & 3 \\
\hline & MW & 2,419 & 4,324 & 1,607 & 6,216 & 6,605 \\
\hline \multirow{2}{*}{ Area centroid } & $\begin{array}{c}\text { Latitude (decimal } \\
\text { degrees) }\end{array}$ & 35.56342 & 35.11532 & 40.95078 & 40.13330 & 41.69974 \\
\hline & $\begin{array}{c}\text { Longitude (decimal } \\
\text { degrees) }\end{array}$ & -121.77974 & -121.39522 & -124.63619 & -124.73094 & -124.76659 \\
\hline $\begin{array}{c}\text { 20-year mean wind } \\
\text { speed at } 150 \mathrm{~m} \\
\text { (centroid) }\end{array}$ & $\mathrm{m} / \mathrm{s}$ & 9.80 & 9.43 & 10.81 & 11.60 & 12.02 \\
\hline $\begin{array}{c}\text { Significant wave } \\
\text { height }\end{array}$ & $\mathrm{m}$ & 2.47 & 2.47 & 2.61 & 2.60 & 2.61 \\
\hline $\begin{array}{c}\text { Distance from site to } \\
\text { cable landfall (export } \\
\text { cable) }\end{array}$ & $\mathrm{km}$ & 43.5 & 48.7 & 42.0 & 29.5 & 43.7 \\
\hline $\begin{array}{c}\text { Assumed distance } \\
\text { from cable landfall to } \\
\text { point of } \\
\text { interconnection }\end{array}$ & $\mathrm{km}$ & 5.0 & 5.0 & 5.0 & 5.0 & 5.0 \\
\hline $\begin{array}{c}\text { Construction, } \\
\text { operations, and } \\
\text { maintenance port }\end{array}$ & $\mathrm{N} / \mathrm{A}$ & Port Hueneme & Port Hueneme & Humboldt Bay & Humboldt Bay & Humboldt Bay \\
\hline $\begin{array}{l}\text { Distance from site to } \\
\text { port }\end{array}$ & $\mathrm{km}$ & 317.7 & 247.5 & 55.5 & 122.4 & 122.2 \\
\hline Mean water depth & $\mathrm{m}$ & 1,013 & 640 & 832 & 835 & 807 \\
\hline
\end{tabular}


Assuming an offshore wind turbine power density of $3 \mathrm{MW} / \mathrm{km}^{2},{ }^{14}$ the five study areas could support $21,172 \mathrm{MW}$ of offshore wind capacity, or roughly 91 terawatt-hours in generation. ${ }^{15}$ This would correspond to more than $35 \%$ of the state's current electric use (Energy Information Administration 2020). This comparison is indicated here purely for illustrative purposes. The capacity densities of the layouts considered for energy production calculations (e.g. wake losses) in this study are in the range of $6 \mathrm{MW} / \mathrm{km}^{2}$ to $7 \mathrm{MW} / \mathrm{km}^{2}$, rather than $3 \mathrm{MW} / \mathrm{km}^{2}$, but when inter-array buffers, navigation lanes, and other set-backs are accounted for the array densities can approach $3 \mathrm{MW} / \mathrm{km}^{2}$. Additionally, developers would likely create optimized layouts that differ from the ones used in the energy production analysis.

Figure 3 shows the bathymetry of the OCS off California and the California state waters inside 3 $\mathrm{nm}$. The figure illustrates the steep Pacific shelf, which makes most of the OCS deeper than 1,300 $\mathrm{m}$ and outside the analysis domain. As water depths increase, project costs increase incrementally because of increasingly longer mooring lines, potentially longer array cables, and more difficult logistics in anchor installation. However, a water depth of 1,300 $\mathrm{m}$ does not represent a hard technology limit for floating offshore wind turbines.

${ }^{14}$ A power density of $3 \mathrm{MW} / \mathrm{km}^{2}$ is often used to estimate generation capacity for a given area (Musial et al. 2016b).

${ }^{15}$ Assuming the average net capacity factors of $49 \%$ estimated for the base year 2019 across the five study areas (Section 4). 


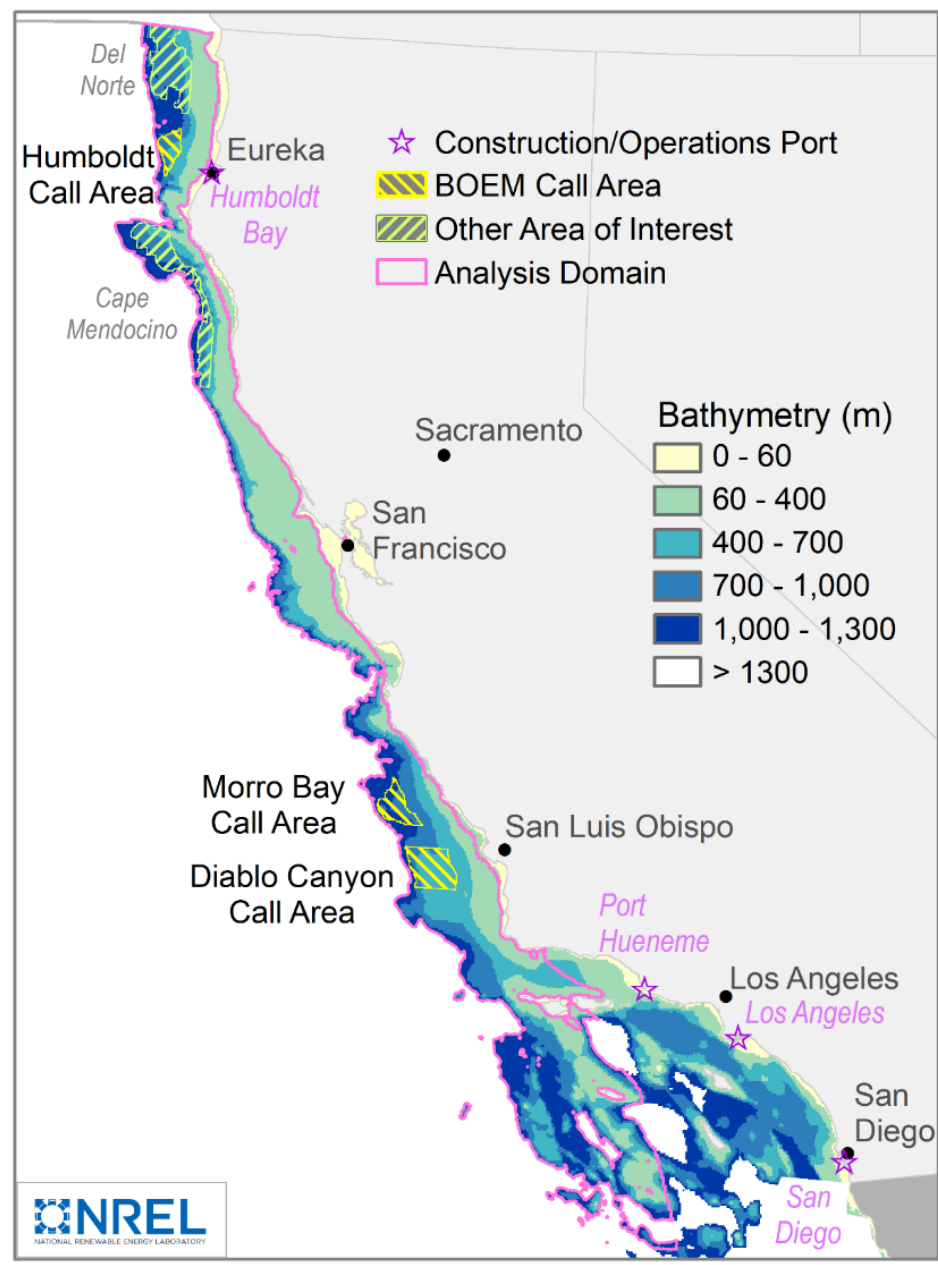

Figure 3. Ocean bathymetry map of California including the five study areas

Data sources: National Oceanic and Atmospheric Administration (NOAA) Coastal Relief Model (https://ngdc.noaa.gov/mgg/coastal/crm.html) and NOAA ETOPO1 Global Relief Model (https://ngdc.noaa.gov/mgg/global/global.html).

We determined the mean wind speeds for the centroid of each wind farm site in the analysis domain. The significant wave heights are annual average values, and the data source and processing are described in Beiter et al. (2016). The distances shown in Table 1 were calculated as the average distance from the analysis sites within each study area to the respective port or grid infrastructure point. The export cable length is calculated by the straight-line distance from the centroid of each analysis site to shore. The direct route is modeled without consideration for competing ocean or land-based uses or exclusion zones (e.g., marine protected areas). A standard length of $5 \mathrm{~km}$ is assumed for the onshore spur line from the cable landfall to the onshore grid. The actual length of onshore transmission and associated costs will vary based on projectspecific decisions, such as the construction of a new substation or upgrades to existing transmission infrastructure. 
The cost of grid connection and bulk transmission ${ }^{16}$ expansion is a major source of uncertainty for the study. Significant deficiencies in the bulk transmission system's ability to carry gigawattscale offshore wind power to load centers were identified at some study areas, especially on the northern coast. Major bulk transmission system build-out and substation upgrades will likely be necessary, depending on the location, to interconnect commercial-scale offshore wind with the CAISO market. In addition, the cost allocation for upgrading this system to accommodate offshore wind has not yet been decided among developers, state policymakers, utilities, or private investors. As such, the cost of bulk power system upgrades is not included in the LCOE or CapEx values reported in this study. However, the lack of cost data for bulk transmission upgrade costs might limit the adoption of offshore wind in the CPUC capacity expansion model RESOLVE. This could be particularly relevant for study areas on the north coast where bulk transmission costs are not accurately represented in RESOLVE. On the central coast, where offshore wind grid connection points could be feasible at the Diablo Canyon nuclear plant and the retired power plant at Morro Bay, bulk transmission costs are better understood.

The authors recommend future work be conducted in this area to determine the costs associated with offshore wind interconnection and transmission upgrades.

\footnotetext{
${ }^{16}$ In the context of this study, the bulk transmission system is the network that connects electricity from the onshore substation of utility-scale offshore wind generators to local substations for distribution to end-use consumers (Beiter et al. 2018).
} 


\section{Technology Assumptions}

The time frame for this study extends from 2019 through 2032. Cost information is generated for 4 reference COD years $(2019,2022,2027,2032)$. The 2019 cost data are based on available industry prototype data and consultation. The cost data for 2022 through 2032 are generated by NREL cost models. Technology assumptions are made for each of these reference years and are described in this section. The primary technical assumptions are specific to the floating platform support structure and the turbine. In Section 3.1, we define the floating platform technology type and present the qualitative descriptions of the technology trade-offs from a market-based perspective.

In Section 3.2, we describe the modeled turbine characteristics. In general, we chose a more conservative approach to the offshore turbine technology assumptions than in previous cost studies conducted for Oregon (Musial et al. 2019a) and California (Musial et al. 2016a). This conservatism (e.g., baseline 2019 technology, higher specific power, lower power coefficient) is intended to increase confidence that the modeled technology development scenarios can be achieved in the designated time frame. The rationale for these technology definitions is presented in Section 3.2. There are also many second-order technology assumptions that are explained in greater detail in Section 6.

\subsection{Floating Offshore Wind Support Structures}

Globally, the development of floating offshore wind technology is motivated largely by the prospect of expanding offshore wind into areas beyond those that have been proven for conventional fixed-bottom technology. In the United States, more than $58 \%$ of the total technical offshore wind resource is in water depths greater than $60 \mathrm{~m},{ }^{17}$ where floating technology is thought to become more economical than fixed-bottom technology. In Europe, $80 \%$ of the resource is in water depths where the resource is more suitable for floating wind (Musial et al. 2016b).

Floating offshore wind is an emerging technology that is quickly advancing toward commercial status. At the end of 2019, the total floating wind pipeline was 7,663 MW, based on projects that have announced their planned capacity (Musial et al. 2020b). Of this total, there were 13 floating offshore wind projects installed around the world representing $84 \mathrm{MW}$ of capacity. Nine projects (62.13 MW) were installed Europe and seven (22.06 MW) in Asia. There are 1,549 MW of floating offshore wind projects that have reached the permitting stage. Among these permitted projects, there are 12 pilot-scale projects (10 MW to $50 \mathrm{MW}$ ) advancing in Europe, totaling 292 MW, that developers have announced to be in operation by 2022. Experience from these projects will inform commercial-scale floating wind development, which may begin in Asia as early as 2024 and is expected to help accelerate its cost reduction.

\footnotetext{
${ }^{17}$ Note that the technical offshore wind resource potential is specified here for water depths greater than $60 \mathrm{~m}$ from Musial et al. (2016b). In this report, the considered analysis domain is defined with a lower boundary of $40 \mathrm{~m}$.
} 
Figure 4 illustrates three archetypes for floating wind turbine substructure technology being developed. Each of these substructure archetypes have evolved or been adapted from deep-water oil and gas production platforms.

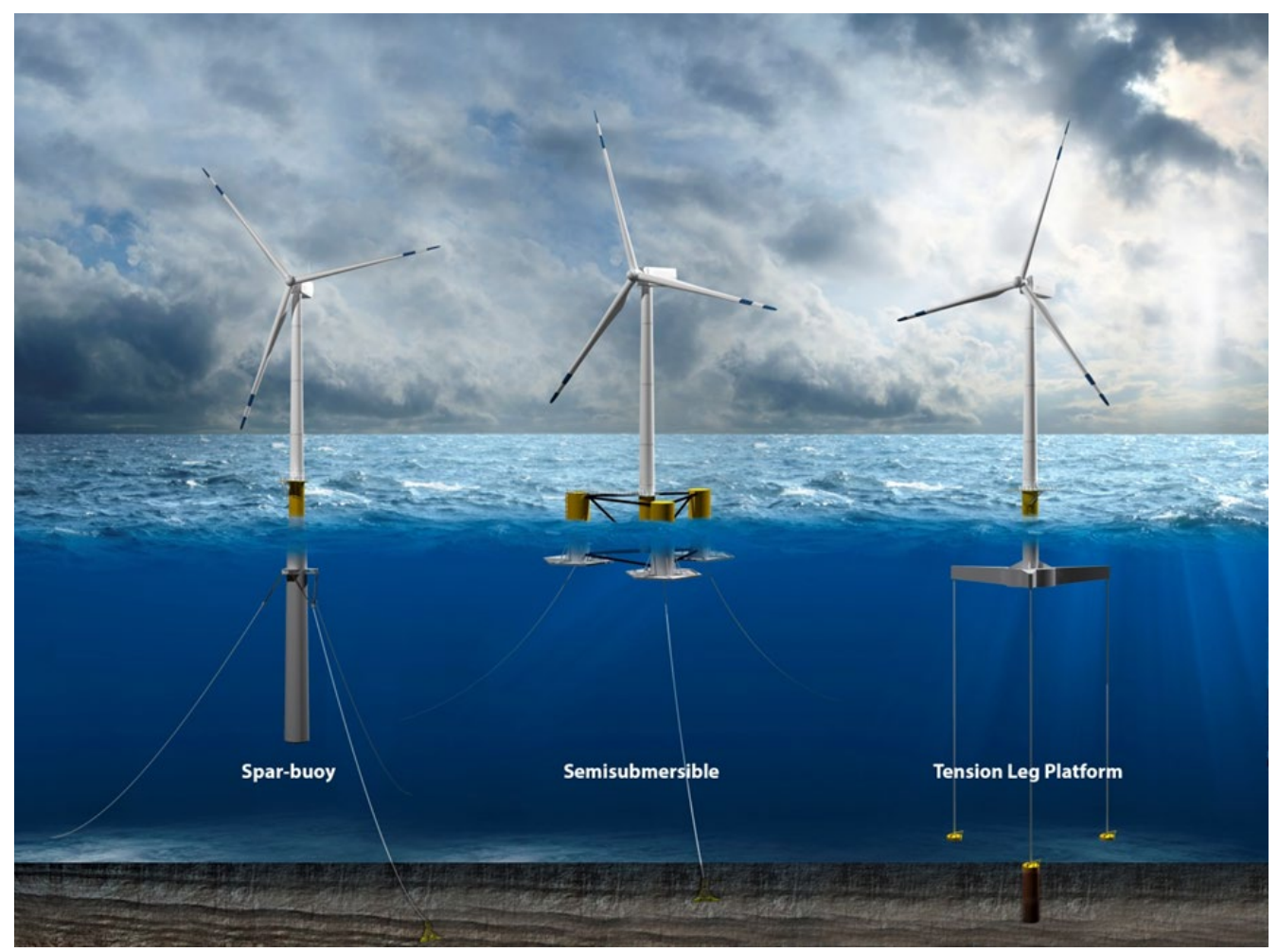

Figure 4. Substructure archetypes for floating offshore wind systems including the spar buoy, semisubmersible, and tension leg platform. Illustration by Josh Bauer, NREL

All these concepts have advantages and disadvantages. The semisubmersible design depends primarily on buoyancy and water plane area to maintain static stability. It has the key advantage of being stable enough to support a wind turbine before connecting the mooring lines. Because of its shallow draft, the system can be fully assembled at quayside and towed to its open-ocean operating site with a minimal amount of expensive labor at sea. Semisubmersibles can also be disconnected from their moorings at sea and towed to shore for maintenance at quayside to avoid expensive lift vessels that may otherwise be required for some repairs of major components. The most recent pilot project installed in late 2019 was Wind Float Atlantic. It is a 25.2-MW wind plant in Portugal that uses Principle Power, Inc. semisubmersibles with 8.4-MW MHI Vestas turbines, the largest floating turbines to date.

Commercial applications include the Kincardine Offshore Wind Farm (Scotland), which delivered its first power in September 2018. Although many developers have not yet committed to a specific platform technology type, the semisubmersible is the most common type among those projects that have announced their intended platform architecture (Musial et al. 2020b).

The spar buoy is stabilized by ballast and has a deeper draft (i.e., the substructure penetrates farther below the water surface), thereby avoiding surface wave action (Musial and Ram 2010). A 30-MW pilot-scale floating project — the world's first commercial floating wind power 
plant—was deployed by Equinor in October 2017 off Peterhead, Scotland, using spar technology. The deep draft of the spar required Equinor to assemble the wind turbine systems at sea in a sheltered deep-water area, which is rarely found in most coastal regions. This unique assembly requirement adds cost and may not be scalable to larger projects or to parts of the world where deep-water assembly is not available. As such, a commercially viable version of the spar may require some modification.

The tension-leg platform gets its static stability from mooring-line tension. Therefore, it is generally unstable until the mooring lines are attached. It can be difficult to deploy but is stable once installed and has the advantage of having a smaller footprint on the seabed. The unstable deployment challenge makes it difficult to assemble at quayside and may increase expensive labor at sea. New concepts are under development to lower labor at sea and promise lower deployment and assembly costs. One tension-leg platform concept comes from a Dutch company, SBM Offshore, which won a contract to deliver three floating tension-leg platforms for the 24-MW Provence Grand Large pilot wind energy project in the French Mediterranean in November 2016. The SBM tension-leg platform substructure is unique because its buoyancy system is at the surface during assembly and stabilizes the system to enable turbine installation before attaching the mooring lines. In general, the demonstration of the tension-leg platform technology is lagging the other archetypes.

Many variations of these archetypes exist, but most variants are hybrids that combine the physical principles of operation from three archetypes with practical experience. The next generation of floating platforms is embracing the hybridization of the archetype concepts to achieve cost reductions, which result from the application of practical design criteria known to facilitate load reductions. Examples of some of these practical design criteria include limiting turbine nacelle accelerations, reducing labor at sea, and accommodating the existing marine infrastructure in system designs including the emerging supply chain (Barter et al. 2020).

For this study, we modeled the semisubmersible for all four COD years. This choice was based on the observation that semisubmersible substructures are the most common, comprising $89 \%$ of all projects that have announced their intended substructure type. Semisubmersibles are naturally suited to port assembly and commissioning, and some limited field experience exists. The choice of the semisubmersible is not intended to imply that it is superior to other contenders, but rather it embodies most of the attributes which enable it to effectively represent the current and future cost of offshore wind. This study has no specific supply chain scenario associated with the fabrication of semisubmersibles. The semisubmersible costs in this study reflect a local supply chain and imports of key components where feasible, yet the estimated LCOE does not include any costs associated with developing or maintaining this local supply chain.

\subsection{Turbine Technology Assumptions}

Regardless of size, the wind turbine is the most important component of a wind power plant and has the greatest impact on cost. In addition to its contribution to CapEx, it is responsible for all energy production, the most important parameter for calculating LCOE. Wind turbine efficiency (i.e., the percentage of the wind's kinetic energy that is delivered to the grid) can be broken down into the following:

- The aerodynamic efficiency in converting the wind's kinetic energy to mechanical energy 
- The mechanical/electrical efficiency of the drivetrain components in converting the mechanical energy to electricity

- The conversion losses in delivering the individual turbines' electricity to the grid.

This section focuses on the assumptions regarding the first two bullets provided earlier, which in general are not influenced by the scale of the wind turbine. ${ }^{18}$ Modeled losses can be influenced by turbine scale and are described in Section 4 .

An increasing turbine size was assumed over the specified time frame of the four reference COD years: 2019, 2022, 2027, and 2032. The rate of size increase was based on NREL's engineering experience with turbine and substructure technology advancement and our comprehensive research on economic market trends. Larger turbines are considered one of the major technology drivers responsible for lowering cost in offshore wind, including floating wind, because increasing turbine size can lead to reduced balance-of-system costs (e.g., support structures and moorings, array cables, and installation costs) and unit O\&M costs. Recent LCOE reductions can, in part, be attributed to the use of larger offshore-specific wind turbines (Musial et al. 2020b). Current market data and NREL modeling efforts (Shields and Nunemaker 2020) indicate that the trend toward larger machines is likely to continue (Musial et al. 2020b). MHI Vestas has released its 9.5-MW and 10-MW wind turbines to the offshore market with the first commercial deployments well underway (MHI Vestas 2018). In addition, General Electric (GE) and Siemens Gamesa have announced 12-MW and 14-MW turbines for commercial availability in 2022 and 2024, respectively (GE 2018; Siemens Gamesa 2020).

For this study, we assumed that the largest available turbine capacities for CODs in 2019, 2022, 2027 , and 2032 are $8,10,12$, and $15 \mathrm{MW}$, respectively. Given the possible introduction of the Siemens Gamesa 14-MW turbine in 2024, this trajectory could be conservative, but historically it can take several years for the turbine supply chain to mature before serial production is fully established, so turbine original equipment manufacturer announcements are buffered by our assumptions to account for possible delays in commercial implementation.

To represent these larger turbines, we began with the International Energy Agency's (IEA) Wind Task 37 15-MW reference turbine, which provides a detailed open-source design of a large offshore wind turbine (Gaertner et al. 2020). This 15-MW reference turbine is the result of a recent industry collaboration between NREL, the Technical University of Denmark, and members of IEA Wind. It was based on our current knowledge of 2020 offshore wind technology but has not been optimized at the 15-MW scale. It was developed to serve as a baseline design for exploring potential innovations at the 15-MW scale (which do not yet exist) to enable a broader group of design innovators to participate. This reference turbine is the best-available turbine design in the public domain for a turbine of this size and was used as the turbine basis for all reference COD years. However, the design parameters were conservative because the reference turbine design does not contain any technology innovations beyond what is available in 2020, such as possible design innovations that could further improve performance.

\footnotetext{
18 The primary effect of upscaling on energy production is to raise the average wind speed by increasing the hub height.
} 
The power curve for the 15-MW reference turbine, corresponding to 2032, was scaled down to represent the 12-MW, 10-MW, and 8-MW turbines in 2027, 2022, and 2019, respectively. As such, the same level of conservatism is contained in each of these designs. The IEA 15-MW reference turbine was downscaled because it is a publicly available detailed design and includes a thrust coefficient curve, which is essential for performing wake loss assessment in FLOw Redirection and Induction in Steady State (FLORIS), an open-source collection of Python-based wind farm wake modeling and optimization tools (NREL 2019b). The power coefficient and thrust coefficient curves are plotted in Figure 5.

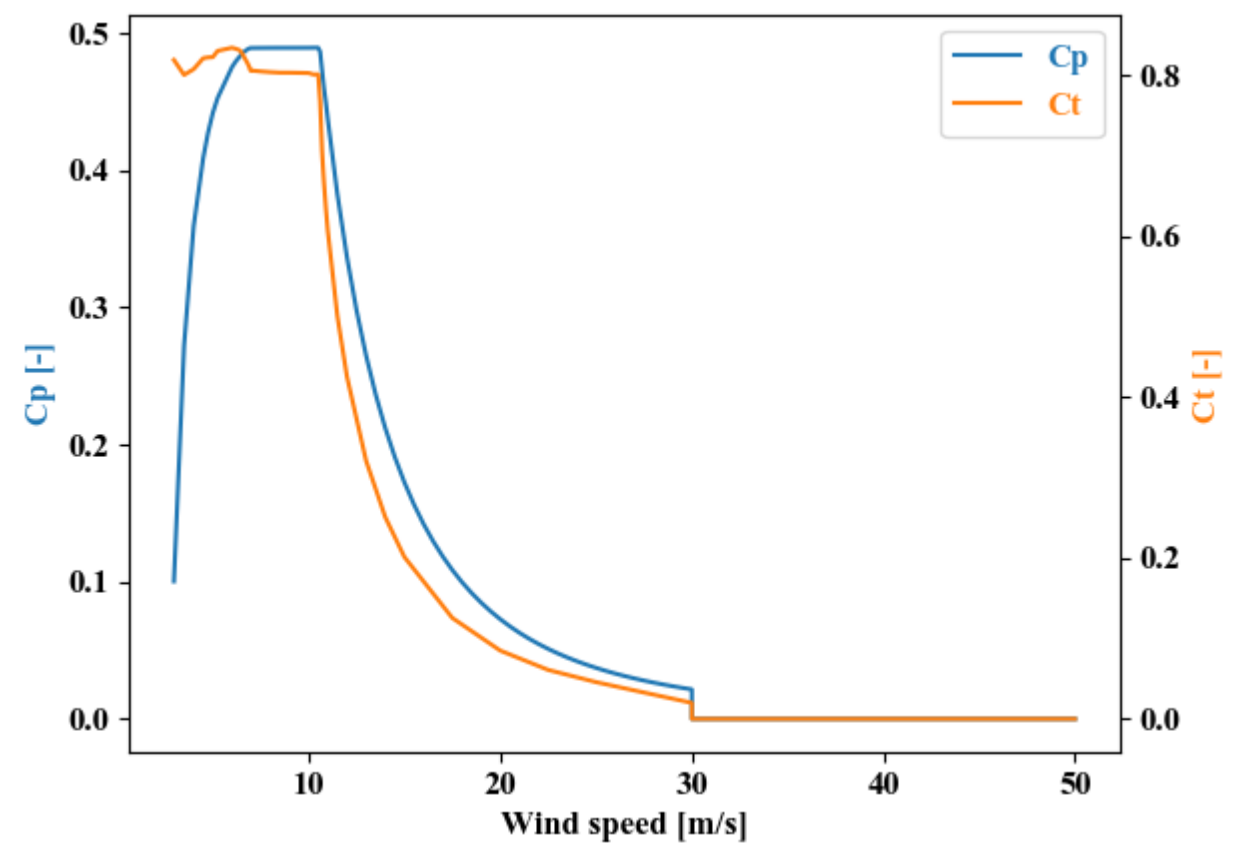

Figure 5. Power and thrust coefficient curves for the 15-MW reference wind turbine from Gaertner et al. (2020)

To downscale the 15-MW power curve to the smaller turbines, both the non-dimensional power coefficient and thrust coefficient curves for the reference turbine were held constant for the downscaled turbines. Rotor diameter was scaled to maintain a specific power of 332 watts $(\mathrm{W}) / \mathrm{m}^{2}$, the same specific power as the $15-\mathrm{MW}$ reference turbine. Hub height was set to maintain a 30-m clearance between the rotor tip and the mean sea level for all turbines. The resulting turbine parameters are shown in Table 2, along with the major technology assumptions for the modeling and results described later. 
Table 2. Technology Assumptions for the California Offshore Floating Wind Cost Analysis

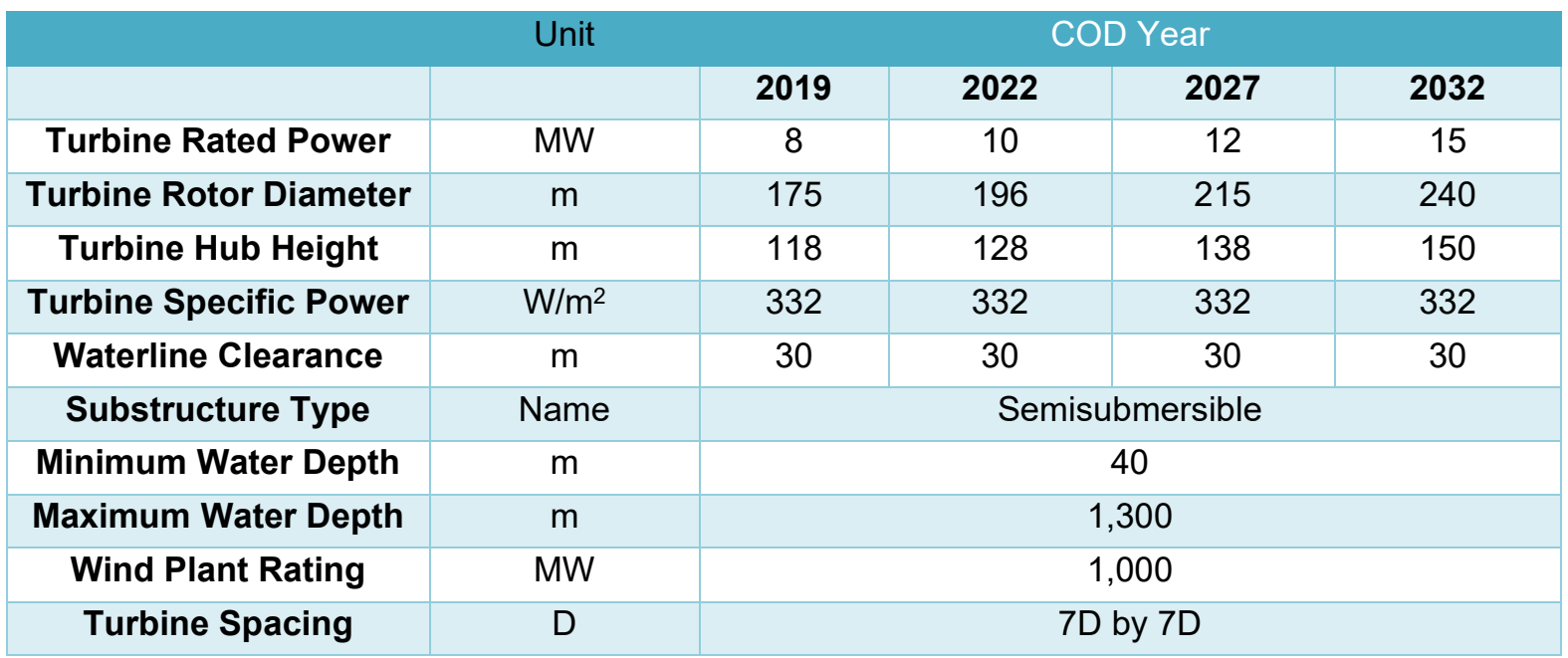

The resulting power curves for each turbine are shown in Figure 6. They embody typical features included in all variable-speed pitch-controlled wind turbine power curves. Cut-in wind speeds are about $3 \mathrm{~m} / \mathrm{s}$, the point at which the turbine begins to produce power. Region 2 of the power curve extends from the cut-in wind speed until it reaches its rated power level at $10.88 \mathrm{~m} / \mathrm{s} .{ }^{19} \mathrm{In}$ Region 2, the power increases with approximately a cubic relationship to the wind speed. When the turbine reaches rated power, power production levels off and the rated power level is maintained. Region 3 of the power curve extends between the rated wind speed and cut-out wind speed. At cut-out, the turbine is automatically shut down by feathering the blades to a zeropower position.

Typically, a 25-m/s cut-out wind speed is sufficient to capture the vast majority of the available winds at most sites without sacrificing energy production. Cut-out for the IEA Task 37 15-MW reference turbine occurs at $25 \mathrm{~m} / \mathrm{s}$, but the new offshore wind resource assessment of California has revealed that many of the California sites on the OCS have a significant fraction of average wind speeds above $25 \mathrm{~m} / \mathrm{s}$. The resulting lost energy warrants that the reference power curves be modified by extending cut-out wind speed to $30 \mathrm{~m} / \mathrm{s}$. The wind speed distributions presented later in Figure 10 (Humboldt) and Figure 12 (Del Norte) highlight two sites where the frequency of wind above $25 \mathrm{~m} / \mathrm{s}$ is significant, resulting in energy losses due to the lower wind speed cutout of about $2 \%$ to $4 \% .{ }^{20}$ We consider this increase of the cut-out wind speed from $25 \mathrm{~m} / \mathrm{s}$ to 30 $\mathrm{m} / \mathrm{s}$ a low-risk modification and a relatively minor design change that can be accommodated by the turbine designers if the conditions are known in advance.

The 15-MW reference and the 8-MW, 10-MW, and 12-MW scaled-down versions have a higher specific power (i.e., $332 \mathrm{~W} / \mathrm{m}^{2}$ ) than turbines used in previous floating cost studies conducted by NREL (i.e., $311 \mathrm{~W} / \mathrm{m}^{2}$ in 2032), such as the Oregon cost study conducted by Musial et al.

\footnotetext{
${ }^{19}$ The part of the power curve between cut-in and rated power is called Region 2 . The part of the power curve where the pitch system is maintaining rated power is called Region 3.

${ }^{20}$ Note cut-out wind speed is chosen at the wind speed where further operation above that point will result in additional wear without significant energy gain.
} 
$(2019 a)^{21}$ and will result in a small capacity factor penalty. It is not yet known what the optimum specific power rating should be for these energetic California sites, but higher specific power machines typically have lower relative energy capture in the same wind resource when compared to machines with lower specific power. This is because for a given nameplate capacity, there is less available energy passing through the smaller rotor plane of a higher specific power wind turbine. As such, the turbines in this California study have 6.7\% less swept area than the Oregon cost study, which indicates additional conservatism for the California turbines. In addition, the Oregon cost study assumed power coefficients that were approximately $2 \%$ higher than existing machines.

Most of the factors mentioned previously relate directly to the aerodynamic energy conversion of the wind. Another assumption of this reference design is in the conversion of mechanical energy to electrical energy. The reference wind turbine assumes that generator efficiency is a fixed constant at $93 \%$, which may be conservative for direct-drive machines, especially if most of the operating hours are above rated wind speed. This value comes from a simplified electromagnetic and structural model of a permanent magnet outer rotor-inner stator generator built in the WISDEM GeneratorSE module (Gaertner et al. 2020). Generator efficiencies were determined by computing electrical and mechanical losses at rated and off-design shaft rotational speeds. The effect of applying the $93 \%$ generator efficiency is to delay rated power, effectively shifting Region 2 and the rated wind speed to the right on the power curve. This means a lower Region 2 curve and overall lower energy capture relative to a turbine with a higher generator efficiency.

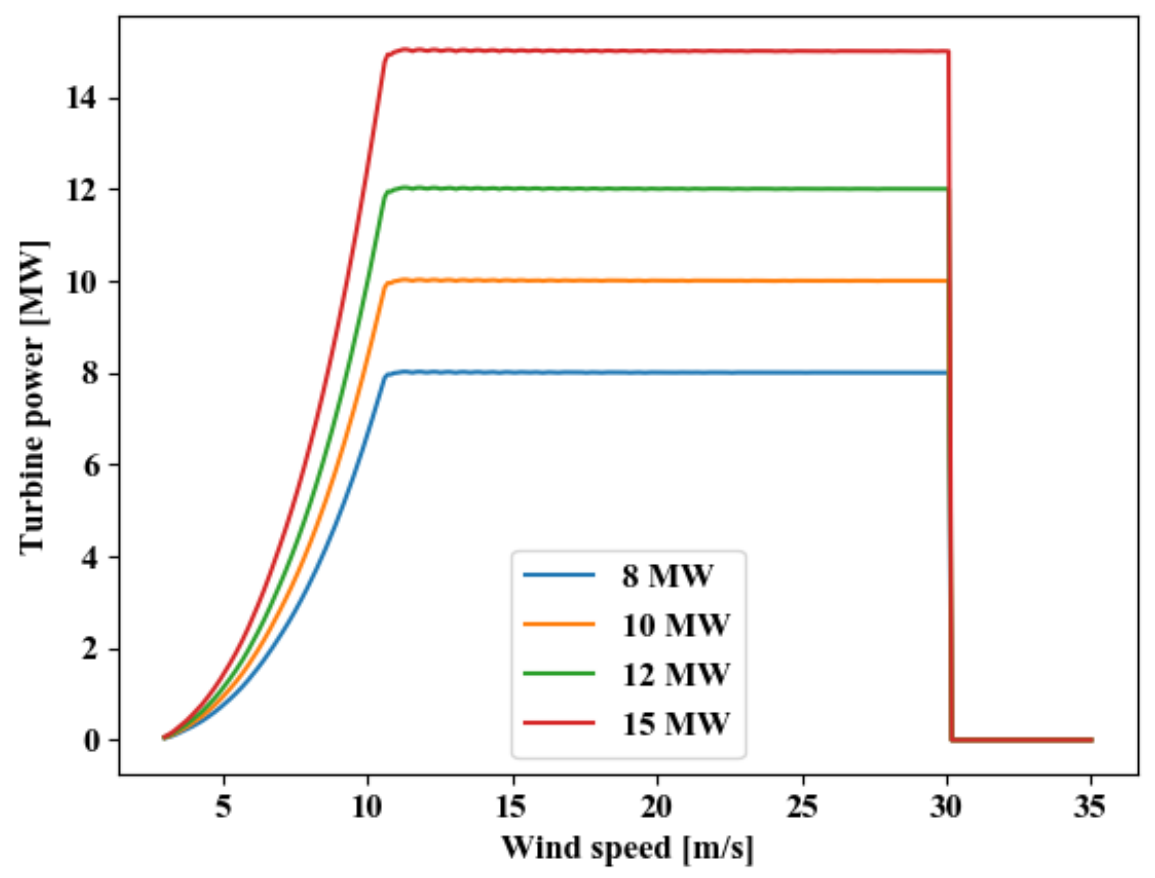

Figure 6. Offshore wind turbine power curves corresponding to $2019,2022,2027$, and $2032^{22}$

\footnotetext{
${ }^{21}$ Note that the GE Haliade-X 12-MW wind turbine has a specific power of $316 \mathrm{~W} / \mathrm{m}^{2}$.

22 Note that $1 \mathrm{MW}=1,000 \mathrm{~kW}$.
} 
Aside from the turbine-specific technology assumptions, Table 2 indicates water depth boundaries, plant size, and turbine spacing. The minimum and maximum water depths indicated do not imply any technology limit but provide geographic boundaries to guide the analysis. The 1,300-m maximum water depth was selected as an outer boundary, which was increased from $1,000 \mathrm{~m}$ in previous studies. It is not intended to be a hard technology limit but provides a useful boundary for the cost and resource studies (Optis et al. 2020). The selection of this boundary and the inner 40-m boundary have no impact on the cost analysis. The water depths used are the actual depths of the study areas. The project size of 1,000 MW was chosen and is assumed to be representative of future project sizes. Although early floating projects in the 2022 to 2027 time frame may not scale immediately to $1,000-\mathrm{MW}$ project sizes, based on announced fixed-bottom projects, we assume that this project scale is and will be representative of the mature floating industry (Musial et al. 2020b). NREL performed a sensitivity on this parameter to determine that there is about a $2 \%$ cost benefit in scaling up from $600 \mathrm{MW}$ to $1,000 \mathrm{MW}$, although this does not consider benefits from bulk pricing, supply chain efficiencies, or more efficient management costs. The turbine spacing assumption of 7 rotor diameters (D) by 7 rotor diameters is considered relatively tight and probably not an optimum within an array loss and cost trade space, especially with prevailing wind directions so consistently coming from one uniform direction. As such, we consider the wake loss calculations in this study to be conservative and are subject to improvement during actual implementation. Finally, a project financial lifetime of 30 years and construction period of 2 years was assumed for cost modeling purposes.

Although not explicitly stated in Table 2, the study does not account for infrastructure investments in supply chain, ports, and the land-based grid. These infrastructure investments could negatively influence the first projects and increase their threshold barriers. Consequently, the LCOE for the initial projects will be negatively impacted if these costs are passed on to the developers. Other interested parties might support infrastructure development and assume part of the associated investments for establishing this new source of renewable energy. 


\section{Annual Energy Production Calculation Methodology and Results}

Annual energy production (AEP) is a primary driver in determining LCOE. First, the gross AEP is determined from the wind resource data from the five study sites and the wind turbine power curves for each COD year. This represents the theoretical energy production without losses. Then, a series of energy loss calculations are made to determine the net AEP, or the energy delivered to the grid from the modeled wind farm. The gross and net energy production values are expressed in terms of gross and net capacity factors (GCF and NCF), or the fraction of a year the power plant would need to operate at its full capacity to generate the net AEP.

We used FLORIS to estimate both wake losses and gross AEP in floating offshore wind farms in California (NREL 2019b). The wake losses computed by FLORIS are combined with other plant losses computed with ORCA to yield the net AEP. The key modeling assumptions and methodology are outlined before the GCF, losses, and NCF results are presented.

\subsection{Wind Resource Data}

This study uses a state-of-the-art wind resource data set to provide the best possible assessment of the AEP for floating offshore wind power plants in California (Optis et al. 2020). This new California data set (referred to as CA20) was produced by NREL using the Weather Research and Forecasting numerical weather prediction model to improve upon NREL's Wind Integration National Dataset (WIND) Toolkit (Draxl et al. 2015). The CA20 data cover a 20-year modeling period (2000-2019) instead of 7 years used in the WIND Toolkit (2007-2013) and leverages recent advancements in the atmospheric modeling community to provide the best assessment of the offshore wind resource in California to date. The resulting 20-year mean wind speeds at 100 $\mathrm{m}$ are shown for the OCS offshore California in Figure 7. 


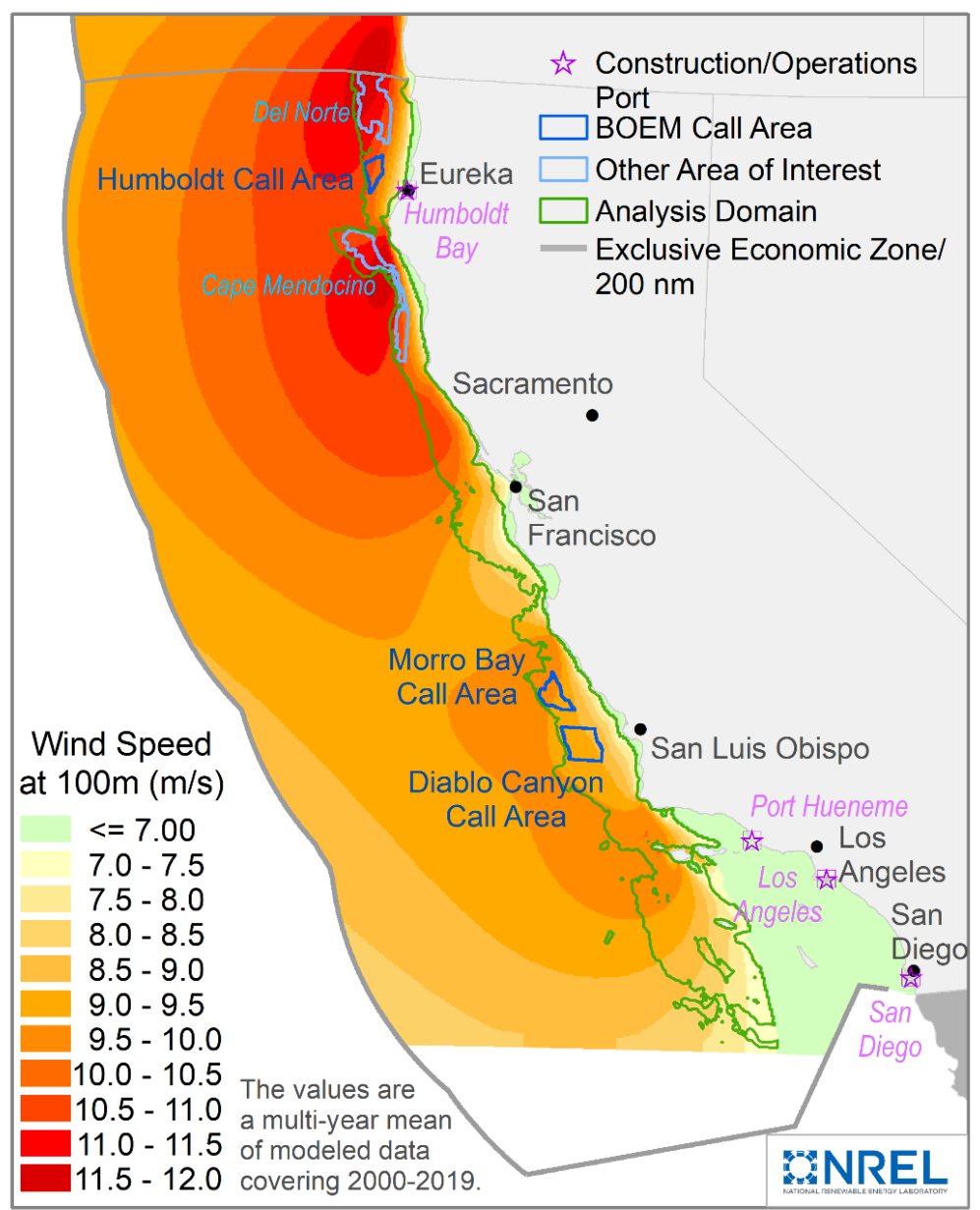

Figure 7. Mean annual wind speed for the California OCS based on the new CA20 data set. Reproduced from Optis et al. (2020)

Note: Wind speed at a $100-m$ elevation

The results of the CA20 resource study indicate an increase in the mean wind speeds for most of the OCS offshore California compared with 2013 WIND Toolkit data (Optis et al. 2020). This increase is shown in Figure 8, which maps the annual mean wind speed on the OCS for the CA20 data (left), the WIND Toolkit data (center), and the difference between them (right). The increases in the 100-m mean wind speed for the CA20 data are as high as $2 \mathrm{~m} / \mathrm{s}$ in some locations, representing up to about a $20 \%$ increase in mean wind speed in some of the study areas. We determined the increases in the 100-m mean wind speeds at the centroids of the California Call Areas to be 9.7\%, 17.4\%, and 19.7\% for Humboldt, Morro Bay, and Diablo Canyon, respectively. 

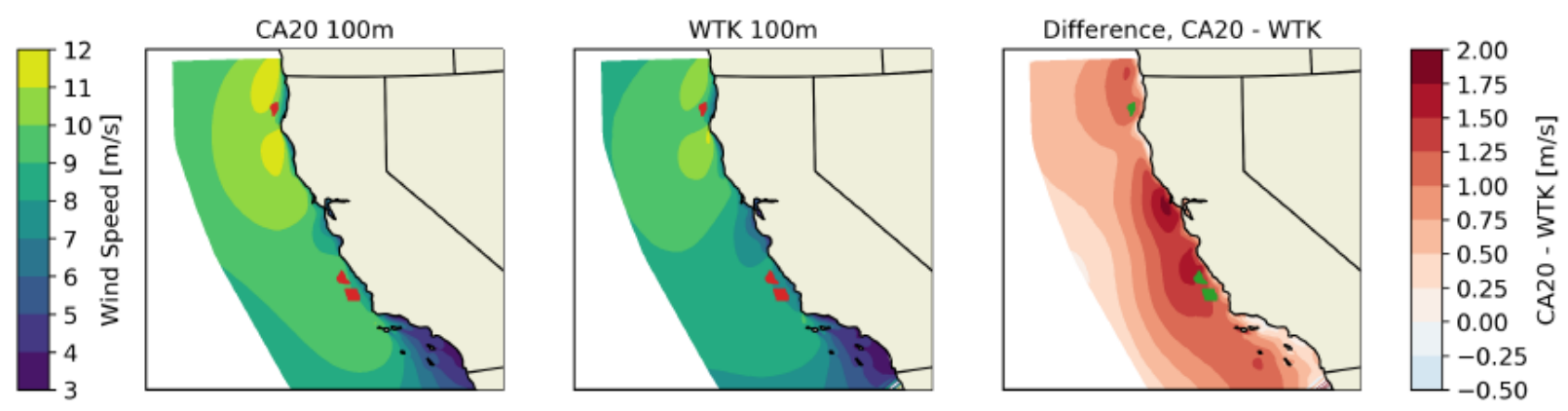

Figure 8. Comparing the mean annual 100-m wind speeds from the new data set CA20 (left) and the WIND Toolkit (WTK, center). The difference between the maps is shown on the right. Reproduced from Optis et al. (2020)

Optis et al. (2020) attributes much of the increase in the modeled wind resource to an updated planetary boundary layer scheme. CA20 uses the Mellor-Yamada-Nakanishi-Niino planetary boundary layer scheme and ERA5 reanalysis data instead of the Yonsei University scheme ERAinterim reanalysis product used in the WIND Toolkit. The choice of planetary boundary layer scheme impacts how turbulence distributes momentum in the model, and therefore the vertical wind shear profile. The high frequency of stable atmospheric conditions contributes to this because the two schemes diverge under these conditions. Other sources of the differences may include the extensive upgrades to the Weather and Resource Forecasting model between Version 4.1.2 (used in CA20) and Version 3.4 (used in the WIND Toolkit and released back in 2013), and the choice of topographic and land-use data.

The increase in the offshore wind resource across the OCS offshore California means an increased technical offshore wind resource potential, which has further implications for the cost of energy and wind energy development in California. These impacts are investigated further in Section 567.5.

\subsubsection{Study Area Wind Characteristics}

Wind roses and histograms of the wind distributions at the centroids of the five study sites and wind roses based on the full 20-year CA20 data set, at an elevation of $150 \mathrm{~m}$, are presented in Figure 9 through Figure 13. Note that $150 \mathrm{~m}$ is used because this height represents the assumed hub height of the turbine used for the AEP analysis in COD 2032 . The cut-in $(3 \mathrm{~m} / \mathrm{s})$, rated $(10.88 \mathrm{~m} / \mathrm{s})$, and cut-out $(30 \mathrm{~m} / \mathrm{s})$ wind speeds are indicated in the wind speed histograms on the left side. 


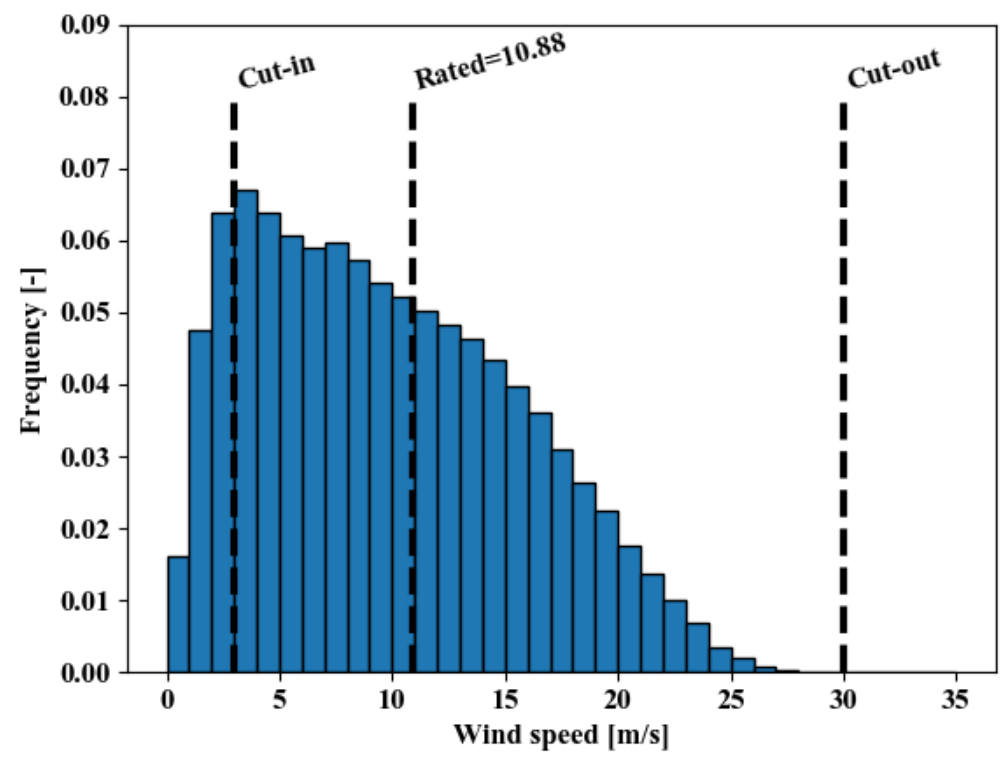

(a)

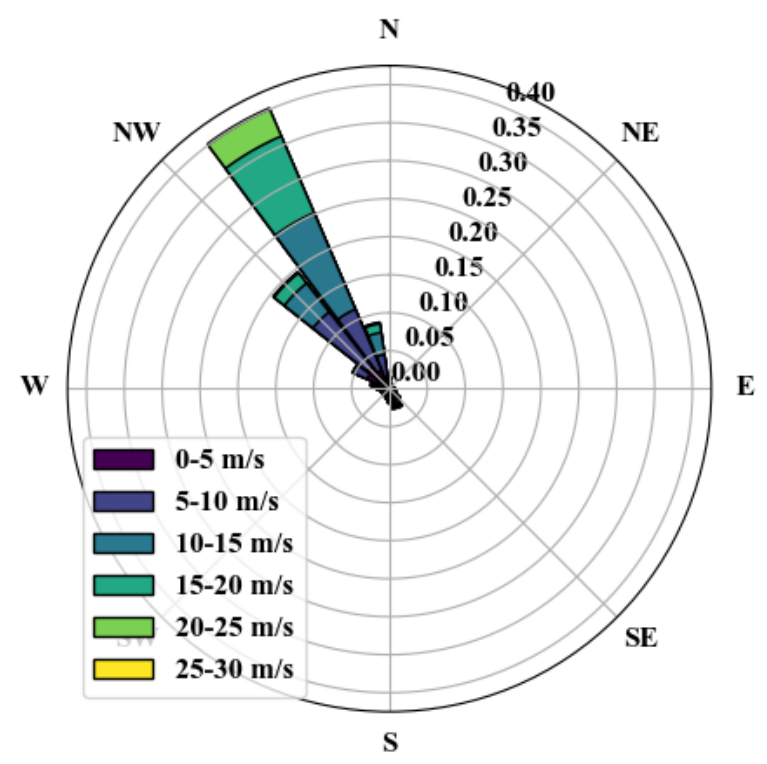

(b)

Figure 9. (a) A 150-m histogram of wind speed distribution and (b) wind rose at Site 1: Morro Bay. Cut-in, rated, and cut-out wind speeds indicated in (a). 


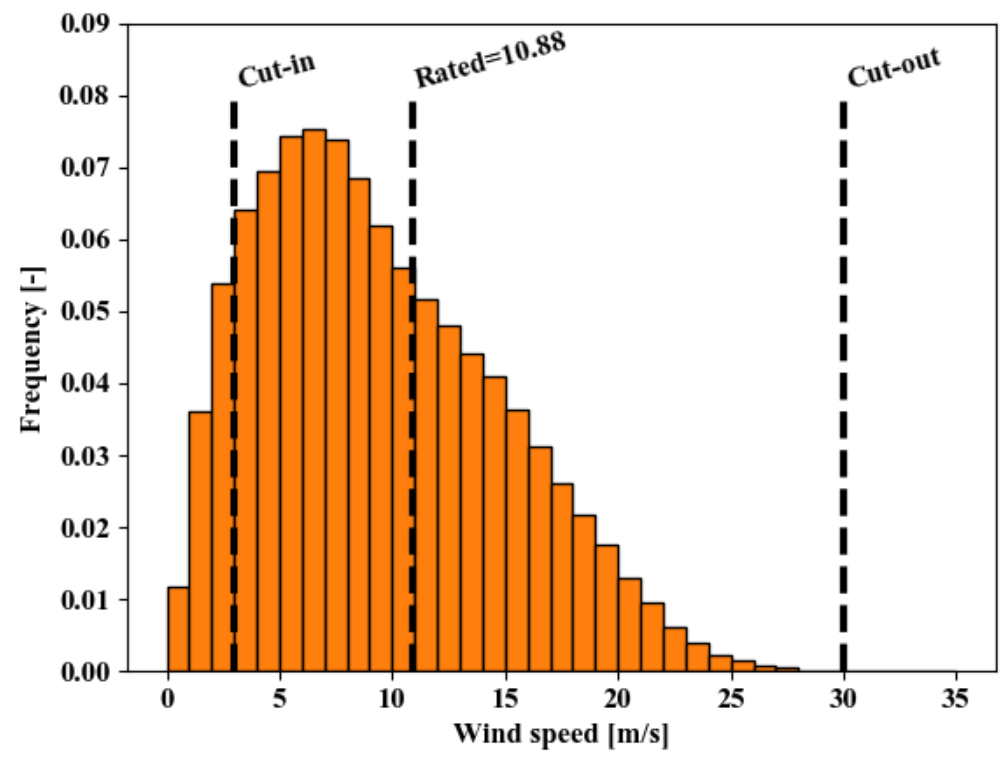

(a)

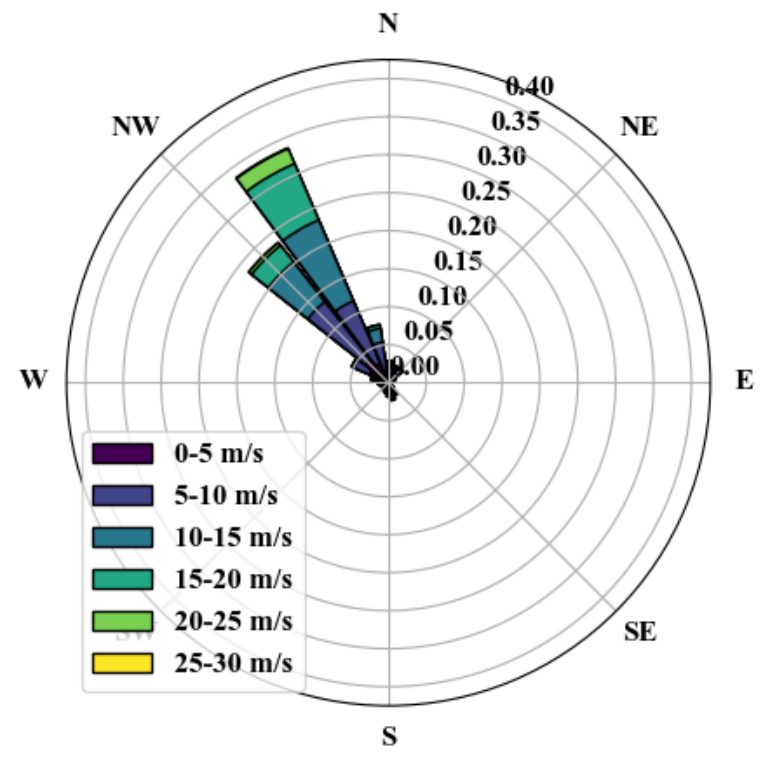

(b)

Figure 10. (a) A 150-m histogram of wind speed distribution and (b) wind rose at Site 2: Diablo Canyon. Cut-in, rated, and cut-out wind speeds indicated in (a). 


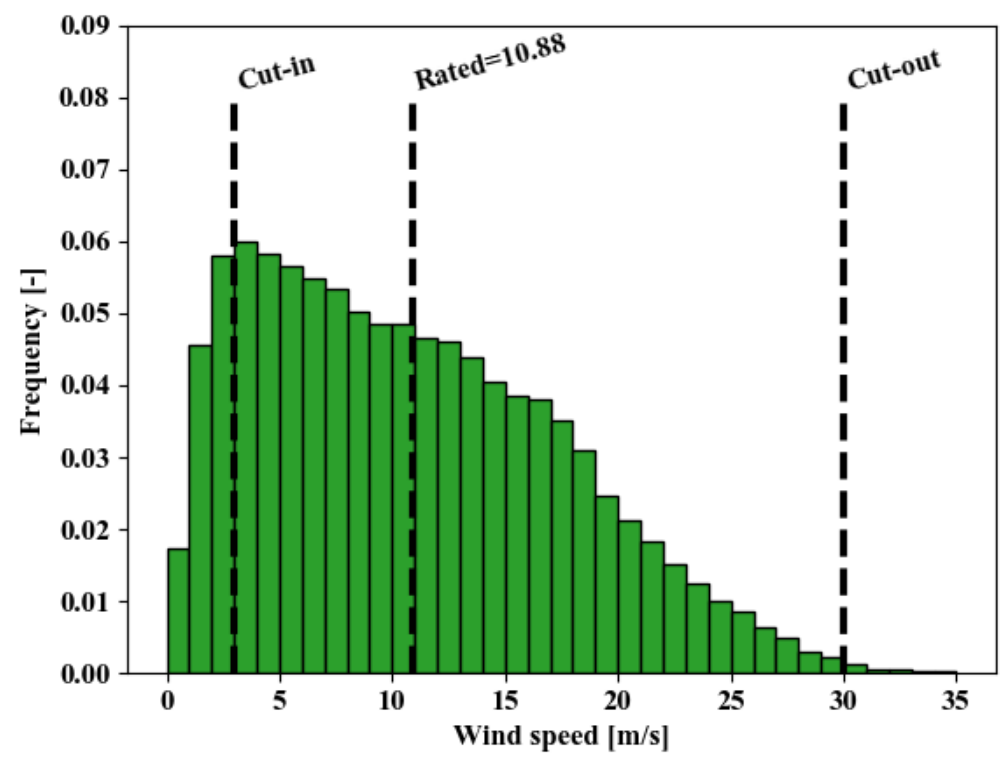

(a)

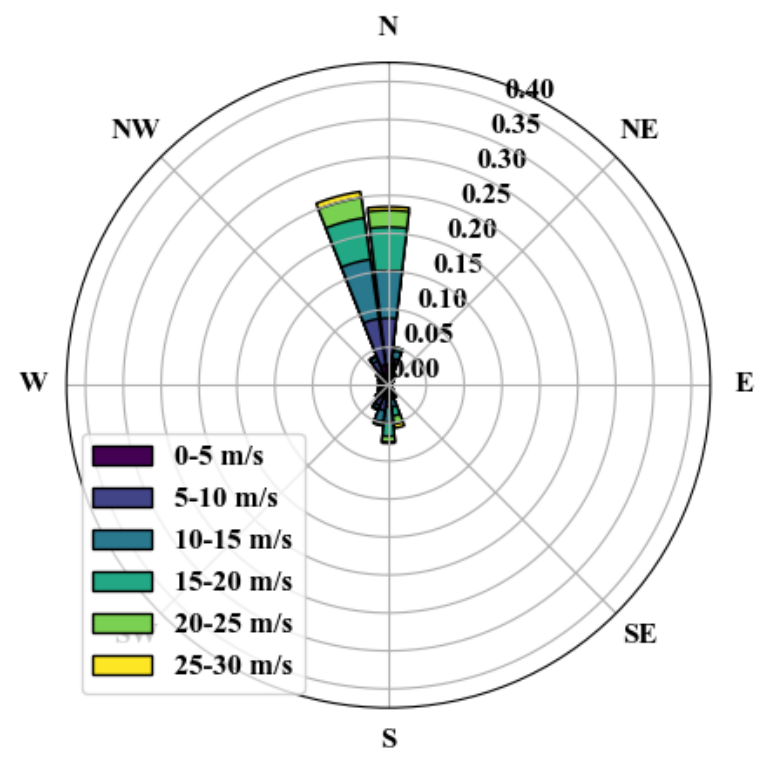

(b)

Figure 11. (a) A 150-m histogram of wind speed distribution and (b) wind rose at Site 3: Humboldt. Cut-in, rated, and cut-out wind speeds indicated in (a). 


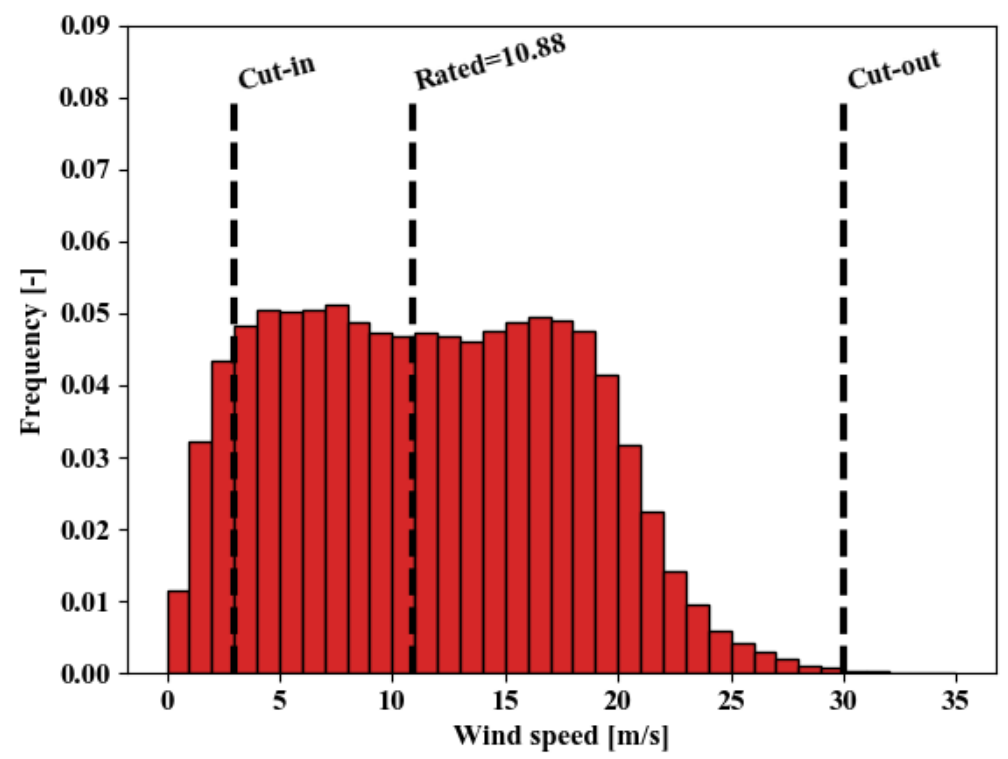

(a)

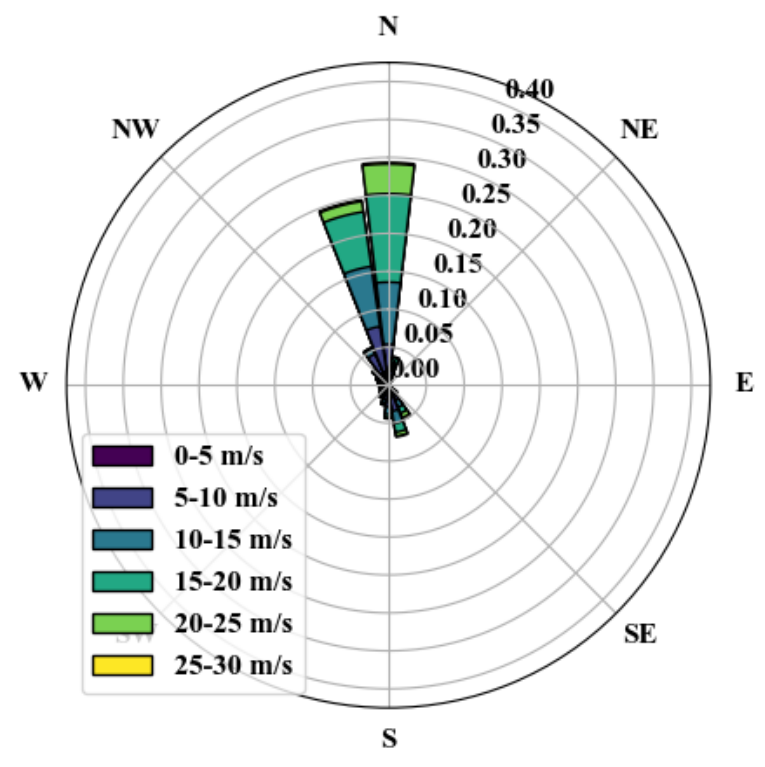

(b)

Figure 12. (a) A 150-m histogram of wind speed distribution and (b) wind rose at Site 4: Cape Mendocino. Cut-in, rated, and cut-out wind speeds indicated in (a).

Note that compared to the other four sites, the wind distribution at the centroid of Cape Mendocino has a nearly flat shape from the cut-in wind speed to around $20 \mathrm{~m} / \mathrm{s}$. This represents a good portion of the wind turbine operational range. 


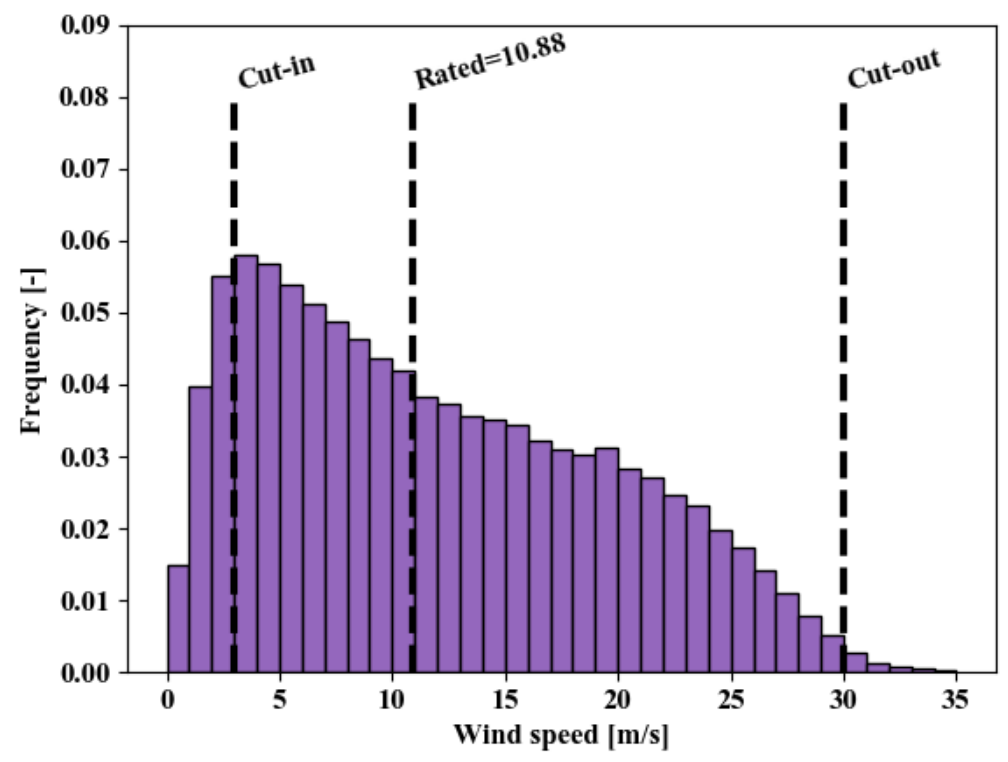

(a)

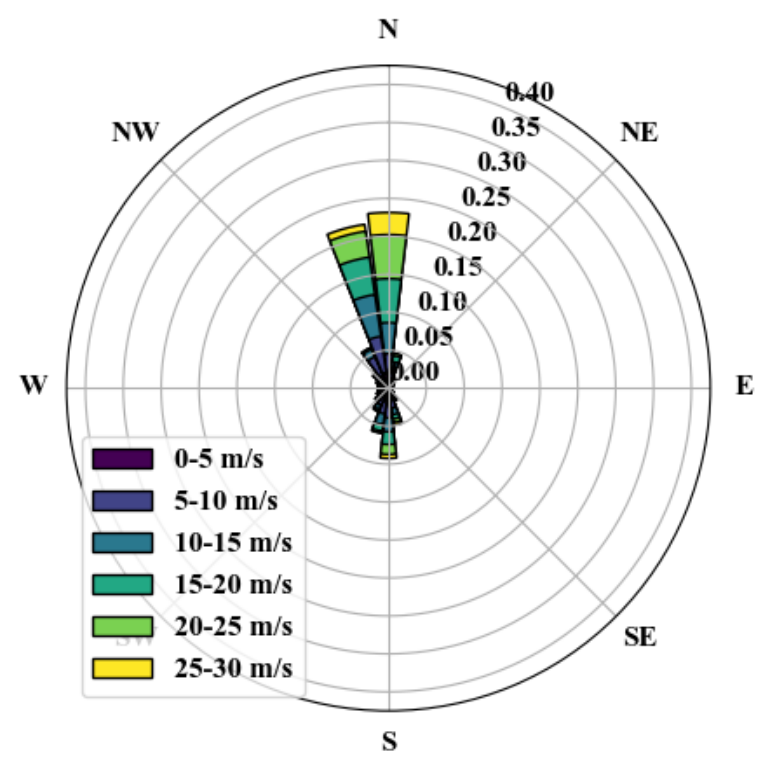

(b)

Figure 13. (a) A 150-m histogram of wind speed distribution and (b) wind rose at Site 5: Del Norte. Cut-in, rated, and cut-out wind speeds indicated.

Note in the wind speed distribution at the centroid of Del Norte that wind speeds between $25 \mathrm{~m} / \mathrm{s}$ and $30 \mathrm{~m} / \mathrm{s}$ are relatively frequent, representing about $5.6 \%$ of the time covered in the 20 -year CA20 data set. Only $0.6 \%$ of the time is spent at wind speeds greater than $30 \mathrm{~m} / \mathrm{s}$. This informed the decision to extend the operational range of the turbine power curves used in the AEP assessment to a cut-out wind speed of $30 \mathrm{~m} / \mathrm{s}$. The justification for this is described in Section 3.2 . 
Another key trend in the wind roses across the California sites is that the winds are very predictable and come predominantly from the north or northwest in a very tight band. This will likely enable plant layouts with tighter row spacing and possible reduced losses from wind turbine wake effects relative to a rectangular array, as modeled in the wake loss analysis.

In addition to the wind distributions, the mean wind profiles at the study site centroids are presented in Figure 13, which shows the 20-year mean wind profiles at the study site centroids. These profiles comprise 20-year means at different heights, including the hub heights of the turbine models used for different COD years in this study: $118 \mathrm{~m}$ (2019), $128 \mathrm{~m}$ (2022), $138 \mathrm{~m}$ (2027), and $150 \mathrm{~m}$ (2032). Figure 13 indicates that the sites with the greatest average vertical wind shear are the sites in Northern California.

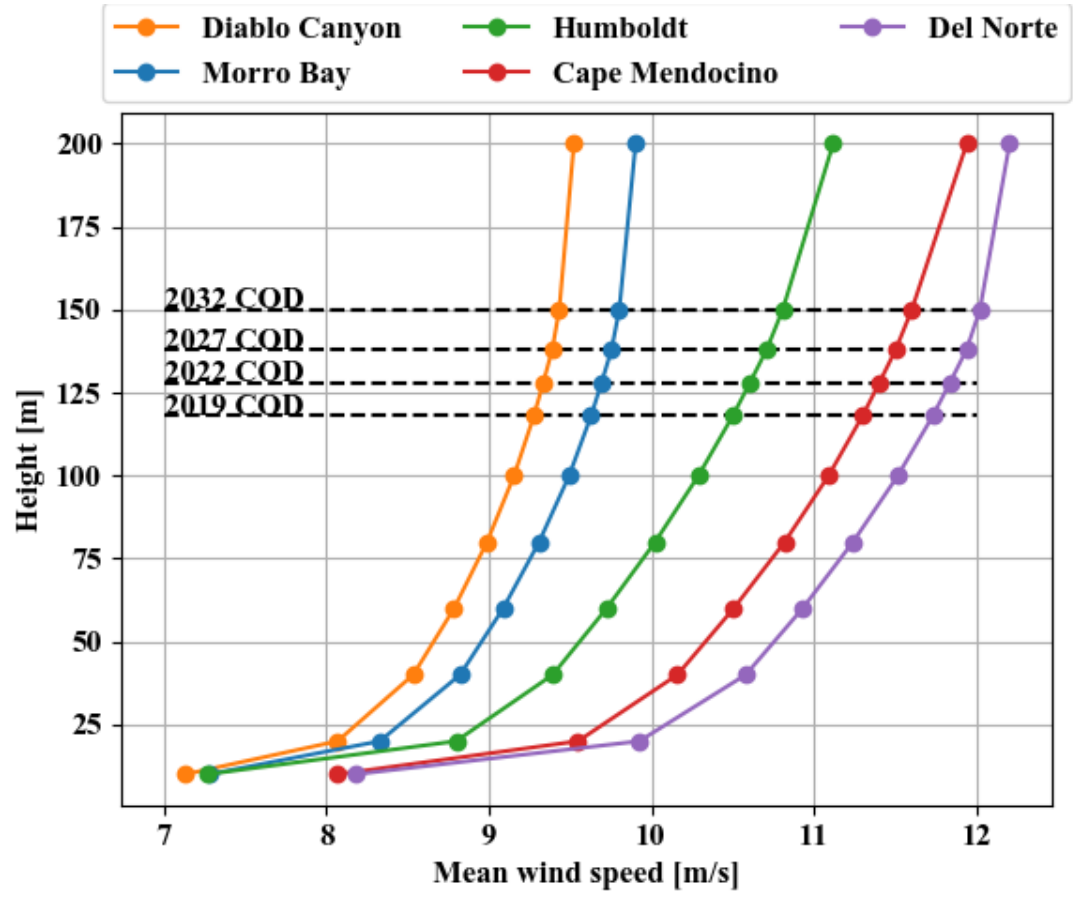

Figure 14. 20-year mean wind profiles at the study site centroids. Assumed hub heights of $118 \mathrm{~m}$, $128 \mathrm{~m}, 138 \mathrm{~m}$, and $150 \mathrm{~m}$ are noted for the COD years investigated.

\subsection{Wind Power Plant Model}

The wind power plant model is made up of the wind turbine model, turbine layout, and the flow model. FLORIS is used to calculate the gross AEP and wake losses. These data are fed into ORCA to apply additional losses and compute the NCF and LCOE. Integrating FLORIS with ORCA for the energy yield and wake loss analysis significantly expands the analysis capabilities of ORCA than versions used in previous reports (Musial et al. 2019a, 2016a). Previously, Openwind simulations were fixed for a 600-MW wind power plant of 6-MW turbines and used wind resource data from the WIND Toolkit (Draxl et al. 2015). Coupling ORCA with FLORIS offers greater flexibility in varying plant and turbine capacities, plant layouts, specific turbine models, and wind resource data. Additionally, FLORIS improves the fidelity of results and transparency of modeling assumptions in terms of understanding energy production at a turbine 
level and modeling inputs. This gives better insight into cost analysis, especially as the industry evolves and different plant and turbine configurations are considered.

\subsubsection{Wind Turbine}

The turbine models used in this report are based on the IEA Task 37 15-MW reference wind turbine (Gaertner et al. 2020). The key parameters for the energy production analysis are the turbine hub height, rotor diameters, and power coefficient and thrust coefficient curves. See Section 3.2 for the turbine specifications and curves.

\subsubsection{Plant Layout}

The plant layout considered in this report is intended to serve as a generic basis of comparison for the sites across the OCS offshore California. The layout is not optimized to account for sitespecific wind resource data, bathymetry, geohazards, array cable arrangements, or other cost drivers. The reference power plant considered in this investigation has a nominal total plant capacity of 1,000 MW. The actual plant capacity for each COD year is the number closest to $1,000 \mathrm{MW}$, which is evenly divisible by the turbine capacity, as only integer numbers of turbines are considered. The exact plant capacity is used in calculations of gross and net capacity factors.

Consistent with the 2019 NREL cost study for floating wind in Oregon (Musial et al. 2019a), turbines were spaced 7D apart with a configuration as close to a square grid as possible. The plant layout for COD 2022, shown in Figure 14, has equal numbers of turbines along rows and columns, because the 100 turbines (i.e., $10 \mathrm{MW}$ each) needed to reach the 1,000-MW plant capacity is a perfect square. In cases where the number of turbines is not a perfect square, such as the 67 15-MW turbines needed in COD 2032, a partial column is filled on the east side of the plant. See Appendix C for more detail and plots of the layouts for each COD year.

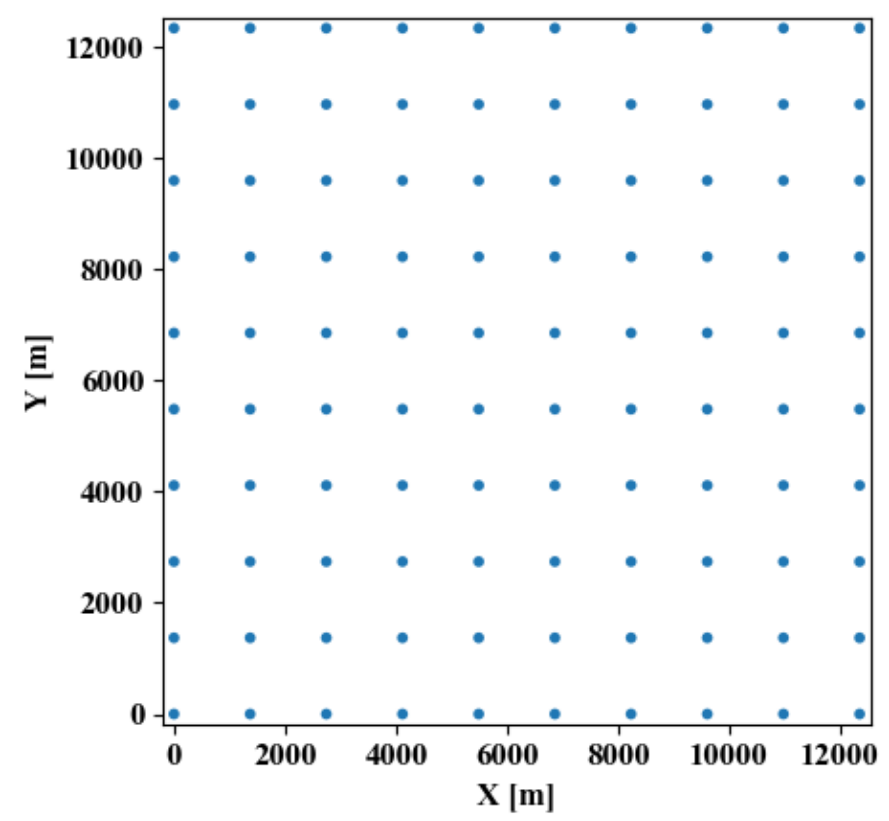

Figure 15. Plant layout for the 2022 (10-MW wind turbines). The dot radius represents one rotor diameter. 
This generic square turbine layout and 7D spacing is considered conservative in terms of wake losses. We showed that the wind roses presented in Figure 9 through Figure 13 have an extremely dominant and predictable prevailing wind direction from the north and northwest, which presents a significant opportunity to further lower wake losses with more optimum turbine and row spacing. Decreasing row spacing in the direction perpendicular to the dominant flow could potentially allow for a greater density of installed capacity within a given area.

\subsubsection{Flow Model in FLORIS}

FLORIS includes a set of engineering tools for computationally inexpensive analysis of the steady-state wake characteristics in a wind farm. The steady-state wake conditions modeled by the type of engineering models available in FLORIS lack the fidelity of large-eddy simulation or direct numerical simulations, but FLORIS can be embedded into NREL's cost model without a substantial computational burden. Lower-fidelity engineering wake models were found to perform reasonably well for energy yield estimates compared to higher fidelity techniques (Nygaard 2015; Walker et al. 2015).

The flow model in FLORIS consists of an engineering wake model to obtain the velocity deficit in a single wind turbine wake with a wake superposition method to account for wakes of multiple turbines. Turbulence and wake deflection models are also implemented in FLORIS. A Gaussian wake model and a sum of squares wake summation method are used (King et al. 2020). Tuning parameters are consistent with those used by Annoni et al. (2018) per the recommendations of the FLORIS development team at NREL. A free-stream turbulence intensity of $6 \%$ is prescribed to the inflow, as this is thought to be conservative for offshore wake recovery based on consultation with NREL experts.

\subsection{Gross Energy Production}

Gross AEP represents the AEP without losses. This idealized value serves as a reference and is derived from the wind distribution and turbine power curve. The gross capacity factor (GCF) allows for a comparison of wind resource between different wind energy sites and plant sizes. The GCF and NCF results for this study are presented in Sections 4.4 and 4.5.

\subsection{Loss Categories}

The net AEP represents the predicted AEP delivered to the land-based grid. It accounts for a wide range of losses that are applied to the gross energy production. Loss categories are described in this section, and their calculated magnitudes for the five study sites are presented in Section 4.5 along with the NCF results. The International Electrotechnical Commission (IEC) outlines a broad list of wind power plant loss categories, which are provided in Table 3 . The table highlights which losses are considered in the analysis with ORCA and how they are accounted (Filippelli 2019). 
Table 3. IEC Loss Categories for Wind Farms

\begin{tabular}{|c|c|c|c|}
\hline Category & Description & $\begin{array}{l}\text { Included } \\
\text { in ORCA }\end{array}$ & How Accounted? \\
\hline \multicolumn{4}{|l|}{ Wake Effect } \\
\hline Internal wake effects & Wake effects internal to the wind power plant & Yes & FLORIS \\
\hline External wake effects & Wake effects external to the wind power plant & No & N/A \\
\hline Future wake effects & $\begin{array}{l}\text { Wake effects that will impact future energy projections } \\
\text { based on either confirmed or predicted new project } \\
\text { development or decommissioning }\end{array}$ & No & $\mathrm{N} / \mathrm{A}$ \\
\hline \multicolumn{4}{|l|}{ Availability } \\
\hline Turbine availability & $\begin{array}{l}\text { Turbine availability (energy-based), considering } \\
\text { warranted availability, noncontractual availability, restart } \\
\text { after grid outage, site access, downtime (or speed)-to- } \\
\text { energy ratio, first year/plant start-up availability }\end{array}$ & Yes & $\begin{array}{l}\text { Bulk availability } \\
\text { assumption }\end{array}$ \\
\hline $\begin{array}{l}\text { Balance of plant } \\
\text { availability }\end{array}$ & $\begin{array}{l}\text { Availability of substation and collection system, other } \\
\text { nonturbine availability, warranted availability, site access, } \\
\text { first year/plant start-up }\end{array}$ & Yes & $\begin{array}{l}\text { Bulk availability } \\
\text { assumption }\end{array}$ \\
\hline Grid availability & $\begin{array}{l}\text { Grid being outside, grid connection agreement } \\
\text { operational parameters, actual grid downtime, delays in } \\
\text { restart after grid outages }\end{array}$ & Yes & $\begin{array}{l}\text { Bulk availability } \\
\text { assumption }\end{array}$ \\
\hline \multicolumn{4}{|c|}{ 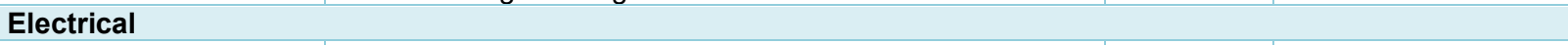 } \\
\hline Electrical efficiency & $\begin{array}{l}\text { Electrical losses between the low- or medium-voltage side } \\
\text { of the turbine transformers and the energy measurement } \\
\text { point }\end{array}$ & Yes & $\begin{array}{l}\text { Only electrical losses } \\
\text { from export cables } \\
\text { considered }\end{array}$ \\
\hline $\begin{array}{l}\text { Facility parasitic } \\
\text { consumption }\end{array}$ & $\begin{array}{l}\text { Turbine extreme weather packages, other turbine and/or } \\
\text { plant parasitic electrical losses (while operating or not } \\
\text { operating) }\end{array}$ & No & N/A \\
\hline \multicolumn{4}{|l|}{ Turbine Performance } \\
\hline $\begin{array}{l}\text { Suboptimal } \\
\text { performance }\end{array}$ & $\begin{array}{l}\text { Performance deviations from the optimal wind plant } \\
\text { performance as a result of software, instrumentation, and } \\
\text { control setting issues }\end{array}$ & Yes & $\begin{array}{l}0.1 \% \text { for onboard } \\
\text { equipment }\end{array}$ \\
\hline $\begin{array}{l}\text { Generic power curve } \\
\text { adjustment }\end{array}$ & $\begin{array}{l}\text { Expected deviation between advertised power curve and } \\
\text { actual power curve performance in standard conditions }\end{array}$ & No & $\mathrm{N} / \mathrm{A}$ \\
\hline $\begin{array}{l}\text { Site-specific power } \\
\text { curve adjustment }\end{array}$ & $\begin{array}{l}\text { Accommodating for inclined flow, turbulence intensity, } \\
\text { density, shear, and other site-/project-specific } \\
\text { adjustments }\end{array}$ & Yes & $\begin{array}{l}0.1 \% \text { for rotor } \\
\text { misalignment }\end{array}$ \\
\hline High wind hysteresis & $\begin{array}{l}\text { Energy lost in the hysteresis loop between high wind } \\
\text { speed cut-out and recut-in }\end{array}$ & Yes & $1 \%$ for hysteresis \\
\hline \multicolumn{4}{|l|}{ Environmental } \\
\hline Icing & Performance degradation and shutdown caused by icing & Yes & $\begin{array}{l}1 \% \text { total for icing and } \\
\text { blade soiling } \\
\text { combined }\end{array}$ \\
\hline Degradation & $\begin{array}{l}\text { Blade fouling, efficiency losses, and other environmentally } \\
\text { driven performance degradation }\end{array}$ & Yes & See above cell \\
\hline Environmental loss & $\begin{array}{l}\text { High-/low-temperature shutdown or de-rate, lightning, } \\
\text { hail, and other environmental shutdowns }\end{array}$ & Yes & $\begin{array}{l}0.5 \% \text { caused by high } \\
\text { temperature } \\
\text { shutdown, } 0.1 \% \\
\text { caused by lightning }\end{array}$ \\
\hline Exposure & $\begin{array}{l}\text { Tree growth or logging, other building development, and } \\
\text { so on }\end{array}$ & No & N/A \\
\hline \multicolumn{4}{|c|}{ Curtailments/ Operational Strategies } \\
\hline Load curtailment & Speed and or direction curtailments to mitigate loads & No & $\mathrm{N} / \mathrm{A}$ \\
\hline Grid curtailment & $\begin{array}{l}\text { Power purchase agreement/off-taker curtailments, grid } \\
\text { limitations }\end{array}$ & No & $\mathrm{N} / \mathrm{A}$ \\
\hline $\begin{array}{l}\text { Environmental/ } \\
\text { permit curtailment }\end{array}$ & $\begin{array}{l}\text { Birds, bats, marine mammals, flicker, noise (when not } \\
\text { captured in the power curve), and so on }\end{array}$ & No & $\mathrm{N} / \mathrm{A}$ \\
\hline $\begin{array}{l}\text { Operational } \\
\text { strategies }\end{array}$ & $\begin{array}{l}\text { Any periodic up-rating, down-rating, optimization, or } \\
\text { shutdown not captured in the power curve or availability } \\
\text { carve outs }\end{array}$ & No & N/A \\
\hline
\end{tabular}


Note that ORCA combines the loss categories like efficiencies of different stages in a series of processes. This can be thought of as:

$$
L_{\text {total }}=1-\left[\left(1-L_{1}\right) *\left(1-L_{2}\right) \ldots *\left(1-L_{n}\right)\right]
$$

where $L_{\text {total }}$ represents the total loss, and $L_{1}, L_{2}$, and $L_{n}$ are the losses considered. This differs from direct summation of the loss categories. Similarly, the total losses represent the percentage of the GCF that is lost before delivery to the grid, whereas the GCF and NCF are expressed relative to the energy if the power plant was always operating at full capacity. This means the NCF and total losses will not directly add as percentages to total the GCF.

\subsubsection{Wake Losses}

A wake forms behind a turbine as it extracts momentum from the wind. Wind turbine wakes are regions of reduced wind speed and increased turbulence. For a turbine operating in the wake of another, this means lower power production and increased fatigue loads. As the wake propagates downstream, the kinetic energy of the wake is replenished by turbulent mixing with the freestream layers outside the wake boundaries. Eventually at some distance downstream, the wind speed recovers to the point where it is no longer distinguishable from the free-stream wind speed.

Wake losses represent the energy lost as a result of the decreased wind speeds in the turbine wakes interacting with downstream turbines. The wake loss $L_{\text {wake }}$ is computed as:

$$
L_{\text {wake }}=\frac{A E P_{\text {gross }}-A E P_{\text {wakes }}}{A E P_{\text {gross }}}
$$

where $A E P_{\text {gross }}$ represents the gross AEP, and $A E P_{\text {wakes }}$ represents the AEP after wake losses are considered. Both are computed with FLORIS. The magnitude of the wake loss depends primarily on the turbine thrust curve, the wind speed and direction distributions, and the plant layout. Although they may be significant, wake effects from other wind plants or future wind energy development are not considered, and neither are deep-array effects or wind plant blockage effects, such as those discussed in Bleeg et al. (2018). These topics serve as possible points of future improvements in the cost modeling methodology.

\subsubsection{Environmental Losses}

The generic losses include a standard value of $1 \%$ for energy lost as a result of icing or blade soiling. The 1\% loss may be high for offshore sites in southern California where ice or soiling accumulations on blades would be rare, but this loss was applied generically across all sites recognizing that sites in the north may experience greater losses due to icing. Environmental losses also include $0.5 \%$ for low-/high-temperature shutdowns and $0.1 \%$ for lightning losses. Effects from building development or tree growth are ignored offshore. These assumptions for generic environmental losses should be reassessed if actual energy yield assessments are being made but are considered conservative for offshore sites in California where icing, soiling, and lightning conditions may be more benign. These losses are the same values as those used in Musial et al. (2019a). 


\subsubsection{Technical Losses}

A $1 \%$ loss is assumed because of hysteresis, $0.1 \%$ for onboard equipment (parasitic load), and $0.1 \%$ for rotor misalignment loss across all turbines. Hysteresis losses in a wind turbine arise to reduce loads on the turbine when the mean wind speed (often a 10-minute moving average) is fluctuating around the cut-out wind speed. To prevent the turbine from rapidly starting and stopping in this high-wind situation (and the induced loads), the control strategy may shut down when the mean wind speed exceeds the cut-out speed. It will then wait until the mean wind speed falls below a lower threshold than the cut-out speed to resume production. The lost energy from time when the turbine has shut down but has not resumed operation is the hysteresis loss.

\subsubsection{Electrical Losses}

Electrical losses are computed in ORCA for the export system as a function of the distance from the site to the cable landfall and the water depth (Beiter et al. 2016). These losses do not consider the electrical losses in the array cables or power electronics, which provides an opportunity for future model improvement. Inclusion of the collection system electrical losses would likely increase the total losses and decrease the NCF slightly, leading to a small increase in LCOE.

\subsubsection{Availability Losses}

The availability losses use an assumption of $95 \%$ availability, which is held constant over time. The 95\% value was obtained for the Humboldt Call Area using the Shoreline O\&M model. The availability losses are calculated as:

$$
1 \text { - availability }
$$

and represent a blanket loss of $5 \%$ resulting from turbine, plant system, and grid downtime. Note that in practice the availability has a strong dependency on the meteorological ocean (metocean) conditions, which vary across the sites. In winter there is a greater frequency of high wind speeds and large significant wave heights, which impact the ability of maintenance vessels to access the turbines for repairs and leads to lost energy production. Better accounting for the impact of the spatially varying metocean conditions on the availability represents a potential future improvement to the loss module.

\subsubsection{Performance Improvements over Time}

To account for likely improvements in turbine technology that reduce losses over time, a total loss reduction is applied based on the COD year. The total magnitude of these loss reductions by COD 2032 is $2.74 \%$ - the same as those applied at the cost analysis for Oregon (Musial et al. 2019a). Similarly, a GCF increase of 5.03\% is applied over time to account for increases in yield as a result of innovations improving the ability of the turbine to extract energy. The magnitudes of the loss reduction and GCF increase were both derived from Hundleby et al. (2017). These values are shown in Table 4.

\subsection{Net Energy Production Results}

This section details the modeled performance of the nominal 1,000-MW wind plant described in Section 4.2. First, a summary of gross capacity factors, losses, and resulting net capacity factors is provided in Table 4 for the COD years of interest. Further subsections explore the individual 
loss categories and geographic distribution of the net capacity factors across the entire analysis domain offshore California.

Table 4. Gross Capacity Factors, Losses, and Net Capacity Factors for California Study Areas

\begin{tabular}{|c|c|c|c|c|c|}
\hline Item & $\begin{array}{c}\text { Site 1: } \\
\text { Morro Bay }\end{array}$ & $\begin{array}{l}\text { Site 2: } \\
\text { Diablo } \\
\text { Canyon }\end{array}$ & $\begin{array}{l}\text { Site 3: } \\
\text { Humboldt }\end{array}$ & $\begin{array}{c}\text { Site 4: } \\
\text { Cape } \\
\text { Mendocino }\end{array}$ & $\begin{array}{l}\text { Site 5: } \\
\text { Del } \\
\text { Norte } \\
\end{array}$ \\
\hline \multicolumn{6}{|l|}{2019 COD } \\
\hline GCF [\%] & 55.5 & 54.5 & 59.4 & 61.8 & 61.1 \\
\hline $\begin{array}{l}\text { Total losses [\% of gross } \\
\text { production] }\end{array}$ & 15.0 & 16.9 & 15.3 & 14.5 & 15.2 \\
\hline NCF [\%] & 46.5 & 45.3 & 49.9 & 52.6 & 51.7 \\
\hline \multicolumn{6}{|l|}{2022 COD } \\
\hline GCF [\%] & 56.2 & 55.3 & 60.4 & 62.6 & 62.0 \\
\hline $\begin{array}{l}\text { Total losses [\% of gross } \\
\text { production] }\end{array}$ & 14.7 & 16.5 & 15.1 & 14.3 & 15.0 \\
\hline NCF [\%] & 47.2 & 46.1 & 50.8 & 53.4 & 52.6 \\
\hline \multicolumn{6}{|l|}{2027 COD } \\
\hline GCF [\%] & 57.7 & 56.8 & 62.2 & 64.3 & 63.8 \\
\hline $\begin{array}{l}\text { Total losses [\% of gross } \\
\text { production] }\end{array}$ & 14.4 & 16.1 & 14.8 & 14.0 & 14.7 \\
\hline NCF [\%] & 48.7 & 47.7 & 52.6 & 55.0 & 54.3 \\
\hline \multicolumn{6}{|l|}{2032 COD } \\
\hline GCF [\%] & 58.3 & 57.5 & 63.1 & 65.0 & 64.6 \\
\hline $\begin{array}{l}\text { Total losses [\% of gross } \\
\text { production] }\end{array}$ & 14.2 & 15.8 & 14.6 & 13.8 & 14.5 \\
\hline NCF [\%] & 49.4 & 48.4 & 53.5 & 55.8 & 55.2 \\
\hline
\end{tabular}

The northern California sites with stronger wind resources (Humboldt, Cape Mendocino, and Del Norte) have the highest GCF values across all years. Cape Mendocino has the highest NCF because it has the highest GCF and lowest total losses overall. Diablo Canyon has the lowest NCF because it starts with the lowest GCF and has the highest total losses. These losses are broken down in detail in Section 4.5.1.

\subsubsection{Losses}

To further understand how the different sources of losses impact the performance of the nominal wind plant at each of the study sites, the different categories are summarized in Table 5 and can be visualized in Figure 16. The mean loss values across the entire analysis domain are also included in Table 5 for reference. 
Table 5. Losses for California Study Areas for 2019 COD

\begin{tabular}{|l|c|c|c|c|c|c|}
\cline { 2 - 7 } \multicolumn{1}{c|}{} & $\begin{array}{c}\text { Site 1: } \\
\text { Morro } \\
\text { Bay }\end{array}$ & $\begin{array}{c}\text { Site 2: } \\
\text { Diablo } \\
\text { Canyon }\end{array}$ & $\begin{array}{c}\text { Site 3: } \\
\text { Humboldt }\end{array}$ & $\begin{array}{c}\text { Site 4: } \\
\text { Cape } \\
\text { Mendocino }\end{array}$ & $\begin{array}{c}\text { Site 5: } \\
\text { Del } \\
\text { Norte }\end{array}$ & $\begin{array}{c}\text { Analysis } \\
\text { Domain } \\
\text { Mean }\end{array}$ \\
\hline $\begin{array}{l}\text { Wake losses [\% of gross } \\
\text { production] }\end{array}$ & 5.3 & 6.4 & 5.4 & 4.4 & 4.6 & 6.7 \\
\hline $\begin{array}{l}\text { Environmental losses [\% of } \\
\text { gross production] }\end{array}$ & 1.6 & 1.6 & 1.6 & 1.6 & 1.6 & 1.6 \\
\hline $\begin{array}{l}\text { Technical losses [\% of gross } \\
\text { production] }\end{array}$ & 1.2 & 1.2 & 1.2 & 1.2 & 1.2 & 1.2 \\
\hline $\begin{array}{l}\text { Electrical losses [\% of gross } \\
\text { production] }\end{array}$ & 4.3 & 3.9 & 3.9 & 3.6 & 4.0 & 3.6 \\
\hline $\begin{array}{l}\text { Availability losses [\% of } \\
\text { gross production] }\end{array}$ & 5.0 & 5.0 & 5.0 & 5.0 & 5.0 & 5.0 \\
\hline $\begin{array}{l}\text { Total losses [\% of gross } \\
\text { production] }\end{array}$ & 15.0 & 16.9 & 15.3 & 14.5 & 15.2 & 15.6 \\
\hline
\end{tabular}

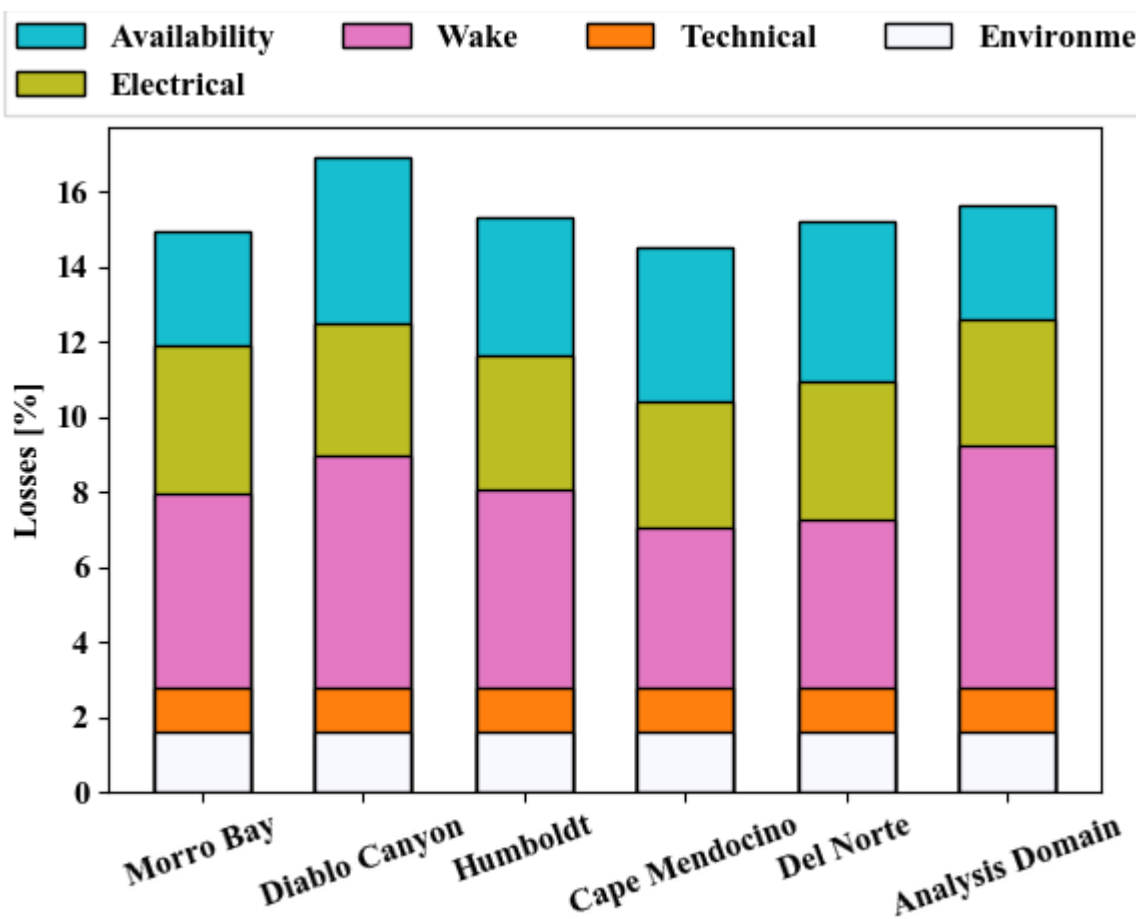

Figure 16. Loss breakdown by site and for the analysis domain for COD 2019. Losses are in $\%$ of gross production.

From Table 5 and Figure 16, it is clear that the largest contributors to the total losses are wake losses, availability losses, and the electrical losses (which only include the losses in the export cables). Note also that the total losses vary primarily because of differences in the wake losses. These are induced by variation in the site-specific wind resources and electrical losses from export cable length differences. All the other loss categories are assumed to be independent of the geospatial parameters for this analysis. Note that in Figure 16 'Analysis Domain' refers to the mean across the analysis domain. 


\subsubsection{Net Capacity Factor}

Figure 17 shows a heat map of the net capacity factors resulting from the California AEP analysis across the analysis domain for the 2019 baseline year. The wind resource has the largest impact on the NCF. This can be observed by comparing Figure 17 with Figure 7, as the NCF generally mirrors the trends in mean wind speed. One key trend to note is that both the $100-\mathrm{m}$ mean wind speed and NCF tend to increase with distance to shore. The exception to this might be near the Channel Islands off the coast of Southern California.

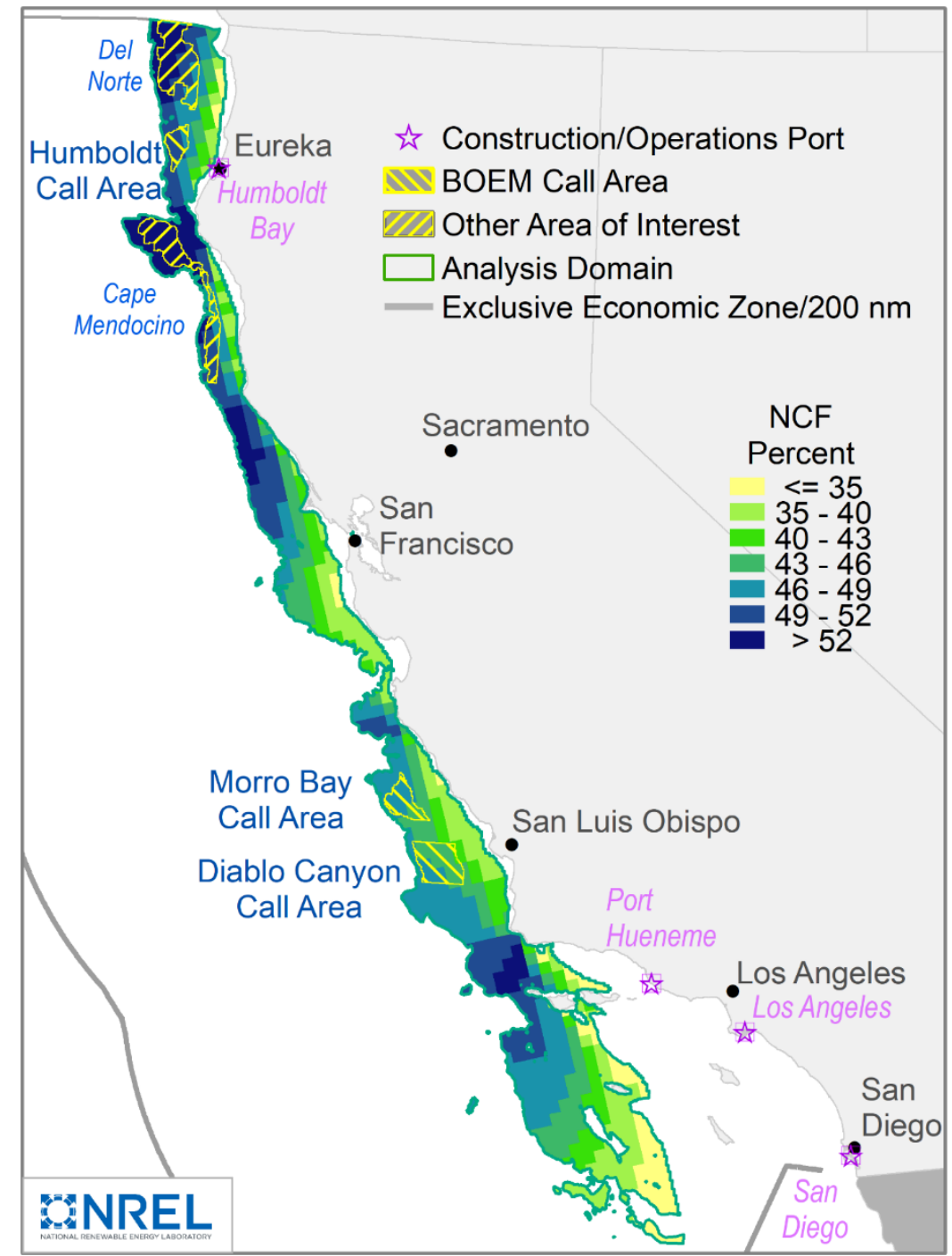

Figure 17. Net capacity factor estimates for the analysis domain offshore California (2019 COD)

The NCF trajectories are presented in Figure 18 (a), which shows that NCF increases steadily from 2019 to 2032. This increase in NCF over time is a result of the assumed decreases in total losses and increases in gross annual energy production (described earlier- see Section 4.4.6) due to technology advancements that are likely to increase energy production. The figure shows the NCF for each of the five study sites, which indicates an increase in NCF geographically from north to south. This geographic increase in NCF (vertical scale) can be attributed almost exclusively to higher average wind speeds found in the north. 


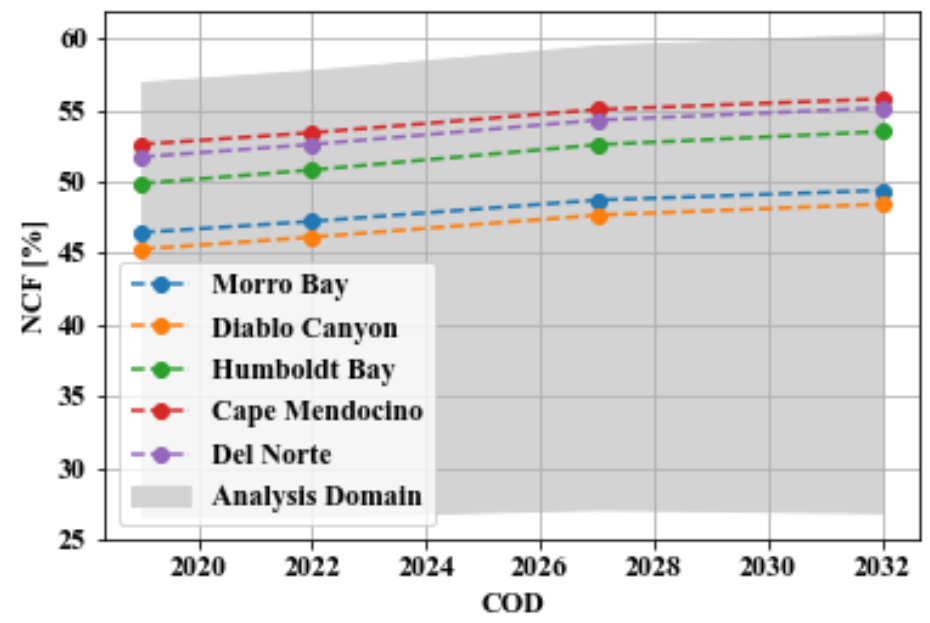

(a)

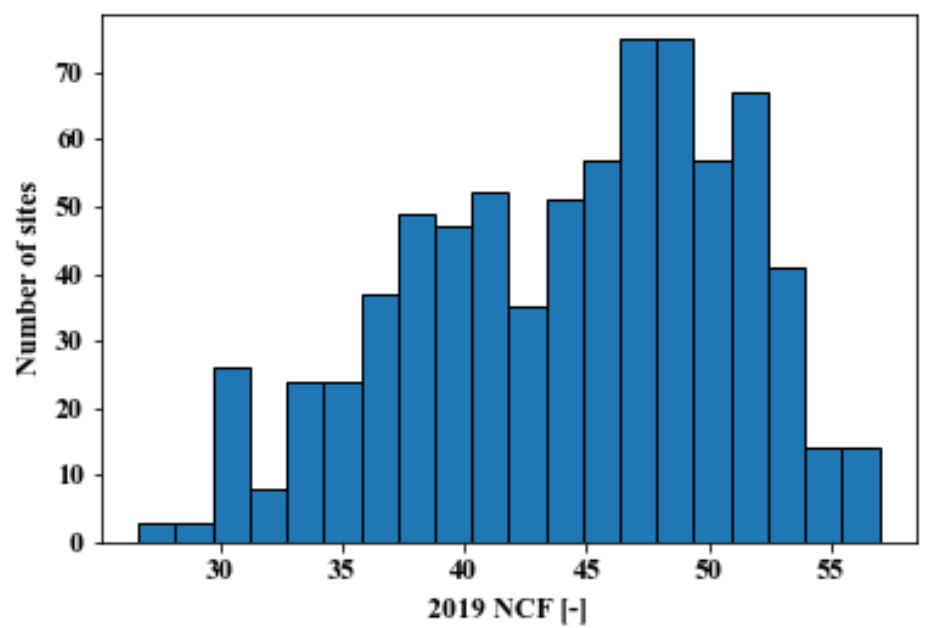

(b)

Figure 18. (a) Estimated capacity factor trajectory of the five California study areas between 2019 and 2032 and (b) a histogram showing distribution of NCF values across the analysis domain sites in 2019

Note: Light grey band in Figure 18 (a) represents the range between the minimum and maximum values across the analysis domain.

Figure 18 (b) shows the distribution of NCF values across the entire California analysis domain in the baseline year of 2019. The northern sites are on the upper end of the range of NCF values (right side) across the whole analysis domain. This general trend continues for all COD years. 


\section{Infrastructure and Logistics}

In this section, we discuss the port and interconnection infrastructure that was selected to model the costs of the five study sites.

\subsection{Construction and Operation Ports}

California is home to several large commercial ports that handle millions of tons of cargo annually (U.S. Department of Transportation, Bureau of Transportation Statistics 2020). ${ }^{23}$ California ports also support military activities, commercial fishing, tourism, and recreational boating. The ability of California's ports to support offshore wind and marine and hydrokinetic development and operations was assessed in a 2016 BOEM report (Porter and Phillips 2016). The report analyzed the suitability of 13 California ports for offshore wind, with 10 selected for more in-depth analysis of their strengths and limitations. Based on characteristics such as navigation channel geometry, crane capacity, available land area, and access to infrastructure, the report assigned scores to each port for the functions of fabrication and construction, assembly, and "quick reaction" (Porter and Phillips 2016). For the purpose of this cost analysis, the "assembly port" category is the most relevant because it identifies ports that can accommodate a completely assembled upright floating wind turbine and substructure. Ports suitable for quick reaction would likely be capable of supporting most day-to-day operations but would not provide a base for towed repair or large repair vessels. Distance to port is a significant driver of construction and O\&M costs. Marine operations make up approximately half of the total turbine operational expenditures (OpEx). In addition, vessel costs contribute nearly half the cost of major component replacements, which account for $16 \%$ of offshore wind turbine OpEx (Yang et al. 2019). As the distance to port increases, vessel transit times and fuel costs become even more significant.

The requirement that precludes many of California's ports from floating wind turbine assembly is the air draft, or height clearance requirement. In contrast to fixed-bottom offshore wind turbines, floating wind turbines can be assembled within a port or harbor and towed to the plant site for connection to mooring lines and power cables. Assembly can also be carried out at sea, using floating or jack-up crane vessels similar to those used for fixed-bottom wind turbines. Assembly at port avoids some of the costs and delays associated with assembly on the open sea, but the height of the assembled turbine and substructure is $175 \mathrm{~m}$ ( $575 \mathrm{feet}[\mathrm{ft}]$ ) or more, far exceeding typical bridge deck clearance heights. The Golden Gate Bridge, for example, has an air draft limit of $67 \mathrm{~m}$, rendering all of the San Francisco Bay ports unsuitable for floating wind turbine assembly (Porter and Phillips 2016). Other bridges, such as the San Diego-Coronado Bridge, limit access to some portions of a port but would not obstruct turbine assembly seaward of the bridge.

Port requirements depend, in part, on the floating substructure type. Berths and channel depths need to be sufficient to accommodate the draft of a floating wind turbine after assembly or when towed to port for repair. Semisubmersible and tension-leg platforms have drafts of approximately $10 \mathrm{~m}$, whereas spar buoys may extend up to $80 \mathrm{~m}$ below the water surface (Porter and Phillips 2016). The horizontal extent of the substructure affects several requirements, including the 
channel width, berths for assembly or repair, and staging area during the construction phase. Estimated values for the width of floating substructures are $8 \mathrm{~m}$ for a spar, $50 \mathrm{~m}$ for a semisubmersible, and 40-70 $\mathrm{m}$ for a tension-leg platform (Porter and Phillips 2016). The width of a berth, dry-dock, or navigation channel must exceed the substructure width by an adequate safety margin, whereas the staging area requirement depends on the throughput of floating turbines expected at the port.

Other considerations for port suitability include proximity to potential offshore wind development, crane capacity, shipbuilding and repair capabilities, access to railways and highways, quayside bearing capacity, and availability of a skilled workforce (Porter and Phillips 2016). Table 6 provides a list of ports considered in this study.

Table 6. Construction and Operations Ports

\begin{tabular}{|c|}
\hline Potential Offshore Wind Ports in California \\
\hline Humboldt Bay \\
\hline Port Hueneme \\
\hline Los Angeles \\
\hline Long Beach \\
\hline San Diego \\
\hline
\end{tabular}

Although the ports in Table 6 have been identified as having the potential to support floating offshore wind, some upgrades may be necessary before operations begin. Physical improvements that may be needed include dredging or widening of navigation channels and berths to provide sufficient clearance for substructures or installation vessels and building or strengthening existing docks to meet quayside bearing capacity requirements. Development of offshore wind support capabilities at any port will require agreements regarding leasing of land and port facilities and may also involve the construction of new facilities, such as dry-docks, cranes, or manufacturing centers. On the Atlantic coast where the industry is already making offshore wind infrastructure investments, costs for large-scale port upgrades to support offshore wind development are in the range of \$100-400 million (Musial et al. 2020b).

Costs analyzed in this study do not include upgrades to port facilities because it is not yet clear what upgrades are needed or who will pay for them. The cost of port improvements may be borne by various parties including port owners, state or local economic development funding, offshore wind developers, or third-party service providers. The primary effect of port selection in this study is to determine a distance from a potentially suitable port to the offshore wind site, which is the main parameter affecting costs. Sites that are farther from a construction port have higher CapEx because of longer installation times, which reflect increased travel time, fuel costs, and higher risk of weather delay. The same distance factors affect OpEx.

\subsection{Points of Grid Interconnection}

Candidate points of electrical grid interconnection for wind power plant sites on the OCS offshore California were limited to substations that met two criteria:

- Distance: within $10 \mathrm{~km}$ of coast 
- Maximum transmission voltage:

$$
\begin{aligned}
& \circ>100 \text { kilovolts }(\mathrm{kV}) \text { north of San Francisco } \\
& \circ>200 \mathrm{kV} \text { in San Francisco and south. }
\end{aligned}
$$

The transmission voltage criteria represent a compromise between providing a broad geographic range of potential interconnection points and the transmission capacity that would be required for a 1,000-MW wind power plant. Subsea export cables for plants of this scale are typically rated at $230 \mathrm{kV}$ or higher. Some of the identified substations have less than the required capacity, particularly in Northern California, and upgrades to existing transmission infrastructure there would likely require new construction to raise voltages. Transmission costs in this analysis do not include costs to upgrade land-based infrastructure (see Table 9). The candidate points of interconnection are shown in Figure 19.

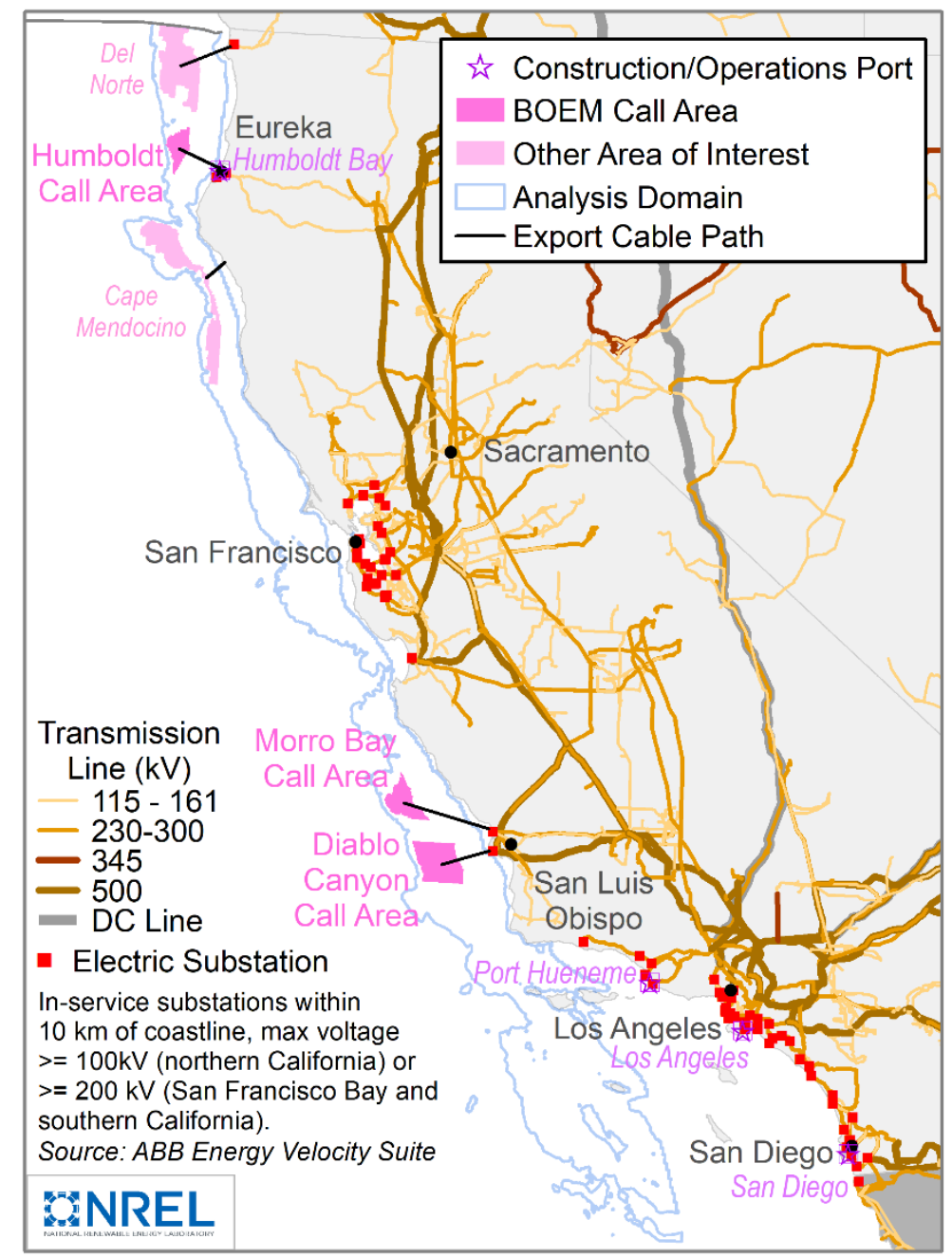
Figure 19. Map of candidate points of interconnection for wind power plant sites on the OCS
offshore California

We considered points of interconnection in more detail for the five study areas, with potential locations listed in Table 7. The black lines in Figure 19 indicate the path from the centroid of each study area to the associated substation or grid feature listed in Table 7. Each of the three 
Call Areas is close to the site of a current or former coastal power plant, which provides access to a substation and - in the case of retired plants - may indicate that transmission capacity is available to handle new generation. Diablo Canyon Power Plant, a 2-GW nuclear plant that is scheduled to retire in 2025, is a potential point of interconnection for sites in the Diablo Canyon Call Area. Sites in the Morro Bay Call Area could connect to transmission at the site of the Morro Bay Power Plant, a retired 650-MW facility. Humboldt Bay Generating Station, an operational 168-MW natural gas power plant, provides an opportunity for interconnection to sites in the Humboldt Call Area, although the transmission system in the area has limited capacity to distribute power outside of the local region.

The other two study areas, Del Norte and Cape Mendocino, are located farther from transmission infrastructure. A substation in Crescent City could provide a point of interconnection for the Del Norte study area. Transmission lines near Crescent City are relatively low voltage (60 to $115 \mathrm{kV}$ ) and the closest access to higher-voltage transmission is in Oregon, which may not serve the objective of bringing power to cities in California. There are $60-\mathrm{kV}$ transmission lines along the coast near the southern portion of the Cape Mendocino study area (south of Fort Bragg), but electrical infrastructure is limited farther north. Even in locations where there is transmission at the $60-$ or $115-\mathrm{kV}$ level, significant investments in new transmission at $230 \mathrm{kV}$ or higher would be required to interconnect a $1,000-\mathrm{MW}$ wind power plant. Section 5.3 briefly examines the required upgrades and costs for specific scenarios in the Humboldt Call Area.

Table 7. Potential Points of Interconnection for the Five California Study Areas

\begin{tabular}{|l|l|l|}
\hline $\begin{array}{l}\text { Study } \\
\text { Area }\end{array}$ & \multicolumn{2}{|l|}{$\begin{array}{l}\text { Point of } \\
\text { Interconnection }\end{array}$} \\
\hline $\begin{array}{l}\text { Diablo } \\
\text { Canyon }\end{array}$ & $\begin{array}{l}\text { Diablo Canyon } \\
\text { Substation } \\
\text { (adjacent to } \\
\text { Diablo Canyon } \\
\text { power plant) }\end{array}$ & $500 \mathrm{kV}$ \\
\hline Morro Bay & $\begin{array}{l}\text { Morro Bay } \\
\text { substation } \\
\text { (adjacent to } \\
\text { Morro Bay } \\
\text { power plant) }\end{array}$ & $230 \mathrm{kV}$ \\
\hline $\begin{array}{l}\text { Cape } \\
\text { Mendocino }\end{array}$ & $\begin{array}{l}\text { Fort Bragg } \\
\text { substation }\end{array}$ & $60 \mathrm{kV}$ \\
\hline Humboldt & $\begin{array}{l}\text { Humboldt Bay } \\
\text { substation } \\
\text { (adjacent to } \\
\text { Humboldt Bay } \\
\text { generating } \\
\text { station) }\end{array}$ & $115 \mathrm{kV}$ \\
\hline Del Norte & $\begin{array}{l}\text { Substation in } \\
\text { Crescent City }\end{array}$ & $60 \mathrm{kV}$ \\
\hline
\end{tabular}

In summary, interconnection opportunities along the California coast are unevenly distributed, with some clear opportunities to interconnect as well as significant stretches of coastline that do 
not have an obvious path to the high-voltage transmission system. For sites where there is a high degree of uncertainty regarding the interconnection route, the choice of modeling assumptions can lead to large variations in the resulting LCOE. To ensure a uniform base for comparison, we calculate interconnection costs for each site using the same methodology. Export cables travel in a straight line along the shortest distance to shore from each site. From that point, designated the cable landfall, we assume that a land-based spur line travels $5 \mathrm{~km}$ before connecting to the bulk system transmission grid.

\subsection{Bulk-System Transmission}

Electricity from offshore wind power plants will need bulk transmission to reach the densely populated areas where loads are concentrated. Major transmission lines in California run through the Central Valley, bringing power to the large urban centers and connecting to Oregon, Arizona, and Nevada. The Morro Bay and Diablo Canyon Call Areas are located in relatively close proximity to generation facilities that will have ceased operation by 2025 . Transmission capacity already exists to bring power from these locations to load centers, although transmission requirements for full build-out of the Call Areas have not been studied in detail. Fewer transmission lines serve less-populated areas of the coast, including the region adjacent to the Humboldt Call Area and other northern wind resource areas. Transmission in these areas has been designed to serve local loads rather than to export power to the rest of the state.

The Schatz Energy Research Center at Humboldt State University carried out a study that examined transmission options for offshore wind from the Humboldt Call Area (Jacobson and Severy 2020). The study considered three wind power plant sizes of approximately 50, 150, and 1,800 MW and modeled the transmission upgrades that would be necessary to provide full deliverability of the offshore wind generation. Significant transmission upgrades were identified in all cases. For the largest plant size, the study examined several conceptual transmission pathways, as shown in Figure 20. These include land-based transmission routes to the east or southeast, or a subsea cable connecting to the San Francisco Bay area via a nearshore or deepwater route. Costs to build these transmission routes ranged from $\$ 1.5-4.5$ billion. In levelized terms, these costs correspond to $14-41$ \$nominal $/$ megawatt-hour (MWh) ${ }^{24}$ Note that the upgrades identified in Jacobson and Severy (2020) are designed for peak and off-peak demand scenarios in which the offshore wind power plant and other local generation are operating at full capacity. The study does not analyze costs for a scenario in which generation is curtailed to match local transmission limits (with or without upgrades). Further assessments would be required to determine the feasibility of new transmission routes, considering aspects such as obtaining rights-of-way, wildfire risks, subsea cable crossings, and impacts to marine habitat.

\footnotetext{
${ }^{24}$ The levelized cost was calculated using the average NCF of $49 \%$ for the five study areas (Section 4), a plant capacity of $1,836 \mathrm{MW}$, and a nominal fixed charge rate of $7.2 \%$ (Section 6).
} 


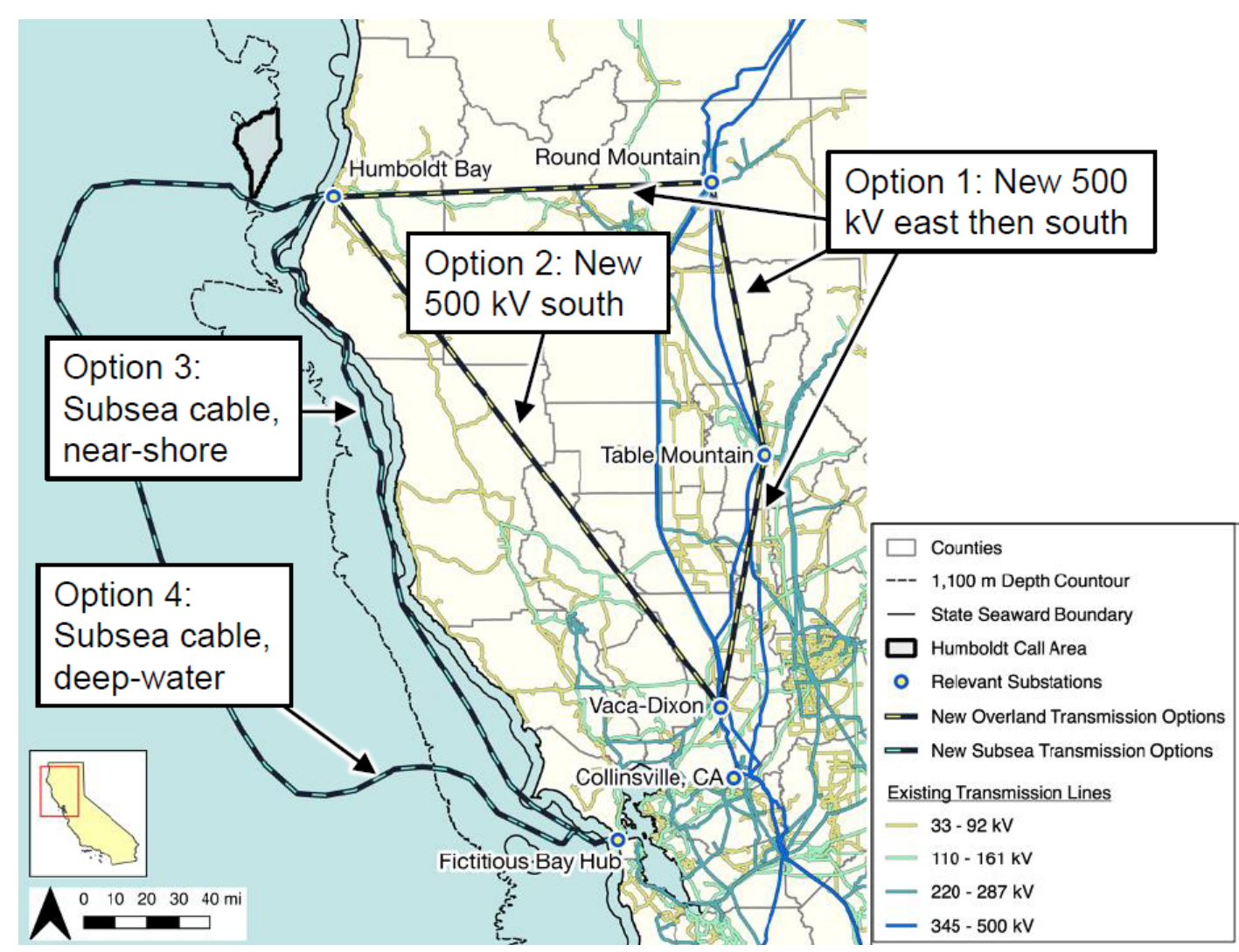

Figure 20. Transmission options for a 1,836-MW offshore wind power plant in the Humboldt Call Area. Figure courtesy of Jacobson and Severy (2020)

Build-out of transmission capacity for the Humboldt Call Area could also affect the transmission options for future offshore wind power plants in Northern California. Sites in the Del Norte area or the northern part of Cape Mendocino might connect to transmission at Humboldt Bay if sufficient new capacity became available. Another possibility is the development of a subsea transmission backbone that would transmit power from several wind plants south to the San Francisco Bay. The Atlantic Wind Connection is an example of a multiplant offshore transmission system that was proposed for the U.S. Atlantic Coast (BOEM 2020c). The merchant transmission model, in which the transmission developer is neither an incumbent utility or a generation owner, is relatively new to the U.S. market and poses significant challenges for developers. Transmission planning must happen early in the project timeline, which exposes transmission developers to the risk that individual offshore wind projects may not be built, and without a guarantee that generation will connect to a transmission line, utilities may not be willing to interconnect (Daniel et al. 2014). Similarly, offshore wind developers face the risk that an independent transmission line may be delayed or not built at all, stranding their generators without a means to deliver power. If these risks can be overcome or mitigated, a transmission backbone could provide an efficient route to connect the large offshore wind resources in Northern California with load centers in the south. Subsea transmission has also been proposed as a means to connect offshore wind projects on the central coast to the Los Angeles area. 


\section{Cost Modeling Method and Assumptions}

For modeling the costs of potential floating offshore wind power plants in the OCS offshore California, we used NREL's ORCA model. ORCA is a deterministic cost model that estimates the LCOE (and its constituent cost and performance components) of a commercial-scale offshore wind power plant at any given U.S. location (Beiter et al. 2016). This section provides details about the model, its underlying spatial cost relationships, and assumptions.

\subsection{ORCA}

ORCA is a cost model developed and maintained by NREL (Beiter et al. 2016). It uses a set of parametric equations for various technological (e.g., turbine rating, substructure type), spatial (e.g., wind speed, water depth, distance to port, wave height), and financial parameters (e.g., debt-to-equity ratio, debt rate, equity rate) to calculate the LCOE using the following definition from Short et al. (1995):

$$
L C O E=\frac{(F C R * C a p E x)+O p E x}{A E P_{\text {net }}}=\frac{F C R *\left(C_{\text {Turbine }}+C_{\text {BOS }}\right)+C_{\text {ops }}+C_{\text {maint }}}{A E P_{\text {net }}}
$$

where:

LCOE $=$ levelized cost of energy $(\$ / M W h)$

$\mathrm{FCR}=$ fixed charge rate $(\% /$ year $)$

CapEx $=$ capital expenditures $(\$ / \mathrm{kW})$

$\mathrm{AEP}_{\text {net }}=$ net average annual energy production $(\mathrm{MWh} /$ year $)$

$\mathrm{OpEx}=$ average annual operational expenditures $(\$ / \mathrm{kW} /$ year $)$

$\mathrm{C}_{\text {Turbine }}=$ turbine capital expenditures $(\$ / \mathrm{kW})$

$\mathrm{C}_{\mathrm{BOS}}=$ balance-of-system capital expenditures $(\$ / \mathrm{kW})$

$\mathrm{C}_{\mathrm{ops}}=$ operational expenditures $(\$ / \mathrm{kW}$-year $)$

$\mathrm{C}_{\text {maint }}=$ maintenance expenditures $(\$ / \mathrm{kW}$-year $)$.

The model can be used to estimate LCOE variation within a region for single or multiple sites. Constraints are implemented in ORCA to capture technological limitations (e.g., as they relate to water depth). ORCA distinguishes between costs that do not vary with the included spatial parameters (i.e., "spatially independent"), those that have a distinct relationship with spatial parameters (i.e., "spatially dependent"), and cost multipliers (Beiter et al. 2016). Examples of the former include offshore wind turbine procurement costs, which are assumed to be site-agnostic given that commercially available models are typically designed for IEC Class 1 sites. In practice, however, wind turbine original equipment manufacturers hold liabilities associated with warranty provisions and may adjust the pricing structure for a given site to account for the perceived level of risk associated with exposure to environmental conditions. Nevertheless, we assume that these costs are constant from one project to another. Spatially dependent costs are (among others) installation costs that are expected to vary with logistical distances (e.g., distance from port to site), water depth, and prevailing metocean conditions. Cost multipliers vary in general with total project cost to reflect the complexity of certain cost items. For instance, engineering and management costs incurred from financial close through commercial operations are applied as a percentage of CapEx. 
The spatially dependent relationships of CapEx, OpEx, and AEP are represented in ORCA as multivariable (typically nonlinear) equations parameterized in terms of technological, financial, and geospatial inputs. These equations were developed using bottom-up engineering and technoeconomic tools (Table 8).

Table 8. Bottom-Up Engineering Tools that Inform the Spatial Relationships in ORCA

\begin{tabular}{|c|c|c|}
\hline $\begin{array}{l}\text { Cost } \\
\text { Component }\end{array}$ & Model & Source \\
\hline BOS & $\begin{array}{l}\text { NREL } \\
\text { Balance of } \\
\text { Station }\end{array}$ & $\begin{array}{l}\text { Maness et } \\
\text { al. (2017) }\end{array}$ \\
\hline $\begin{array}{l}\text { Substructure } \\
\text { and tower }\end{array}$ & $\begin{array}{l}\text { TowerSE } \\
\text { tool }\end{array}$ & $\begin{array}{l}\text { Damiani } \\
(2016)\end{array}$ \\
\hline $\begin{array}{l}\text { Export } \\
\text { system } \\
\text { cable }\end{array}$ & PSCAD & $\begin{array}{l}\text { Manitoba } \\
\text { Hydro } \\
\text { International } \\
(2020)\end{array}$ \\
\hline O\&M & $\begin{array}{l}\text { Energy } \\
\text { Center of } \\
\text { the } \\
\text { Netherlands } \\
\text { (ECN) O\&M } \\
\text { tool }\end{array}$ & $\begin{array}{l}\text { Pietermen } \\
\text { et al. (2011) }\end{array}$ \\
\hline AEP & FLORIS & $\begin{array}{l}\text { NREL } \\
(2019 b)\end{array}$ \\
\hline
\end{tabular}

Each tool has a different capability in modeling the cost or performance of an offshore wind farm. Scenarios with varying spatial inputs were defined for each model. For instance, several scenarios were defined in the Energy Center of the Netherlands (ECN) O\&M tool varying the distance from a given offshore wind site to an O\&M base while holding all else constant. The ECN tool identifies the least-cost O\&M strategy and calculates maintenance costs as a function of the difference between the site and O\&M base (and other factors). We then ran a regression using the scenario data to obtain a general relationship between maintenance costs and the distance between the site and O\&M base. Further details about the bottom-up method for calculating CapEx, OpEx, and AEP net from spatial parameters and financial parameters, such as the fixed charge rate, ${ }^{25}$ are documented in Beiter et al. (2016). The specific assumptions developed for this model and the major cost reduction categories and relationships are discussed in Section 6.2.

The general process and data requirements for estimating LCOE are shown in Figure 21. First, the baseline (i.e., 2019 year) costs of a floating offshore wind plant are calculated. For this calculation, the parametric equations developed from bottom-up engineering models (e.g., NREL's Balance-of-System, O\&M, and FLORIS models) are used in combination with spatial and cost data, as well as assumptions about floating technology, plant size, and others. In a second step, a multimethod approach is used to project future costs from the baseline costs, using

\footnotetext{
${ }^{25}$ The fixed charge rate is used to approximate the average annual payment required to cover the carrying charges on an investment and tax obligations.
} 
a combination of learning curve, turbine upsizing impact, and technology innovation (see Section $6.3)$.

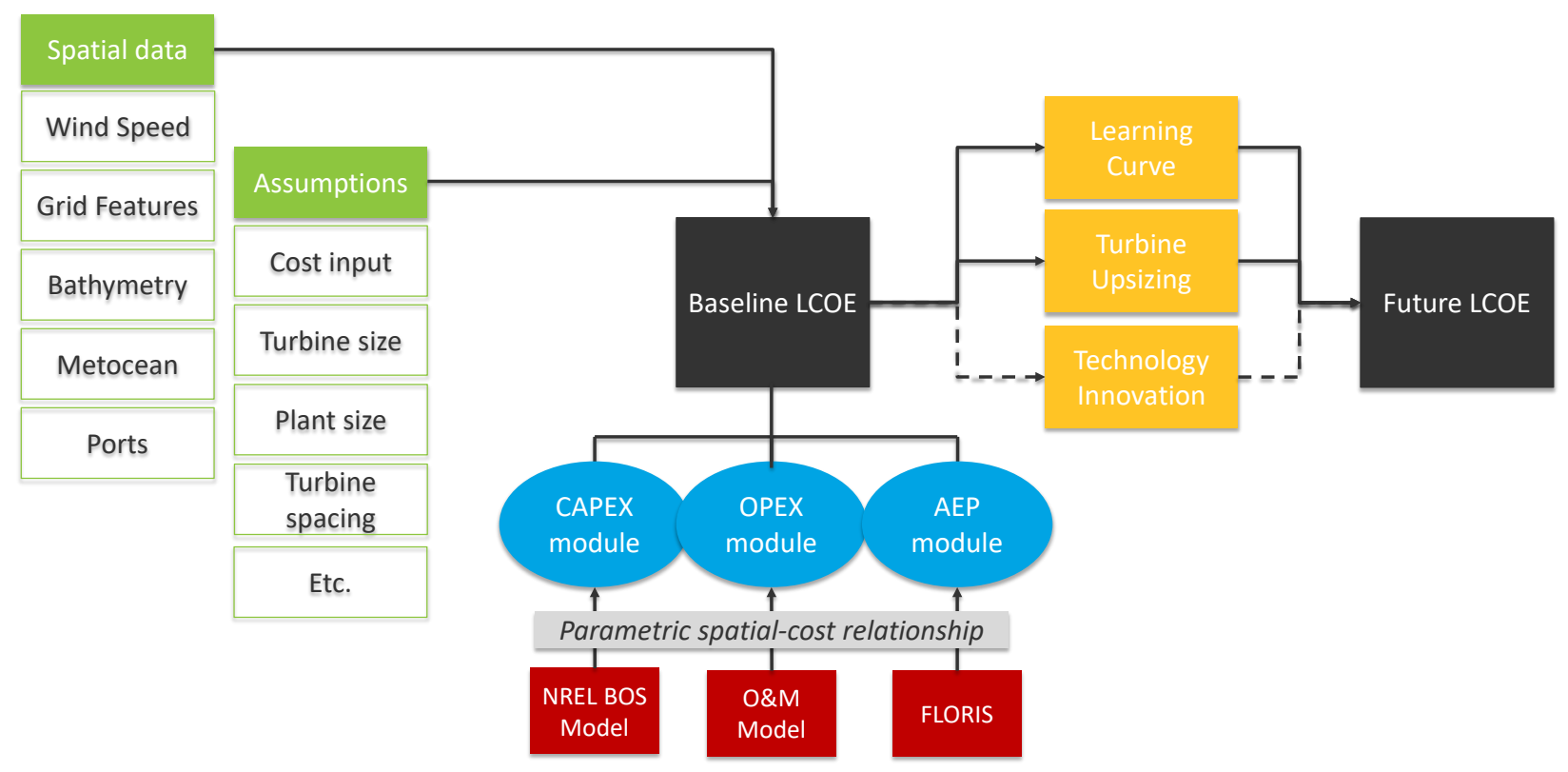

Figure 21. ORCA input-output flow diagram

ORCA has been used for prior analyses assessing the nationwide (Beiter et al. 2017, 2016; Gilman et al. 2016) or regional (Musial et al. 2019a, 2016a) variation in offshore wind fixedbottom and floating costs. With costs changing rapidly over the past few years, new data and contextual information are continuously integrated. ORCA is updated regularly when new data become available, but at any given moment, some offshore wind cost areas may be better represented than others.

\subsection{Analysis Sites}

We calculated LCOE using ORCA at 759 wind farm sites within the analysis domain, which are referred to as analysis sites. These analysis sites represent a spatial average from a larger set of individual turbine position input data points on a square grid. In this analysis, the analysis sites are distributed on a grid with each cell representing a 1,000-MW power plant (described in Section 4.2.2). The analysis sites are filtered to ensure the mean wind speed and water depth limits fall within the limits of the analysis domain from Section 2.1. The analysis sites in the domain are presented in Figure 22. ${ }^{26}$

\footnotetext{
${ }^{26}$ Some of the analysis sites are located in areas near the Morro Bay Call Area under consideration for offshore wind energy by an agency working group, as described in the "Updated Notice of Availability of Outreach on Additional Considerations for Offshore Wind Energy off the Central Coast of CA" filed by the California Energy Commission https://efiling.energy.ca.gov/GetDocument.aspx?tn=234009\&DocumentContentId=66829.
} 


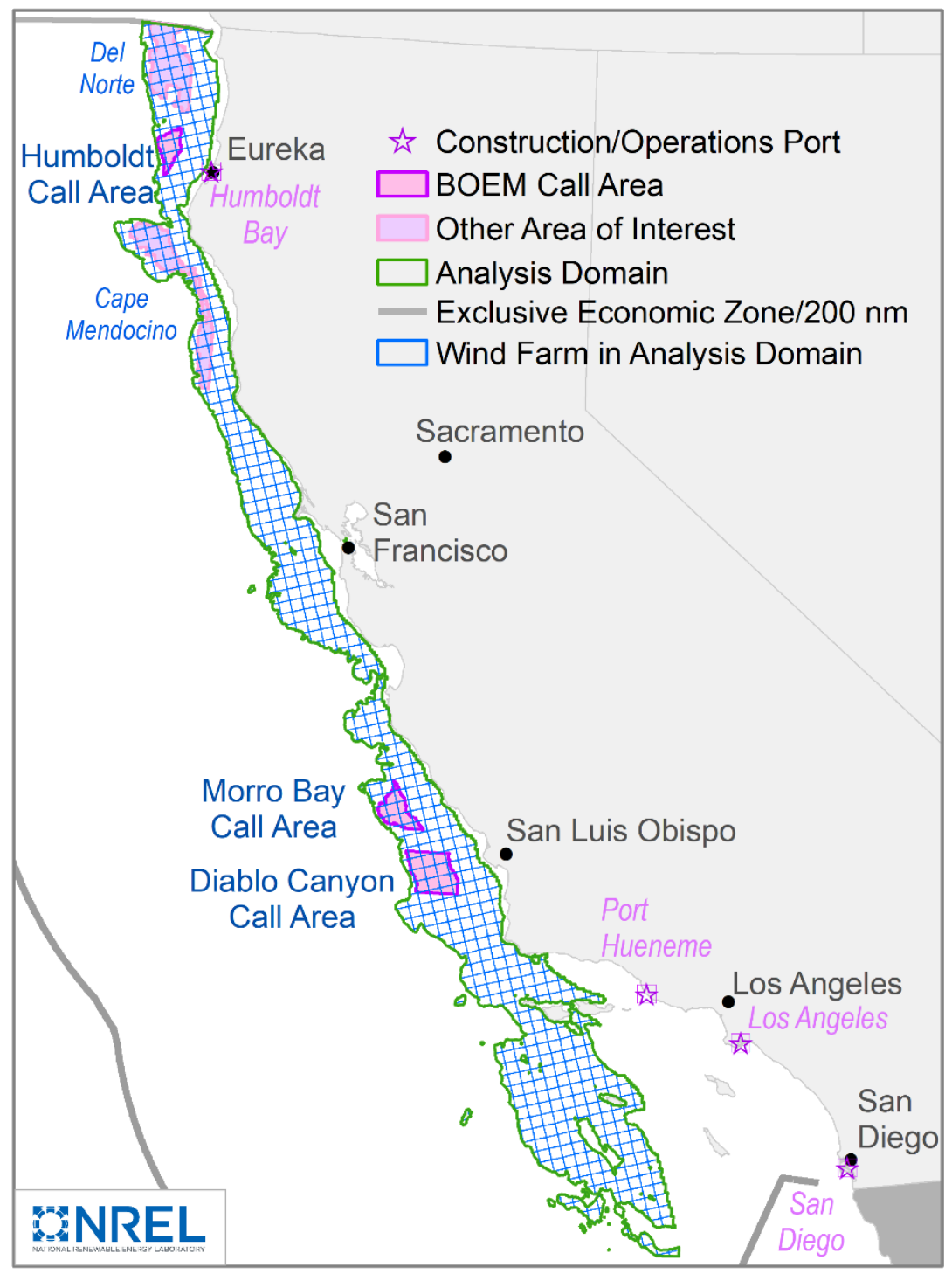

Figure 22. The five study areas within the California analysis domain

Modeled wind farm sites are indicated by blue boundary lines.

\subsection{Modeling Approach for This Study}

To estimate LCOE for the OCS offshore California, ORCA is populated with up-to-date floating offshore wind cost and spatial data. The cost data have been derived from a review of literature and consultation with industry and corresponds to an assessment of current and future technology and power plant configuration (Section 3.2). The spatial data are sourced from various publicly available and proprietary data (see Beiter et al. [2016] for a list of data sources). We adopted the definitions of key cost variables that correspond to the requirements of the CPUC Integrated Resource Planning process (Table 9). 
Table 9. Definition of Key Cost and Performance Terms Used

\begin{tabular}{|c|c|}
\hline Item & Definition \\
\hline Capital costs & $\begin{array}{l}\text { Total capital expenditures of the offshore wind system up to } \\
\text { the land-based grid feature (e.g., onshore substation), } \\
\text { including expenses for turbine, development, engineering \& } \\
\text { management, substructure and foundation, port and staging, } \\
\text { array cable costs, interconnection costs, assembly and } \\
\text { installation, and plant decommissioning } \\
\text { Note that the RESOLVE model used for the IRP process } \\
\text { typically considers capital costs and interconnection costs } \\
\text { separately. }\end{array}$ \\
\hline Interconnection costs & $\begin{array}{l}\text { Capital expenditures of interconnecting a wind farm to a land- } \\
\text { based grid feature (e.g., onshore substation, transmission } \\
\text { line), including expenditures for offshore export cable(s), } \\
\text { offshore substation(s), and spur line(s) from cable landfall to } \\
\text { an inland grid feature (e.g., onshore substation, transmission } \\
\text { line). Expenditures for onshore substation upgrades or any } \\
\text { (high-voltage) onshore bulk transmission is not included. } \\
\text { Expenditures for array cables are not included in the } \\
\text { interconnection costs. Interconnection costs are included in } \\
\text { capital costs. } \\
\text { Note that the RESOLVE model used for the IRP process } \\
\text { typically considers capital costs and interconnection costs } \\
\text { separately. }\end{array}$ \\
\hline Fixed O\&M costs & $\begin{array}{l}\text { Average annual expenditures to operate and maintain the } \\
\text { system's equipment. }\end{array}$ \\
\hline Gross capacity factor & $\begin{array}{l}\text { Ratio of the system's predicted or actual gross electrical } \\
\text { output to the nameplate output. }\end{array}$ \\
\hline Net capacity factor & $\begin{array}{l}\text { Ratio of the system's predicted or actual net (i.e., after } \\
\text { accounting for losses) electrical output to the nameplate } \\
\text { output. }\end{array}$ \\
\hline $\begin{array}{l}\text { Weighted-average cost of capital } \\
\text { (WACC) }\end{array}$ & $\begin{array}{l}\text { The average return required by equity and debt investors. } \\
\text { After-tax; does not include any impact from tax credit } \\
\text { schemes. }\end{array}$ \\
\hline Fixed-charge rate & $\begin{array}{l}\text { Factor to annualize the initial CapEx over the financial lifetime } \\
\text { of the project accounting for a return to debt and equity } \\
\text { sponsors. }\end{array}$ \\
\hline LCOE & $\begin{array}{l}\text { Total project cost expressed in } \$ \text { per megawatt-hour of } \\
\text { electricity generated by the system over its life. }\end{array}$ \\
\hline
\end{tabular}

Importantly, the interconnection costs as defined for this study do not include any costs associated with land-based substation upgrades or bulk system transmission build-out. As highlighted in Section 5.3, injecting power from large-scale offshore wind projects into the CAISO market may require major upgrades and investment, depending on the location, and many of these costs are not yet known.

We follow a nine-step procedure to assess floating offshore wind costs (Figure 21):

1. Develop key technology assumptions about current and future floating technology (Section 2), such as:

- Turbine size and properties 
- Substructure choice

- Plant size and turbine spacing

- Array and export cables.

2. Identify the nearest port and grid interconnection infrastructure (Section 5)

3. Collect spatial (Beiter et al. 2016) and floating cost data (Section 6.3), such as:

- Wind speed (Section 4)

- Distance to grid features

- Distance to construction and operations ports

- Metocean conditions

- Bathymetry.

4. Calculate gross energy production and losses (wake, electrical, environmental, availability) (Section 4)

5. Develop financial assumptions for a floating offshore wind project

6. Run ORCA to estimate baseline (2019) LCOE

7. Develop estimates of global floating offshore wind deployment by 2032 and run the learning curve module (Section 6.2.5)

8. Calculate future LCOE by applying learning-induced effects (as a function of global floating offshore wind deployment) and impact from turbine upsizing to baseline costs and performance (Section 6.2.5)

9. Extrapolate costs and performance between 2033 and 2050 from modeled data between 2019 and 2032 (logarithmic fit).

The focus of this cost analysis are the five study areas, although LCOE is calculated over the entire analysis domain at 759 sites as depicted in Figure 22. We identified assumptions about the port and grid interconnection infrastructure after review of potentially viable options for the five study areas. The approach for the sites outside of study area boundaries was more generic. For sites outside the study area boundaries, the nearest port (selected from Table 6) and grid feature (e.g., transmission line or substation, selected from the ABB Energy Velocity Suite grid data without any restrictions about transmission line or substation voltage) were used for cost modeling purposes. For any single site (including the study areas), these infrastructure assumptions will have to be revisited for cost modeling purposes once more data become available about potential offshore wind infrastructure in California and along the Pacific Coast.

All other assumptions remain the same between the study areas and those sites outside of their boundaries. This grid infrastructure is shown in Figure 19. A factor to account for variation in labor rates and material costs (i.e., a "capital cost multiplier") across different U.S. regions (and within California) is not considered in this study. This is a deviation from prior NREL cost studies (e.g., Musial et al. 2019a and 2016a; NREL 2019a) and was implemented because the data source used for regional offshore wind labor and material cost variation was deemed to not capture the technology-specific labor costs variances (and import opportunities) sufficiently. Costs are calculated for the period 2019 through 2050, so that data can be used in the RESOLVE model, which covers this entire period. The cost and performance values for COD years 2019, 
2022, 2027 and 2032 are estimated with (bottom-up) cost models presented in this study; estimates for any years in between (years 2020, 2021, 2023, etc. such as shown in Table ES-2 and Table 18) and those beyond 2032 are obtained through a logarithmic regression fit from the modeled data (hereafter referred to as "fitted data"). The values obtained through the regression fit deviate slightly from the modeled values. The cost and performance data after 2032 were extrapolated because of a lack of detailed information and data on offshore wind project and technology evolution beyond the early 2030s. Results in this report focus on the period 2019 through 2032. NREL publishes the "fitted" cost and performance results data for every year between 2019-2050 jointly with this report.

\subsection{Modeling Floating Offshore Wind Costs}

Floating offshore wind technology is in a precommercial phase, with small multiturbine arrays being deployed and under development globally (Section 3.1). In this precommercial phase, these smaller-scale projects are generally not competitive with other generation technologies. The largest array to date was commissioned in October 2017 by Equinor off Peterhead, Scotland, and used five 6-MW turbines on floating spar platforms. In July 2020, WindFloat Atlantic was fully commissioned off Portugal, comprising three 8.4-MW turbines. Commercial-scale floating arrays that are over 10 times larger are proposed for the mid-2020s (Musial et al. 2020b).

Limited data are available for the few small-scale floating projects deployed to date. These are not sufficient to represent future commercial-scale floating offshore wind project costs. We combine several methods to estimate the cost of a commercial-scale floating offshore wind system. These are each discussed in the following sections. For reference, Figure 23 depicts estimated LCOE from various literature sources for commercial-scale floating offshore wind power plants. These indicate a reduction from levels of approximately $\$ 110-\$ 175 / \mathrm{MWh}$ in 2019 to about $\$ 60 / \mathrm{MWh}$ by 2032 .

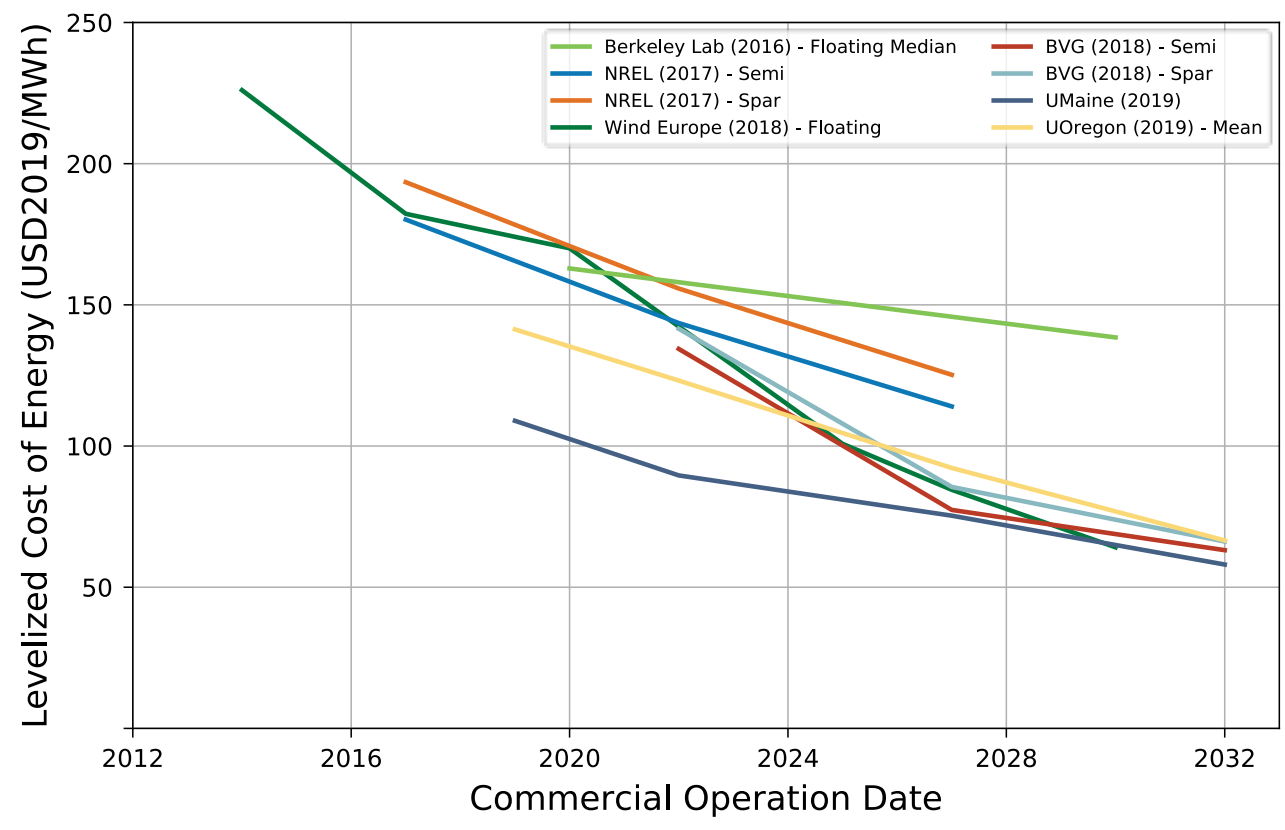

Figure 23. Global LCOE estimates of floating offshore wind technology. Graph derived from NREL analysis 


\subsubsection{Floating Substructure, Array, and Export System Costs}

We obtained cost data from floating offshore wind developers and industry literature to calibrate the baseline (2019) costs of the floating substructure, array, and export system costs (including an offshore substation). These are consistent with an earlier NREL study conducted for Oregon (Musial et al. 2019a). The detailed breakdown for these cost components is not shown here because much of these cost data are proprietary and cannot be disclosed.

\subsubsection{Spillover Learning Effects from the Fixed-Bottom Industry}

Projects using fixed-bottom technology have experienced a rapid technology evolution and LCOE reductions since 2014, commensurate with the technology's growth in commercial deployment. An indication of the decline in fixed-bottom costs is the reduction in strike prices ${ }^{27}$ for offshore wind procurement globally and in the United States (Figure 24). Because the technology has been deployed at commercial scale for several years, cost data are more readily available and have been validated. Cost data on floating offshore wind are rare and when available, they characterize precommercial projects. A floating offshore wind system and its supply chain share many manufacturing and logistical solutions with fixed-bottom offshore wind. In this study, we assume that those cost components (e.g., turbine, project management, operations) that are similar in their functional requirements, manufacturing, or logistics process feature a baseline and future cost that is equivalent to those estimated for a fixed-bottom system (Musial et al. 2019a).

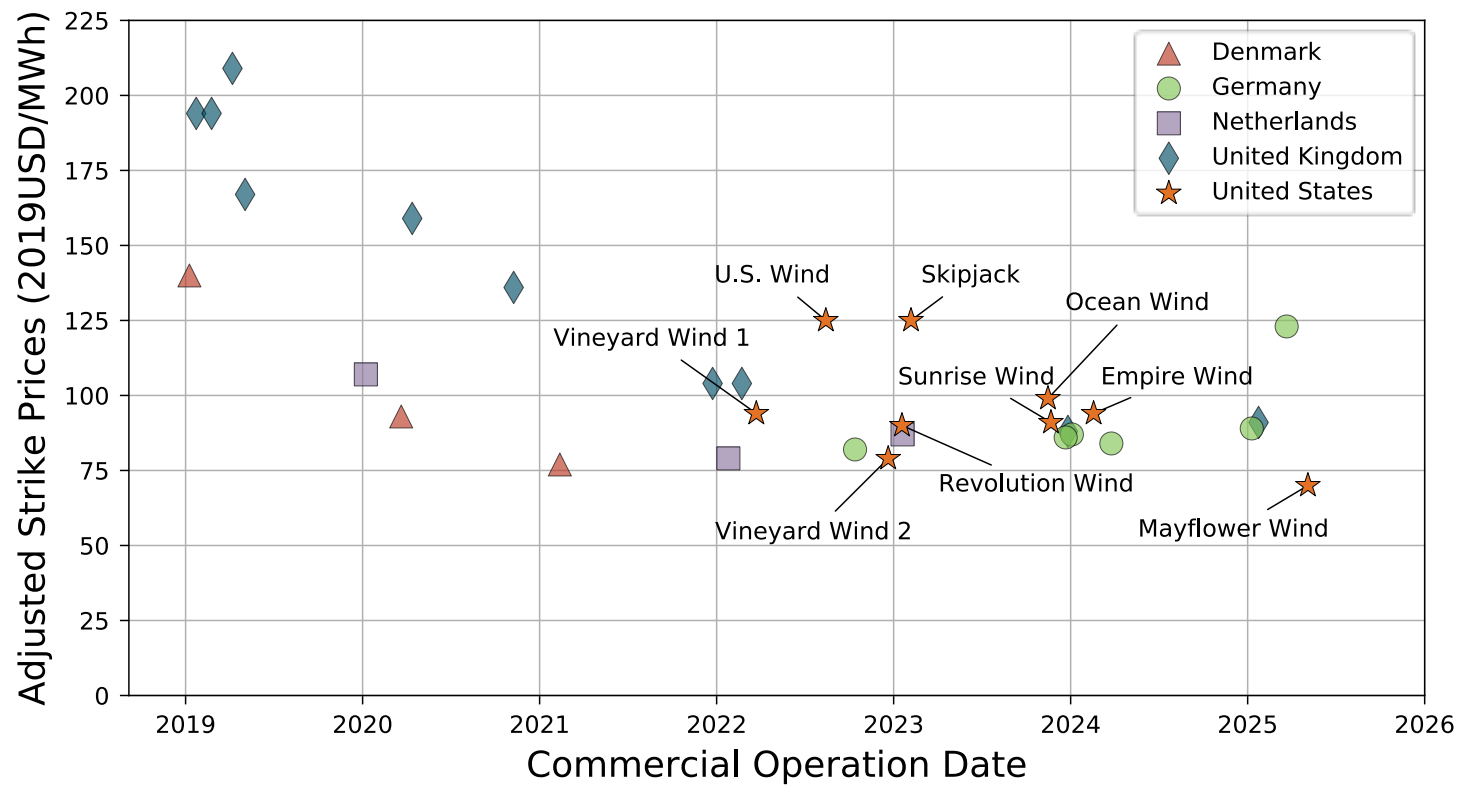

Figure 24. Adjusted strike and contract prices from global offshore wind procurement. Graph derived from NREL analysis

Note: Vineyard Wind 2 was named "Park City Wind" but is shown here with its former name that was used for the original power purchase agreement (Beiter et al. 2019).

${ }^{27}$ A strike price can be defined as a predetermined contract price at which a buyer and seller of energy agree to settle differences with the prevailing wholesale commodity (e.g., electricity) spot price. Typically, the strike price is also the lowest bid price in a renewable energy auction at which an offering is sold (Beiter et al. 2020). 
Several key areas where the floating industry might benefit from fixed-bottom technology advancement and cost reduction spillover have been identified (Musial et al. 2019a):

- Turbine

- Development and project management

- Land-based grid connection

- Soft costs

- Financing structures and terms

- Operations.

These components can typically comprise up to 50\% of total CapEx. Cost data were collected for these components from commercial-scale projects using fixed-bottom technology through industry consultation and a review of literature. They were adapted in this study to represent floating technology.

\subsubsection{Economies of Size}

The increase in turbine rating deployed at offshore wind farms globally has been a clear trend since the industry's inception (Figure 25). As turbine size grows, fewer turbines must be installed, maintained, and operated for the same power output. Effectively, this decreases the per-unit cost of energy (e.g., in terms of $\$ / \mathrm{kW}$ or $\$ / \mathrm{kW}$-year). The impact of turbine upsizing for this study has been assessed using NREL's Offshore Renewable Balance-of-system Installation Tool (ORBIT) model.

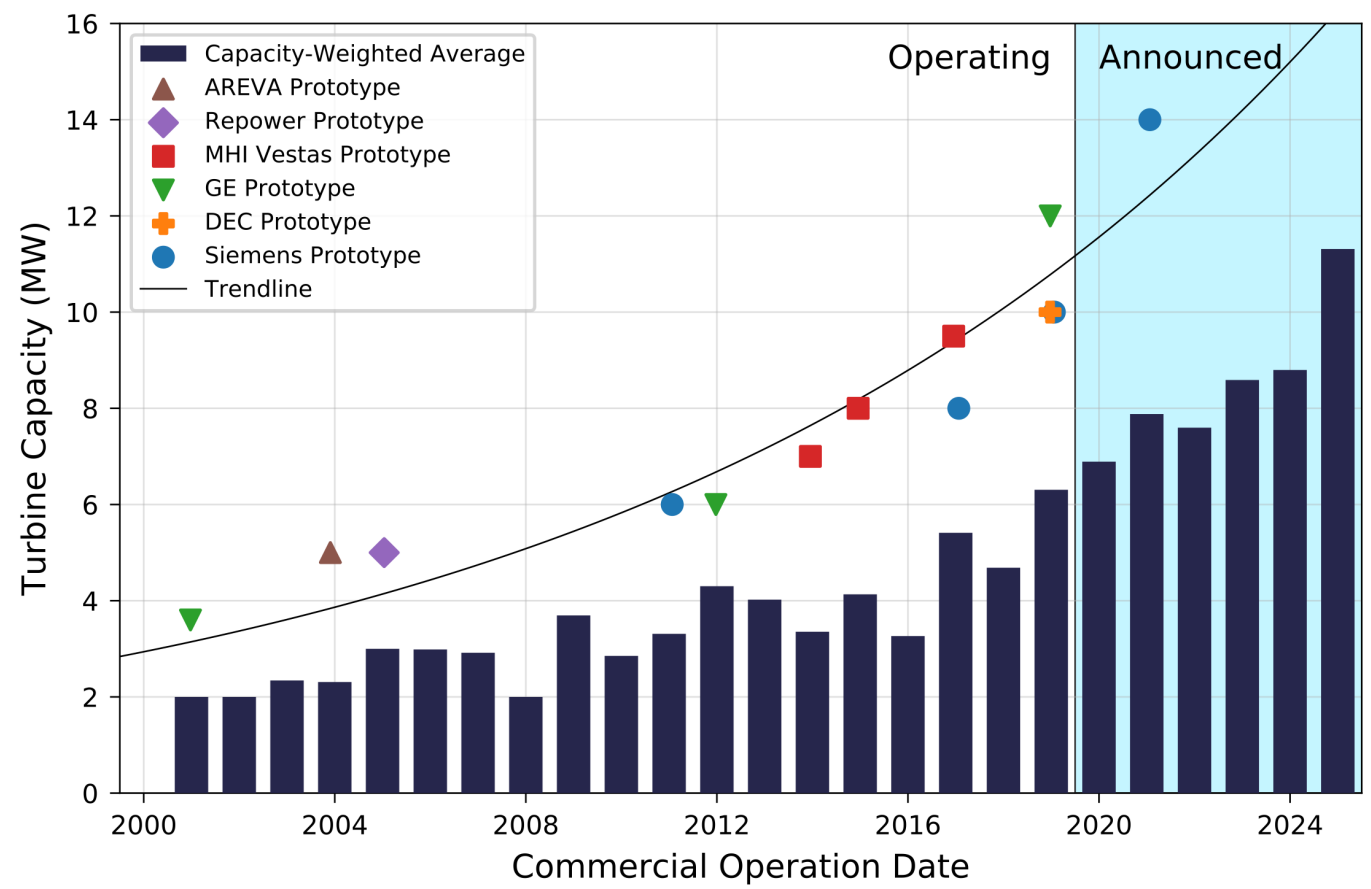

Figure 25. Commercial offshore wind turbine size. Graph derived from NREL analysis

ORBIT is based on systems-level engineering models that calculate the durations of individual installation processes using project geospatial data; vessel and component data sheet specifications; component cost data; and industry standards. Installation times and costs calculated in ORBIT scale with variables such as project size, turbine rating, site location, 
substructure technology, and vessel selection (Shields and Nunemaker 2020). The effect of turbine size is modeled for an assumed increase in turbine rating from $8 \mathrm{MW}$ (2019 COD) to 10 MW (2022 COD), 12 MW (2027 COD), and 15 MW (2032 COD) (Table 2). Further details on the ORBIT modeling methodology are specified in Section 6.3.6.

\subsubsection{Economies of Scale}

As the offshore wind power plant size grows, fixed costs (e.g., port infrastructure, export cable system, offshore substation, management) can be spread over a larger number of turbines. This effectively reduces the per-unit cost of energy (e.g., in terms of $\$ / \mathrm{kW}$ or $\$ / \mathrm{kW}$-year). A similar effect applies to the upscaling of manufacturing and production of components. The impacts of both effects were represented in the modeling of the baseline costs (2019). The effect from economies of scale is particularly large when comparing a pilot-scale to a commercial-scale deployment (Musial et al. 2019a). With today's floating offshore wind technology limited to multiturbine arrays of up to $30 \mathrm{MW}$, costs were scaled to be representative of commercial-scale power plants of 1,000 MW using industry data (Musial et al. 2019a) that were modeled in ORBIT. This scaling approach accounted for necessary changes in project design for an increase in plant capacity from $600 \mathrm{MW}$ to $1,000 \mathrm{MW}$, such as additional offshore substations and export cables; however, component unit costs (such as the cost per tonne for monopile steel) and management costs were held constant, although real projects would likely experience additional economies of scale because of bulk pricing, better supply chains, and more efficiently distributed management costs. As a result, a 1,000-MW project is only considered to reduce CapEx by $2 \%$ relative to a $600-\mathrm{MW}$ project, which is likely a conservative assumption. Economies of size from upscaling of manufacturing and production of components is also captured in the learning curve that is used to estimate future costs coincident with assumed global floating offshore wind deployment globally (see Figure 25 and Section 6.3.6).

\subsubsection{Financial Assumptions}

Finance terms were calibrated to align with those of today's commercial-scale, fixed-bottom projects. A weighted-average cost of capital (WACC) (nominal) of 5.4\% and fixed-charge rate (FCR) (nominal) of 7.2\% were derived from literature (Guillet 2018) and validated through consultation with industry (Table 10). ${ }^{28}$ For simplicity, these values are assumed constant for model years 2019-2032 (COD).

Some conditions have recently been documented for commercial-scale floating offshore wind to access financing terms similar to those of projects using fixed-bottom technology (Weber 2020). These include the floating project to exhibit:

- Experienced project sponsors and supply chain

- Low country sovereign risk

- Proven technology (e.g., as demonstrated through prototypes) and in-depth due diligence

- Limited-to-no revenue risk

- Strong insurance coverage and ample contingency budgets

\footnotetext{
${ }^{28}$ These financing conditions do not consider any state-to-state variations or potential benefits derived from tax
} benefits or other government incentives. 
- Strong contract management (e.g., limited number of construction contracts, full-scope and fixed-price O\&M contracts) and reduction of interface risks (e.g., between the foundation and turbine contracts).

A recent assessment conducted by NREL using a combination of consultation with experts and bottom-up assessment estimates a similar WACC $\mathrm{C}_{\text {nominal }}$ of 5.2\% (research and development scenario) for fixed-bottom offshore wind energy in the United States by the mid-2020s (Feldman et al. 2020).

Table 10. Floating Offshore Wind Financing Assumptions

\begin{tabular}{|c|c|c|c|}
\hline \multirow{16}{*}{ Finance } & FCR (nominal) (after tax) & $\%$ & $7.2 \%$ \\
\hline & FCR (real) (after tax) & $\%$ & $5.3 \%$ \\
\hline & WACC (nominal) (after tax) & $\%$ & $5.4 \%$ \\
\hline & WACC (real) (after tax) & $\%$ & $2.9 \%$ \\
\hline & Capital Recovery Period & $\mathrm{yr}$ & 30 \\
\hline & Share of debt & $\%$ & $75 \%$ \\
\hline & Debt rate (nominal) & $\%$ & $4.4 \%$ \\
\hline & Equity Return (nominal) & $\%$ & $12.0 \%$ \\
\hline & Tax rate & $\%$ & $26 \%$ \\
\hline & Inflation & $\%$ & $2.5 \%$ \\
\hline & CRF (nominal) (after tax) & $\%$ & $6.8 \%$ \\
\hline & CRF (real) (after tax) & $\%$ & $5.0 \%$ \\
\hline & Project Finance Factor & $\%$ & $105 \%$ \\
\hline & Depreciation Basis & $\%$ & $100 \%$ \\
\hline & Depreciation Schedule & & 5-year MACRS \\
\hline & Present Value of Depreciation & $\%$ & $86 \%$ \\
\hline
\end{tabular}

\subsubsection{Cost Projections}

The baseline costs for a commercial-scale floating offshore wind power plant, modeled with a COD in 2019, are projected to decrease for future CODs because of three factors:

- Experiential learning within the industry

- Economies of size realized through higher capacity turbines and larger projects

- Impact of technological innovations.

These effects are modeled for the five California study areas using a learning rate derived for project CapEx, bottom-up cost model runs, and expert elicitation data from literature, respectively. An experience curve describes the decrease in input costs as an increasing number of units of a good or service are produced; these cost reductions are attributed to learning by doing, learning by researching, improved supply chain and manufacturing efficiencies, and investment (Louwen and Subtil Lacerda 2019). In this study, a learning rate of $7.5 \%$ is estimated from a multivariate linear regression of hindcast project CapEx data. This learning rate is used to project future CapEx as a function of the anticipated global deployment of floating wind. In deriving the learning rate, the following factors were controlled for: turbine rating, plant capacity, water depth, distance to shore, and installation country. Controlling for these variables removes their effects from the linear regression, thereby implying that the learning rate is independent of these parameters and can be applied to all projects equally.

As the magnitude of the experiential learning attributed to the learning curve (and therefore cost reductions) scales with the total installed capacity, higher deployment scenarios result in greater 
cost reductions. Low-, mid-, and high-deployment scenarios are defined, which correspond to installed capacities of $4 \mathrm{GW}, 8 \mathrm{GW}$, and $13 \mathrm{GW}$ globally in 2032 based on a range of potential project deployments, as outlined in Table $11 .{ }^{29}$ The resulting percent reductions in CapEx are plotted in Figure 26, and a more detailed description of the derivation of the learning rate is provided in Appendix A.

Table 11. Globally Installed Floating Capacity by 2030

\begin{tabular}{|c|c|c|c|c|}
\hline & \multicolumn{3}{|c|}{ Capacity (MW) } & Source \\
\hline 4C Offshore & \multicolumn{3}{|c|}{8,000} & 4C Offshore (2020) \\
\hline $\begin{array}{l}\text { University of } \\
\text { Strathclyde/DNV GL }\end{array}$ & \multicolumn{3}{|c|}{4,300} & Hannon et al. (2019) \\
\hline Equinor & \multicolumn{3}{|c|}{13,000} & Buchsbaum (2018) \\
\hline Wood MacKenzie & \multicolumn{3}{|c|}{4,200} & $\begin{array}{l}\text { Shreve and } \\
\text { Kragelund (2020) }\end{array}$ \\
\hline $\begin{array}{l}\text { NREL assumption for } \\
\text { this study }\end{array}$ & $\begin{array}{l}\text { LOW } \\
4,000\end{array}$ & $\begin{array}{c}\text { MID } \\
8,000\end{array}$ & $\begin{array}{l}H I G H \\
13,000\end{array}$ & \\
\hline
\end{tabular}

In addition to the impacts from experience curves, the future costs projected in this analysis are impacted by the anticipated growth in turbine rating between 2019 and 2032. Increasing the turbine rating (for a given power plant capacity) has been identified as having the highest potential to reduce LCOE through reductions in balance-of-system, installation, and operation and maintenance costs (Wiser et al. 2016). A number of these impacts are captured within ORCA, because many of the underlying parametric equations depend on either the number of turbines or the identified nameplate capacity. A more detailed analysis was performed to evaluate the impacts of scaling on certain cost categories that were not evaluated in ORCA. This study used ORBIT, NREL's bottom-up offshore wind balance-of-system model (Nunemaker et al. 2020) to model projects with the technology assumptions provided in Table 2, and the percent cost reductions in installation and array cable costs were used in ORCA. The net impact on CapEx from increasing turbine rating is plotted in Figure 26.

\footnotetext{
${ }^{29}$ A recent forecast (published after assumptions for this study were defined for cost model runs) by the Global Wind Energy Council forecasts up to $19 \mathrm{GW}$ of installed global floating capacity by 2030, depending on realized cost reductions (Global Wind Energy Council 2020).
} 


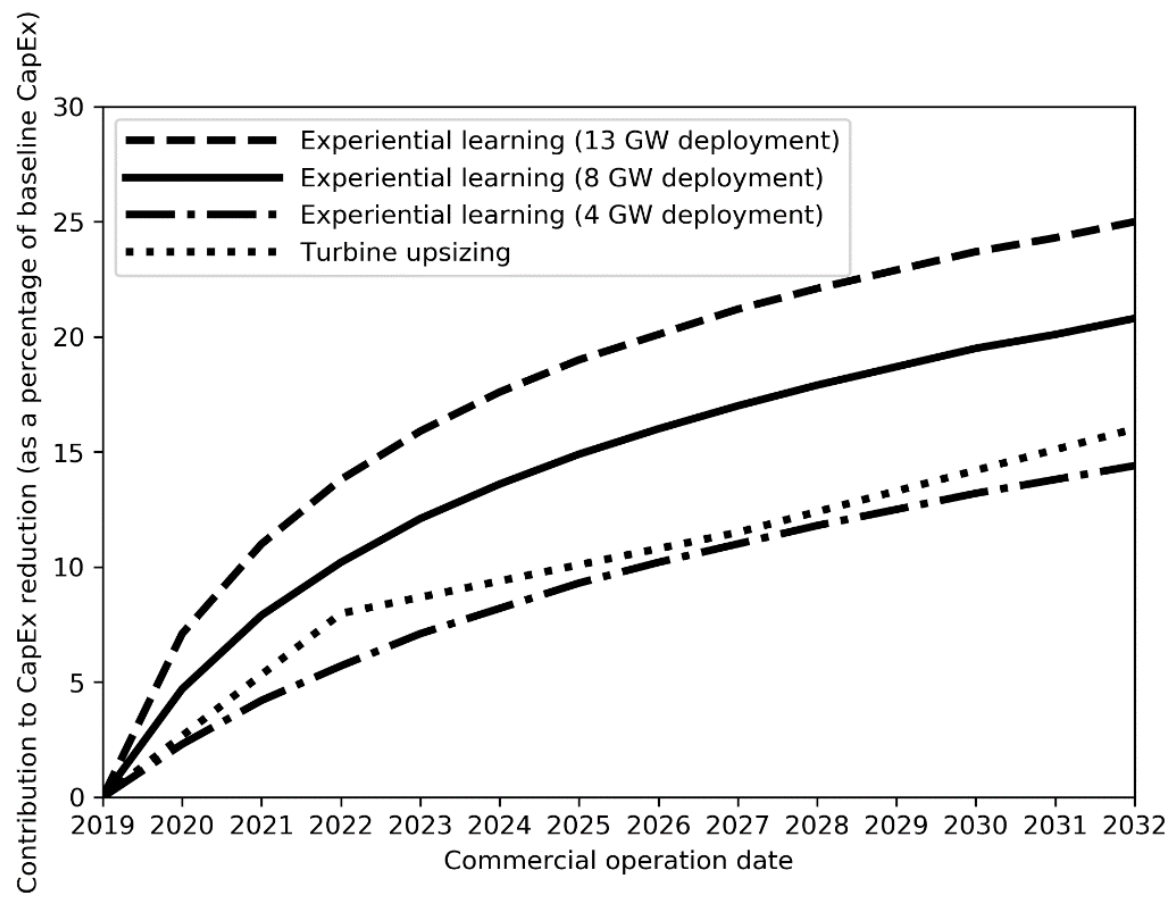

Figure 26. CapEx cost reductions from turbine upsizing and experiential learning attributed to various global floating deployment scenarios

Note: As the experience factor is controlled for turbine rating, the upsizing and experience curve results are combined to estimate total reduction in CapEx.

We derived a final contribution to the cost projections from published expert elicitations, which identify the impact of future technological innovations on LCOE (Valpy et al. 2017; Valpy and English 2014). These reports have been the basis for previous NREL cost assessments (Musial et al. 2019a) and provide valuable insights into the impact of new innovations. Previous reports have used these cost reductions from literature to assess the variation in component-level costs and performance for CapEx, OpEx, and AEP; in this study, the CapEx cost projections are entirely derived from the experience curve and turbine upsizing approach. This is because many of the innovation concepts described in Valpy et al. (2017) and Valpy and English (2014) are intricately linked to developments in the supply chain and cannot be clearly extricated from the experience curve cost reductions. As similar data sets to the one used to develop the CapEx experience curve are not available for OpEx and AEP, these cost projections are taken from literature using the same methodology as in Musial et al. (2019a).

The CapEx and OpEx cost reductions between 2019 and 2032 that are induced by technology innovation can have multiple sources. One of the most comprehensive assessments about technology innovations and their impact on floating offshore wind costs have been generated through expert elicitation (Valpy et al. 2017; Valpy and English 2014). The learning curve approach taken in this analysis aggregates this suite of innovations into a cumulative cost reduction in CapEx. A categorized list of specific technology innovations based on the elicitation conducted by Valpy et al. (2017) and Valpy and English (2014) is included in Appendix A to provide context for the type of developments that are expected to contribute to the overall reduction in CapEx depicted in Figure 26. 


\section{Cost Results}

This section covers the cost results generated by the ORCA cost model using the assumptions and AEP analysis described in previous sections. We also discuss how these LCOE estimates compare to the assumptions of the 2019-2020 IRP (CPUC 2019b). All costs are for 1,000 MW power plants and are presented in \$2019, unless indicated otherwise.

The results for CapEx, OpEx, and LCOE are presented in the following subsections with the discussion focused on the five study areas. Note that CapEx was calculated for three offshore wind installation scenarios (low, mid, and high), which are shown in Section 7.4. In Sections 7.1 and 7.3, results are only shown for the CapEx mid scenario, which is considered the most likely (corresponding to a level of 8,000 MW of globally installed floating offshore wind capacity by 2032). Note that the low-deployment scenario will result in higher costs and conversely the highdeployment scenario will result in lower costs.

\subsection{Capital Expenditures}

The resulting total CapEx values for the baseline year (COD 2019) are presented in Table 12 for the five study sites. The mean value across the entire analysis domain is also included for reference, and the distribution of CapEx is presented in Figure 26. A detailed cost breakdown for the 2019 baseline can be found in Table 21 in the Appendix B.

Table 12. CapEx for the Five Study Areas During the Baseline Year (COD 2019)

\begin{tabular}{|c|c|c|c|c|c|c|}
\cline { 2 - 7 } \multicolumn{1}{c|}{ Item } & $\begin{array}{c}\text { Site 1: } \\
\text { Morro } \\
\text { Bay }\end{array}$ & $\begin{array}{c}\text { Site 2: } \\
\text { Diablo } \\
\text { Canyon }\end{array}$ & $\begin{array}{c}\text { Site 3: } \\
\text { Humboldt }\end{array}$ & $\begin{array}{c}\text { Site 4: } \\
\text { Cape } \\
\text { Mendocino }\end{array}$ & $\begin{array}{c}\text { Site 5: } \\
\text { Del } \\
\text { Norte }\end{array}$ & $\begin{array}{c}\text { Analysis } \\
\text { Domain } \\
\text { Mean }\end{array}$ \\
\hline Total CapEx $[\$ / k W]$ & 4,637 & 4,592 & 4,502 & 4,392 & 4,524 & 4,529 \\
\hline
\end{tabular}

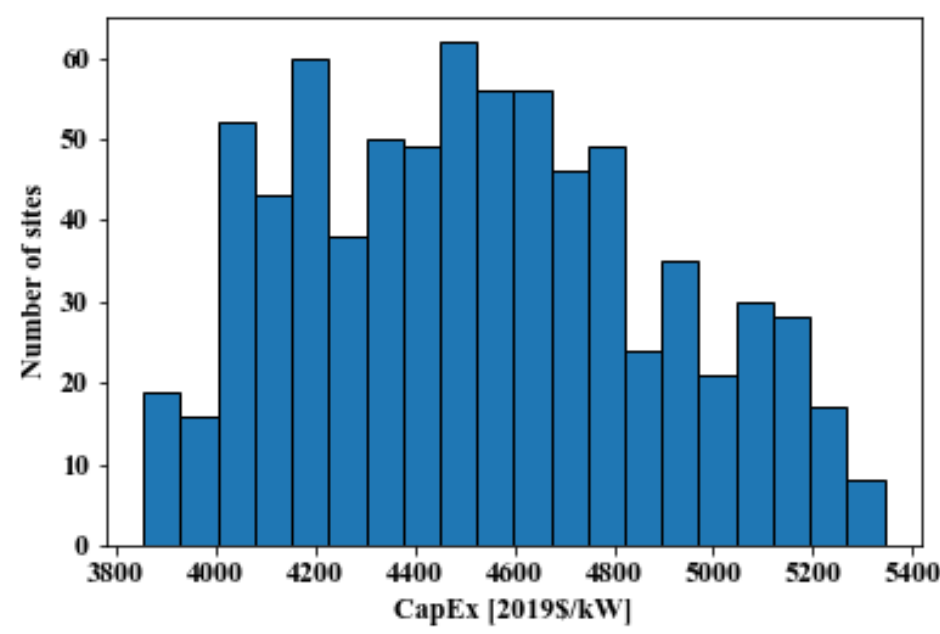

Figure 27. Histogram showing 2019 CapEx distribution across the 759 modeled analysis sites in the analysis domain offshore California 
In the 2019 baseline, CapEx among the five study areas ranges from $\$ 4,392 / \mathrm{kW}$ (Cape Mendocino) to $\$ 4,637 / \mathrm{kW}$ (Morro Bay), with three of the five study areas falling below the mean of $\$ 4,529 / \mathrm{kW}$ across all sites within the analysis domain (Figure 27).

The CapEx among the five study sites varies primarily because of the modeled differences in the export cable length (i.e., the length between the study area and cable landfall) and installation costs (i.e., the distance between the site and the construction port and water depth). We find that Cape Mendocino, Humboldt, and Del Norte have the lowest CapEx. The higher CapEx at the Diablo Canyon and Morro Bay sites can be attributed to the longer subsea cable distances and distances to the construction ports. ${ }^{30}$ The distances are summarized in Table 1 and the impact on total CapEx is observable in Figure 28, which breaks down the component cost categories of the total CapEx. Note that 'Analysis Domain' indicates the mean across the analysis domain. Electrical and installation costs represent the largest sources of difference between the CapEx costs at the study sites.

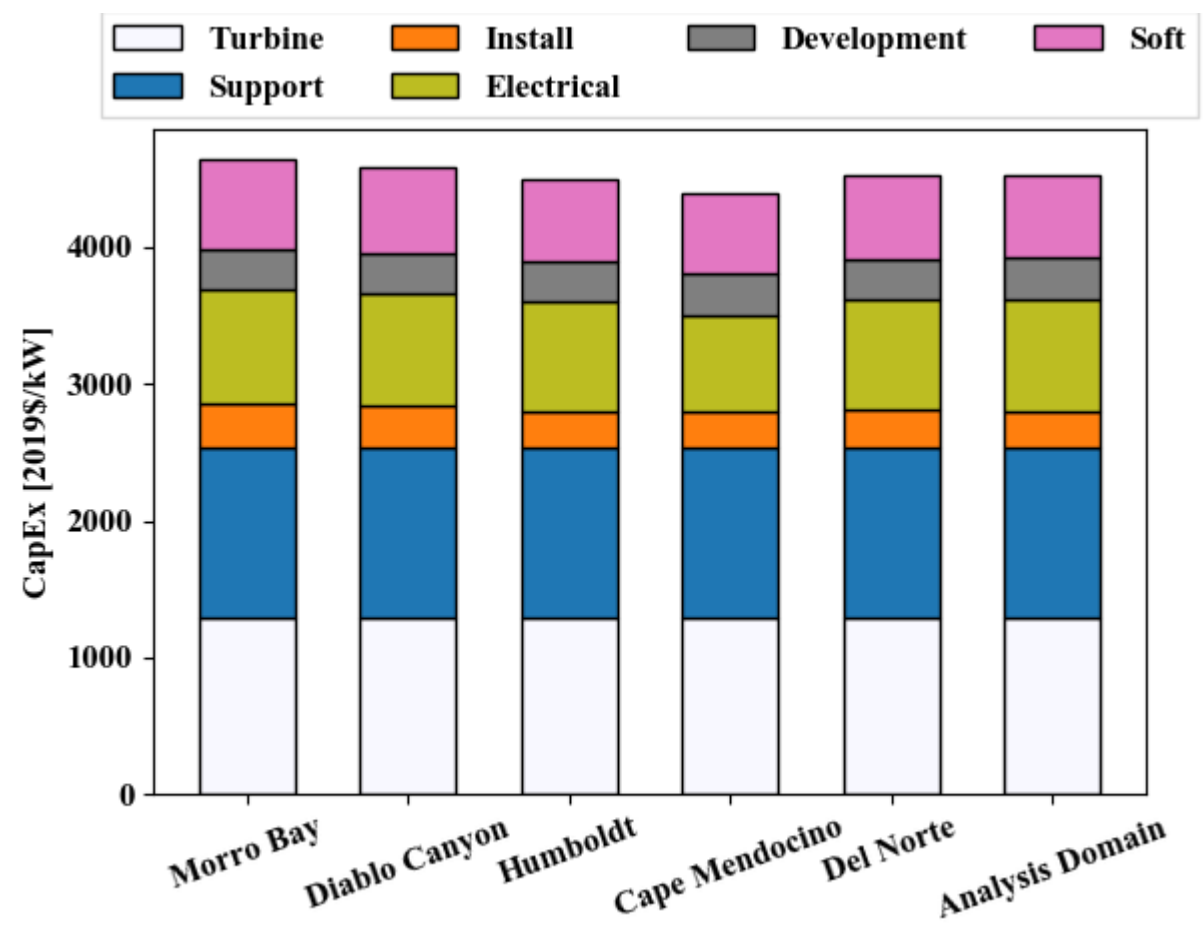

Figure 28. CapEx breakdown of the five study areas in the baseline year (2019)

The other CapEx categories are relatively comparable among the five study areas, some per definition (e.g., turbine CapEx is constant between the sites), others because the relatively small variance in spatial parameters (e.g., water depth) does not result in significant CapEx differences. Note that Morro Bay is commonly assumed to have the clearest path to a land-based grid

\footnotetext{
${ }^{30}$ Note that California construction port facilities are currently not ready for floating offshore wind deployments nearby the Diablo Canyon and Morro Bay sites. Therefore, new port development closer to the study site could potentially be more feasible in some cases than upgrading an existing port farther away. Port requirements are discussed in Section 5.1.
} 
connection because of the retirement of nearby coastal thermal generation plants. This study assumes a generic 5-km distance from cable landfall to point of interconnection but does not reflect any costs associated with bulk transmission expansion and land-based substation upgrades as part of project CapEx or LCOE (see Table 9 and Section 5.3 for further details). These (nonconsidered) costs for bulk transmission expansion and substation upgrades will likely be significantly smaller for sites on the central coast than for the north coast study areas.

In addition to the baseline year CapEx, the predicted CapEx trajectories for the five study sites are presented in Figure 29.

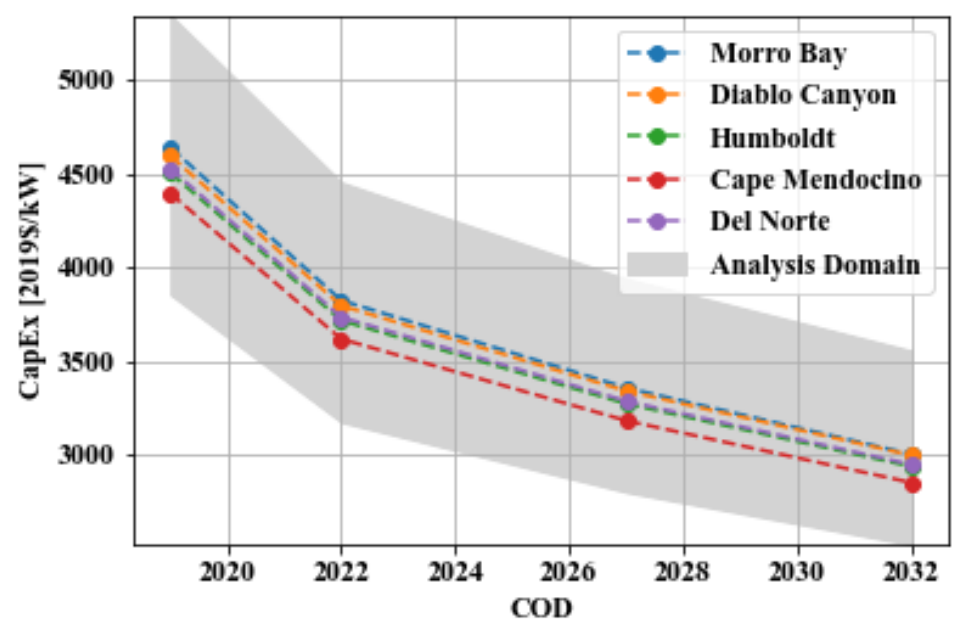

Figure 29. CapEx trajectory of the five California study areas between 2019 and 2032

Note: Light grey band represents the range between the minimum and maximum values across the entire analysis domain.

We estimated CapEx across the five study sites to decline by an average of 35\% between 2019 and 2032 (COD) (under the mid-scenario). This reduction is consistent for all modeled study areas and analysis domain sites. The CapEx reductions are a result of the assumed increase in turbine rating, learning effects incurred by the supply chain, and technology innovation, as described in Section 6.3.6.

Figure 30 presents a map of the modeled CapEx values in the baseline year across the analysis domain offshore California. 


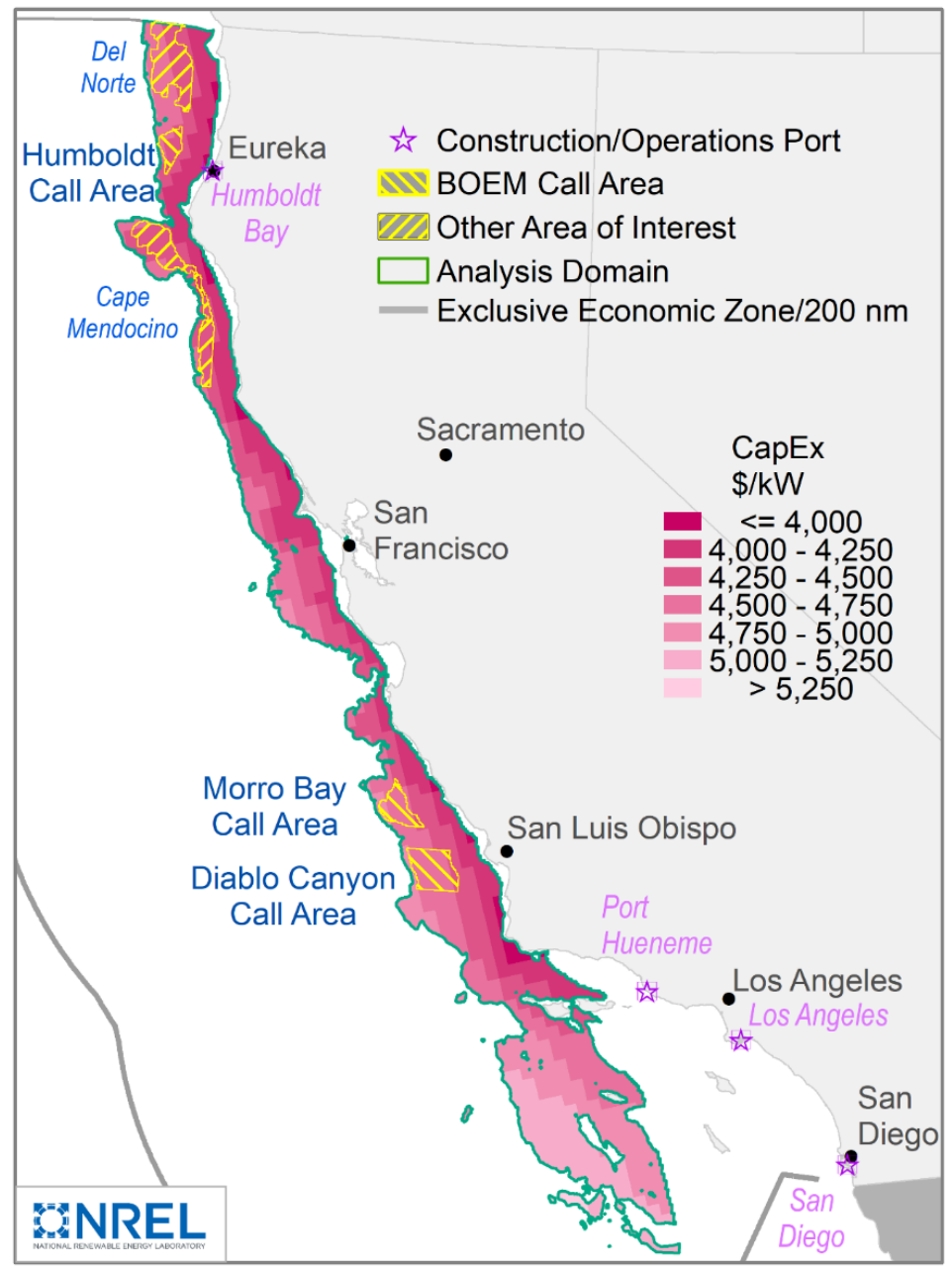

Figure 30. CapEx estimates for the analysis domain offshore California in the baseline year (2019)

CapEx tends to increase with distance from shore because of increased export cable length with greater distances, more challenging wave regimes for operations, and deeper water depths requiring costlier installation procedures. Across the entire analysis domain offshore California, CapEx in the base year (2019) ranges from approximately $\$ 3,850 / \mathrm{kW}$ to $\$ 5,350 / \mathrm{kW}$.

\subsection{Operational Expenditures}

The OpEx is estimated at approximately $\$ 122 / \mathrm{kW}$ for four of the five study sites; Humboldt has an estimated OpEx of $\$ 118 / \mathrm{kW}$ because the modeled O\&M base (port) is much closer than those for the other study areas (see Table 1; approximately $55 \mathrm{~km}$ compared to an average of $200 \mathrm{~km}$ ). This distance drives the maintenance costs, but these costs are also captured in ORCA as a function of the substructure technology (only semisubmersible considered in this analysis) and the average significant wave height at each site. Figure 31 shows the distribution of OpEx costs across the entire analysis domain in the baseline year. A detailed breakdown of OpEx into operation and maintenance expenses is shown in Table 22. A constant operations cost of approximately $\$ 30 / \mathrm{kW}$ is assumed for all analysis domain sites (Table 22). This includes maintenance and various operations expenses (such as for technical operation; management and 
general administration; weather forecasting; condition monitoring; operation of facilities; insurance policies; and annual leases and fees).

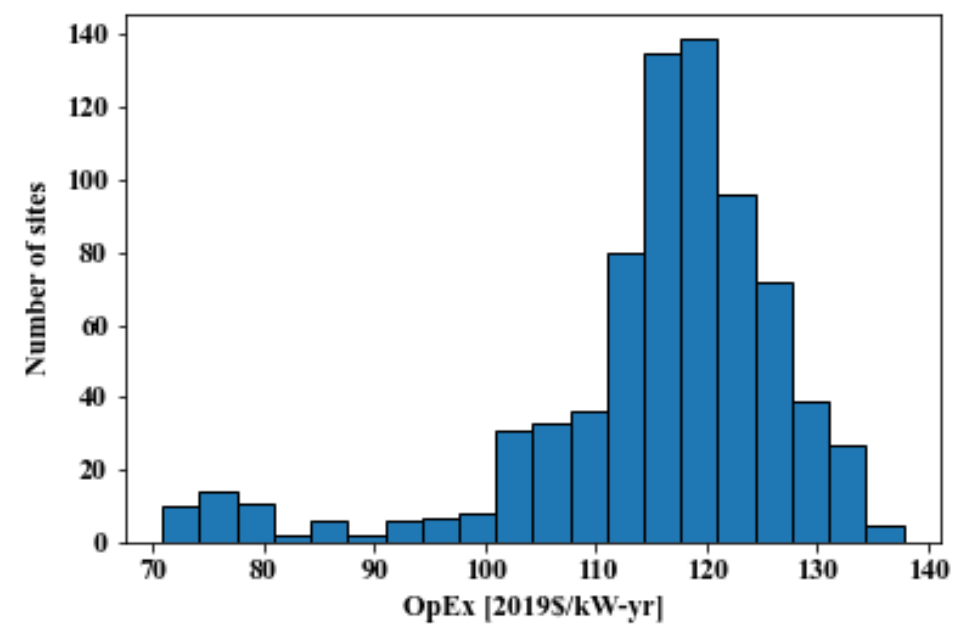

Figure 31. Histogram showing distribution of OpEx costs for the 759 analysis domain sites in 2019

The estimated OpEx for the five study sites is considerably higher than the mean across all analysis domain sites (See Appendix B, Table 22) because the five study sites tend to be located farther from shore and their respective O\&M port than many of the other sites within the analysis domain. Among the entire analysis domain offshore California, OpEx varies between approximately $\$ 71 / \mathrm{kW}$ to $\$ 140 / \mathrm{kW}$ in the base year (2019).

The projected OpEx trajectories are presented in Figure 32. Between 2019 and 2032 (COD), OpEx is estimated to decline by $54 \%$. This cost reduction is induced by technology innovations such as improvements in weather forecasting, increased use of remote sensing and turbine condition-based maintenance, designs that reduce labor at sea, and enhanced personnel access from transfer vessel to turbine.

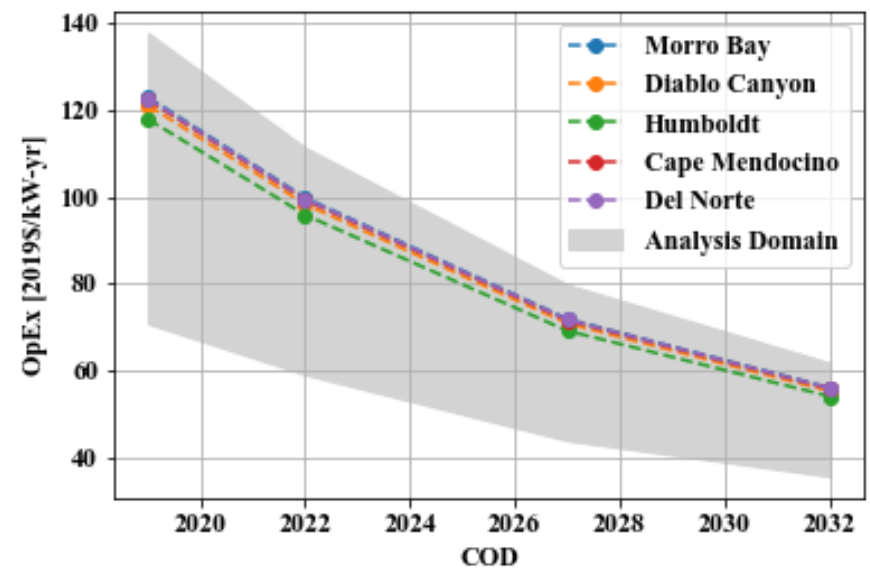

Figure 32. OpEx trajectory of the five study areas between 2019 and 2032

Note: Light grey represents the range between the minimum and maximum values across the entire analysis domain. 
The impact of the distance to the O\&M port on total OpEx can be observed in Figure 33, which allows a geospatial visualization of these data for the modeled points in the California analysis domain.

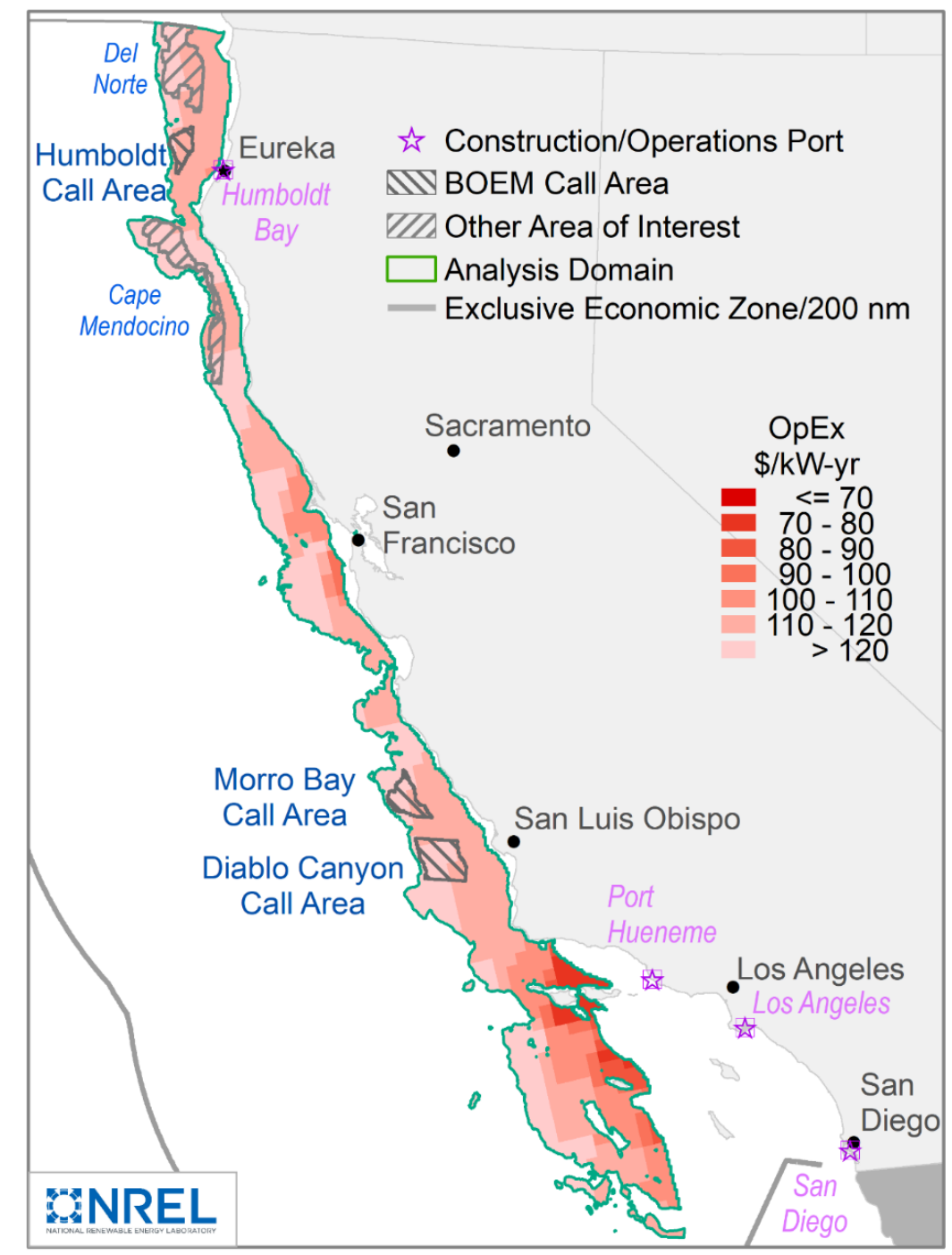

Figure 33. OpEx estimates for the analysis domain offshore California in the baseline year (2019)

\subsection{Levelized Cost of Energy}

LCOE for the five study sites ranges from \$95/MWh (Cape Mendocino) to \$114/MWh (Diablo Canyon) in the baseline year (2019) (Table 13). The study areas with the lowest LCOE, Cape Mendocino (\$95/MWh), Del Norte (\$99/MWh), and Humboldt (\$101/MWh) feature both a lower CapEx and higher NCF than the higher LCOE sites Diablo Canyon (\$114/MWh) and Morro Bay (\$112/MWh). The key drivers are the distance between the site and the point of interconnection (i.e., the export cable costs) and the estimated wind speed. 
Table 13. LCOE Results (CapEx Mid Case Scenario)

\begin{tabular}{|l|c|c|c|c|c|c|}
\cline { 2 - 7 } \multicolumn{1}{c|}{} & $\begin{array}{c}\text { Site 1: } \\
\text { Mear }\end{array}$ & $\begin{array}{c}\text { Site 2: } \\
\text { Miablo } \\
\text { Canyon }\end{array}$ & $\begin{array}{c}\text { Site 3: } \\
\text { Humboldt }\end{array}$ & $\begin{array}{c}\text { Site 4: } \\
\text { Cape } \\
\text { Mendocino }\end{array}$ & $\begin{array}{c}\text { Site 5: } \\
\text { Del } \\
\text { Norte }\end{array}$ & $\begin{array}{c}\text { Analysis } \\
\text { Domain } \\
\text { Mean }\end{array}$ \\
\hline $2019[\$ / M W h]$ & 112 & 114 & 101 & 95 & 99 & 113 \\
\hline $2022[\$ / M W h]$ & 90 & 92 & 81 & 77 & 80 & 92 \\
\hline $2027[\$ / M W h]$ & 73 & 74 & 66 & 62 & 65 & 75 \\
\hline $2032[\$ / M W h]$ & 63 & 64 & 57 & 53 & 55 & 64 \\
\hline
\end{tabular}

Figure 34 presents the LCOE trajectories after the baseline year as well as the distribution of calculated LCOE values across the 759 sites examined in the California study domain (the spread between the minimum and maximum value across the California analysis domain is shown in grey). Across the five study sites, LCOE is estimated to decline by $44 \%$ on average between 2019 and 2032 (COD). This trajectory is induced by the combined reductions from CapEx, $\mathrm{OpEx}$, and increased energy production (as a result of technology improvements and loss reductions).

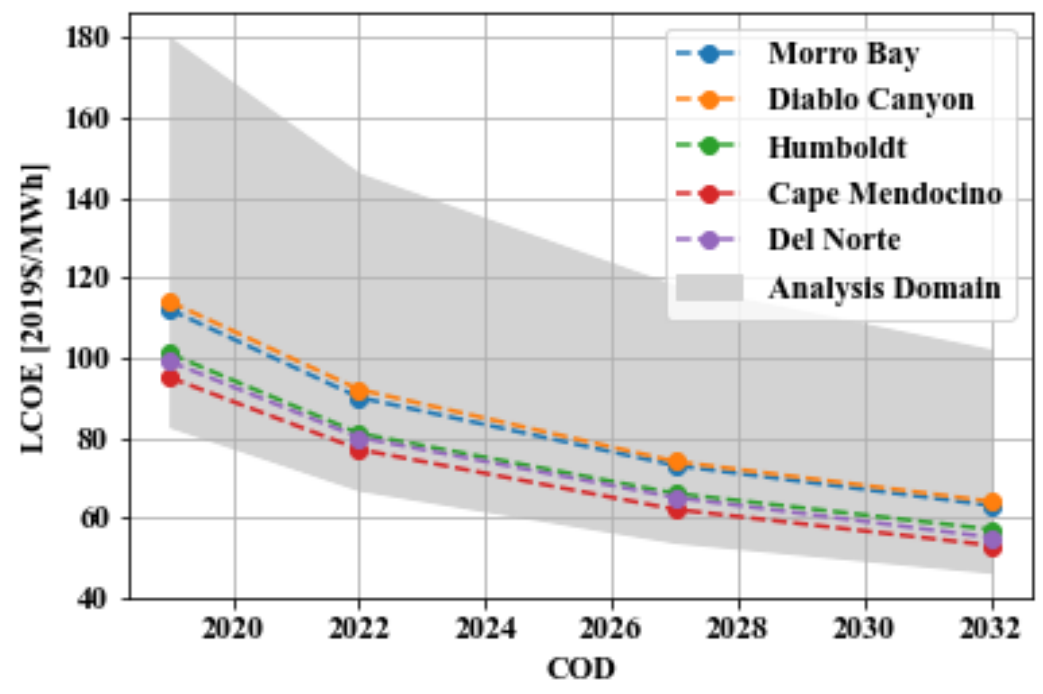

(a) 


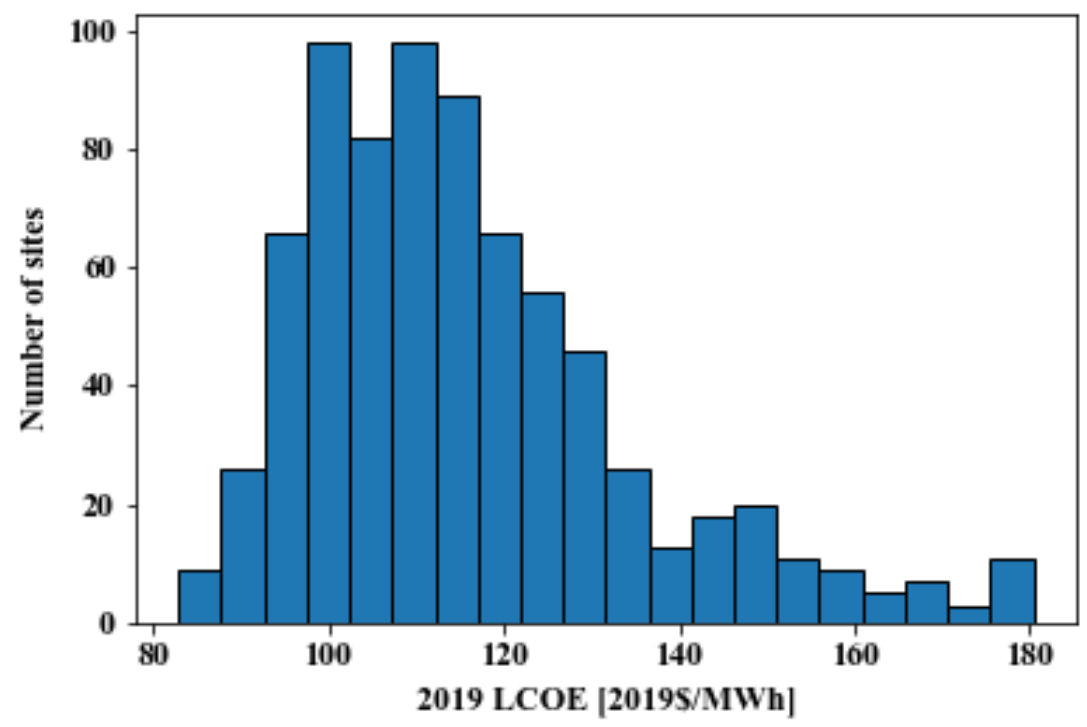

(b)

Figure 34. (a) LCOE (mid) trajectories of the five study areas between 2019 and 2032 and (b) a histogram highlighting the distribution of LCOE values calculated in 2019 for the 759 sites in the analysis domain

Note: Light grey represents the range between the minimum and maximum values across the entire analysis domain.

Compared to the entire analysis domain offshore California (Figure 35), the northern study areas (Cape Mendocino, Del Norte, and Humboldt) are among those sites with the lowest LCOE. The spatial distribution of LCOE for the entire analysis domain for model years 2022, 2027, and 2032 are shown in Figure 36-Figure 38, respectively. 


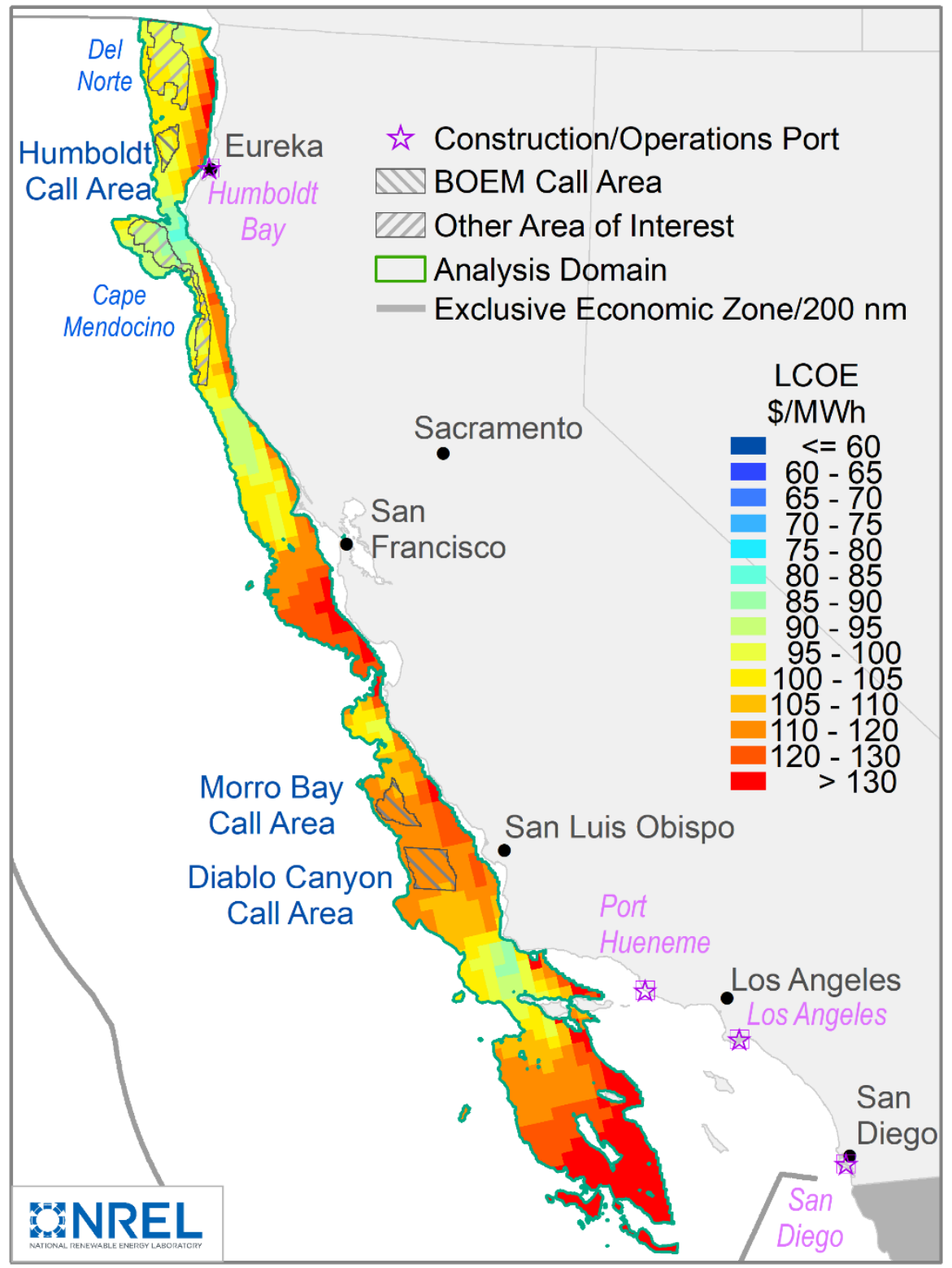

Figure 35. LCOE estimates (mid case) for the analysis domain offshore California (2019 COD) 


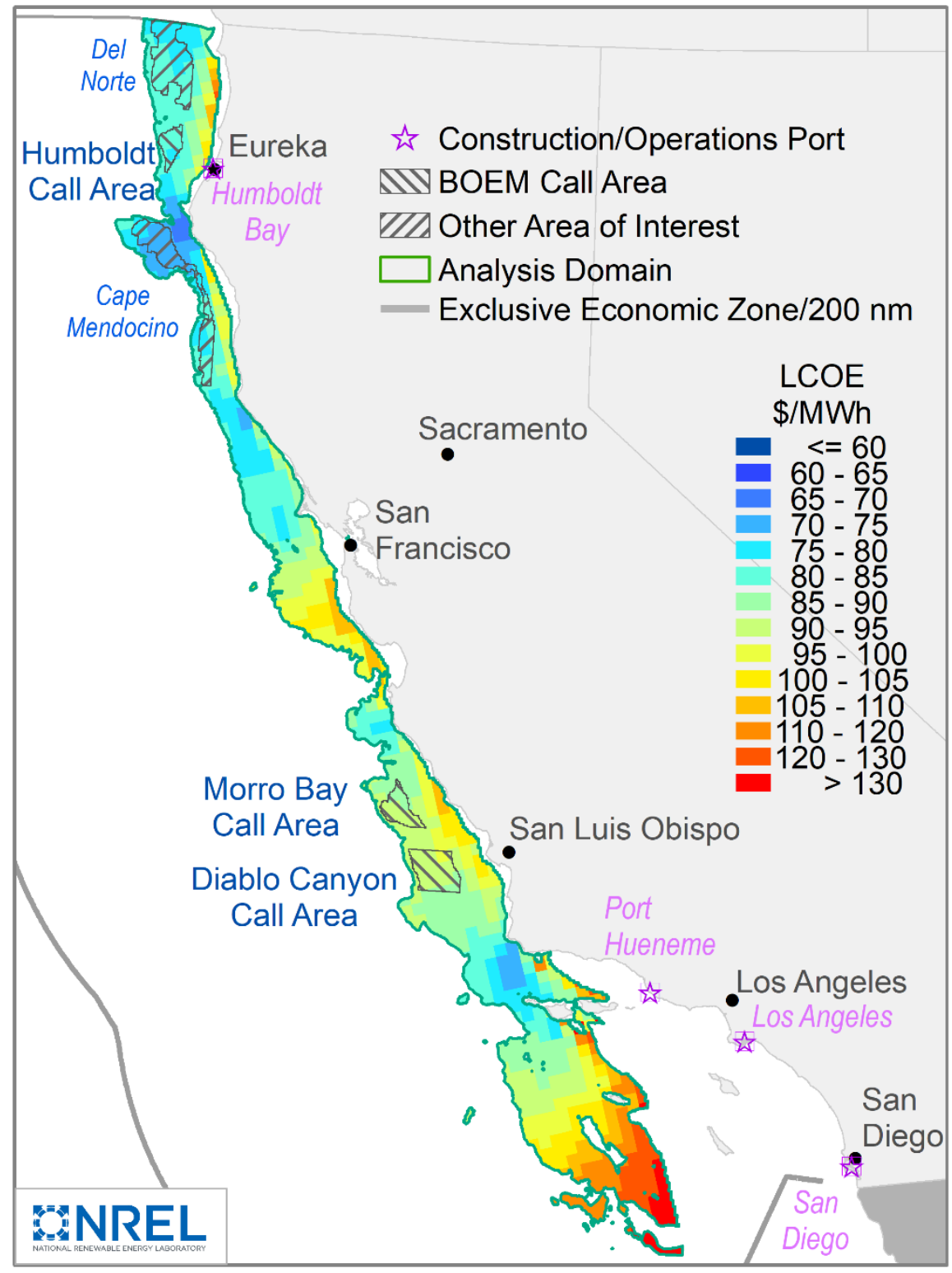

Figure 36. LCOE estimates (mid case) for the analysis domain offshore California (2022 COD) 


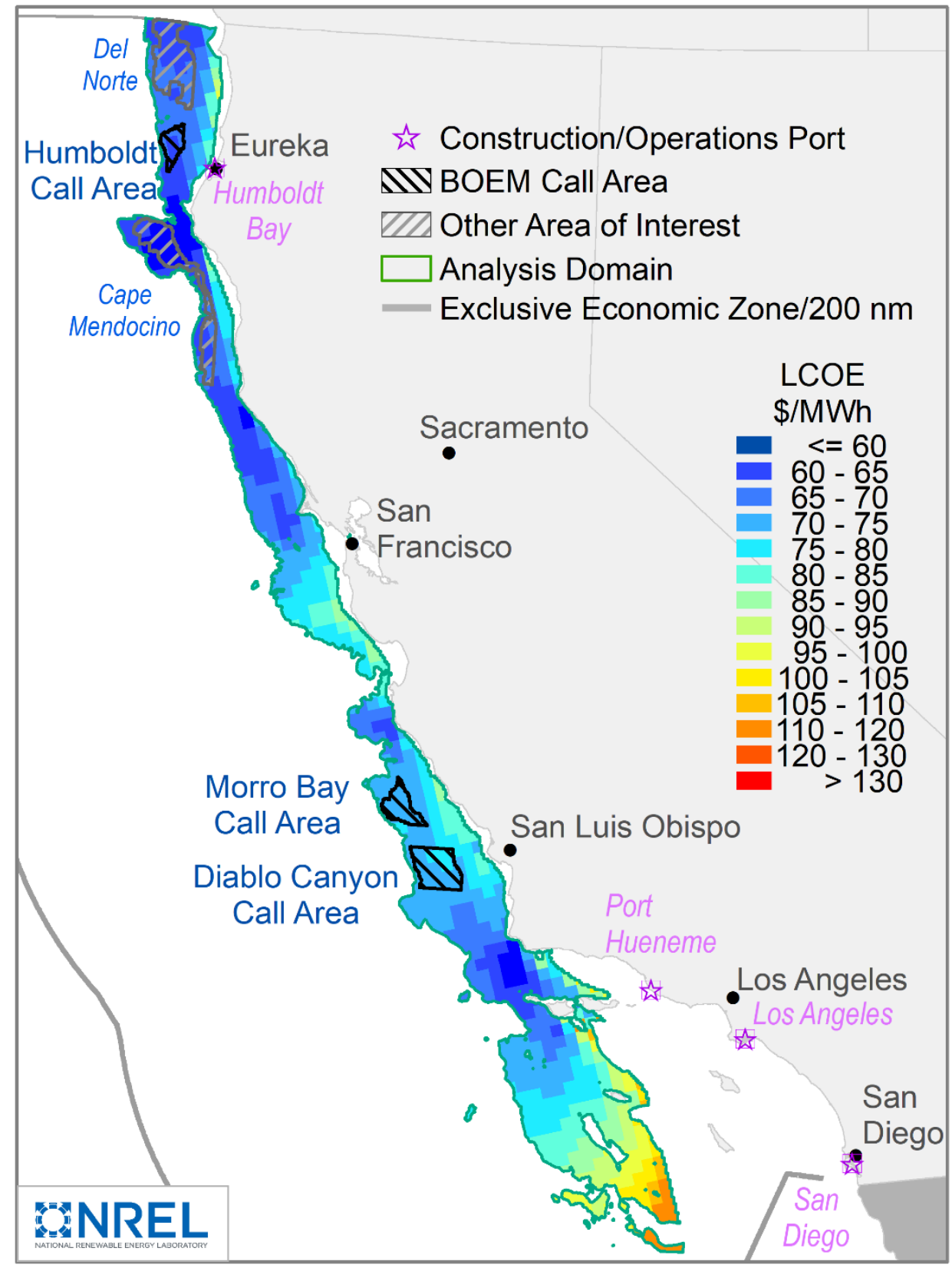

Figure 37. LCOE estimates (mid case) for the analysis domain offshore California (2027 COD) 


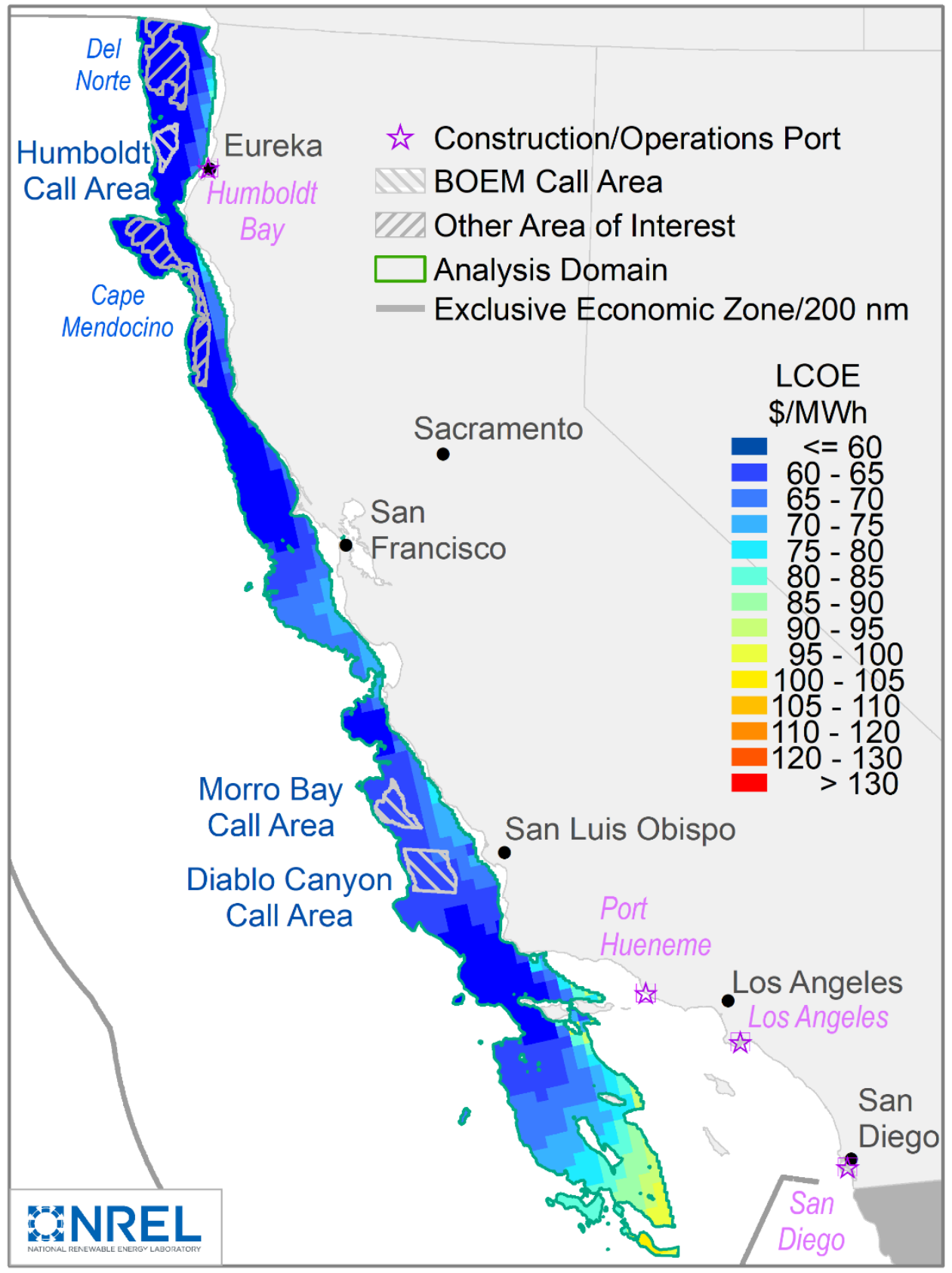

Figure 38. LCOE estimates (mid case) for the analysis domain offshore California (2032 COD)

\subsection{California Floating Cost Scenarios}

We calculated CapEx scenarios to represent the uncertainty around the timing of commercial deployment of floating offshore wind technology worldwide. CapEx trajectories were associated with different levels of floating capacity deployment globally by 2032 :

- Low: $4 \mathrm{GW}$

- Mid: $8 \mathrm{GW}$

- High: $13 \mathrm{GW}$. 
These scenarios were informed by a literature review (Table 11). The resulting CapEx trajectories are shown in Table 14. The associated Figure 39 (CapEx) illustrate the trend over time for the five study areas.

Table 14. CapEx Scenario Results

\begin{tabular}{|c|c|c|c|c|c|c|}
\hline SCENARIO/ YEAR & $\begin{array}{l}\text { Site 1: } \\
\text { Morro } \\
\text { Bay }\end{array}$ & $\begin{array}{l}\text { Site 2: } \\
\text { Diablo } \\
\text { Canyon }\end{array}$ & $\begin{array}{l}\text { Site 3: } \\
\text { Humboldt }\end{array}$ & $\begin{array}{c}\text { Site 4: } \\
\text { Cape } \\
\text { Mendocino }\end{array}$ & $\begin{array}{c}\text { Site 5: } \\
\text { Del } \\
\text { Norte }\end{array}$ & $\begin{array}{c}\text { Analysis } \\
\text { Domain } \\
\text { Mean }\end{array}$ \\
\hline \multicolumn{7}{|l|}{2019} \\
\hline BASELINE [\$/kW] & 4,637 & 4,592 & 4,502 & 4,392 & 4,524 & 4,529 \\
\hline \multicolumn{7}{|l|}{2022} \\
\hline Low deployment [\$/kW] & 4,013 & 3,984 & 3,901 & 3,797 & 3,919 & 3,931 \\
\hline Mid deployment [\$/kW] & 3,822 & 3,794 & 3,715 & 3,616 & 3,732 & 3,743 \\
\hline High deployment $[\$ / k W]$ & 3,669 & 3,642 & 3,566 & 3,471 & 3,583 & 3,593 \\
\hline \multicolumn{7}{|l|}{2027} \\
\hline Low deployment [\$/kW] & 3,598 & 3,580 & 3,508 & 3,410 & 3,522 & 3,538 \\
\hline Mid deployment [\$/kW] & 3,356 & 3,339 & 3,271 & 3,181 & 3,285 & 3,299 \\
\hline High deployment [\$/kW] & 3,186 & 3,170 & 3,106 & 3,020 & 3,119 & 3,132 \\
\hline \multicolumn{7}{|l|}{2032} \\
\hline Low deployment [\$/kW] & 3,244 & 3,239 & 3,174 & 3,081 & 3,185 & 3,205 \\
\hline Mid deployment [\$/kW] & 3,002 & 2,996 & 2,937 & 2,850 & 2,947 & 2,966 \\
\hline High deployment $[\$ / k W]$ & 2,843 & 2,838 & 2,781 & 2,699 & 2,791 & 2,808 \\
\hline
\end{tabular}

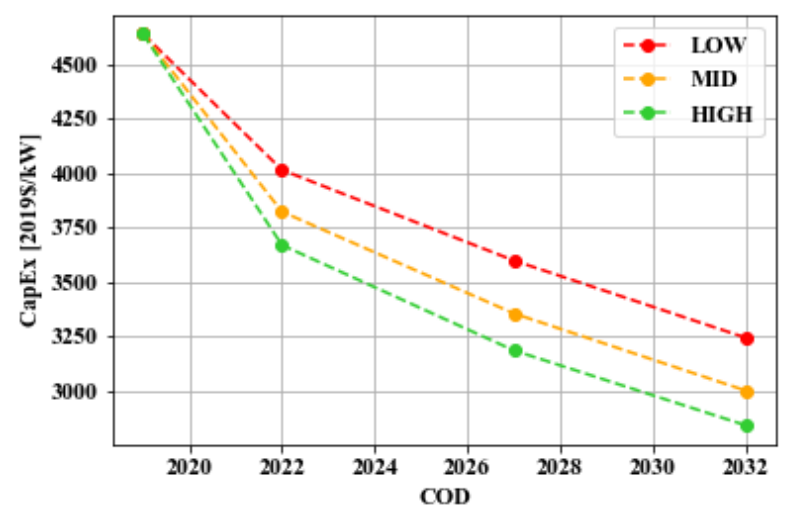

(a) Morro Bay 


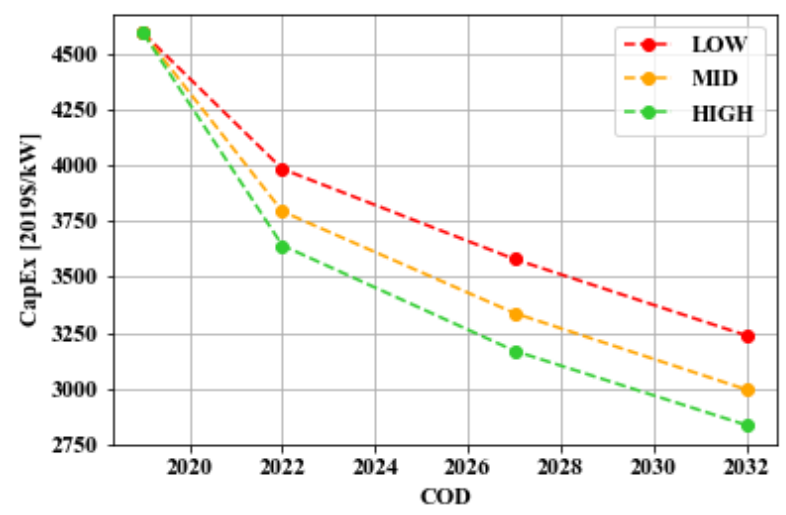

(b) Diablo Canyon

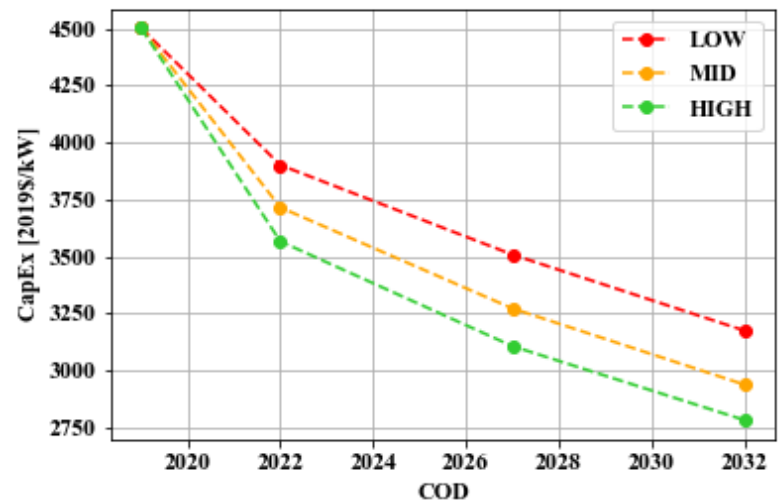

(c) Humboldt

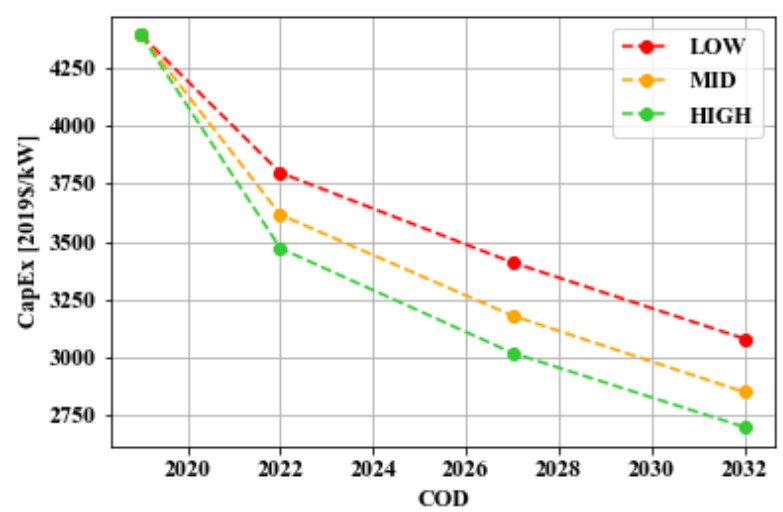

(d) Cape Mendocino 


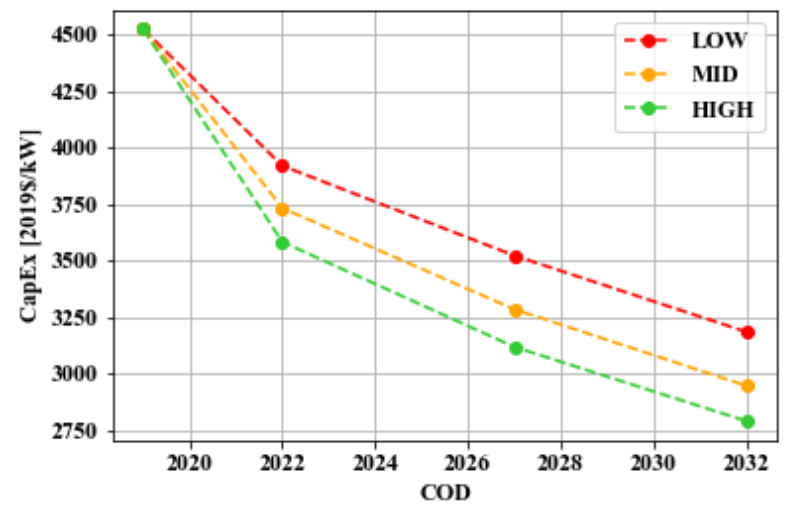

(e) Del Norte

Figure 39 (a)-(e). CapEx scenario trajectories for the five study sites

Note that "Low" refers to the low deployment scenario not low cost.

The LCOE values computed based on the CapEx trajectories are summarized in Table 15, and the trajectories for each site are plotted in Figure 40.

Table 15. LCOE Scenario Results

\begin{tabular}{|c|c|c|c|c|c|c|}
\hline SCENARIO/ YEAR & $\begin{array}{c}\text { Site 1: } \\
\text { Morro } \\
\text { Bay }\end{array}$ & $\begin{array}{l}\text { Site 2: } \\
\text { Diablo } \\
\text { Canyon }\end{array}$ & $\begin{array}{l}\text { Site } 3: \\
\text { Humboldt }\end{array}$ & $\begin{array}{l}\text { Site 4: Cape } \\
\text { Mendocino }\end{array}$ & $\begin{array}{c}\text { Site 5: } \\
\text { Del } \\
\text { Norte }\end{array}$ & $\begin{array}{c}\text { Analysis } \\
\text { Domain } \\
\text { Mean }\end{array}$ \\
\hline \multicolumn{7}{|l|}{2019} \\
\hline Baseline [\$/MWh] & 112 & 114 & 101 & 95 & 99 & 113 \\
\hline \multicolumn{7}{|l|}{2022} \\
\hline Low deployment [\$/MWh] & 94 & 95 & 84 & 79 & 83 & 95 \\
\hline Mid deployment [\$/MWh] & 90 & 92 & 81 & 77 & 80 & 92 \\
\hline $\begin{array}{l}\text { High deployment } \\
\text { [\$/MWh] }\end{array}$ & 88 & 89 & 79 & 74 & 77 & 89 \\
\hline \multicolumn{7}{|l|}{2027} \\
\hline Low deployment [\$/MWh] & 77 & 79 & 70 & 66 & 68 & 79 \\
\hline Mid deployment [\$/MWh] & 73 & 74 & 66 & 62 & 65 & 75 \\
\hline $\begin{array}{l}\text { High deployment } \\
\text { [\$/MWh] }\end{array}$ & 70 & 71 & 63 & 60 & 62 & 72 \\
\hline \multicolumn{7}{|l|}{2032} \\
\hline Low deployment [\$/MWh] & 67 & 68 & 60 & 57 & 59 & 68 \\
\hline Mid deployment [\$/MWh] & 63 & 64 & 57 & 53 & 55 & 64 \\
\hline $\begin{array}{l}\text { High deployment } \\
\text { [\$/MWh] }\end{array}$ & 60 & 61 & 54 & 51 & 53 & 61 \\
\hline
\end{tabular}




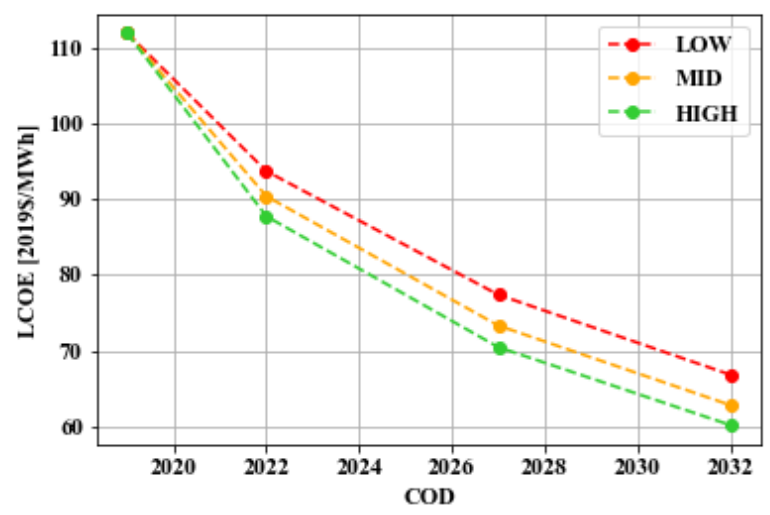

(a) Morro Bay

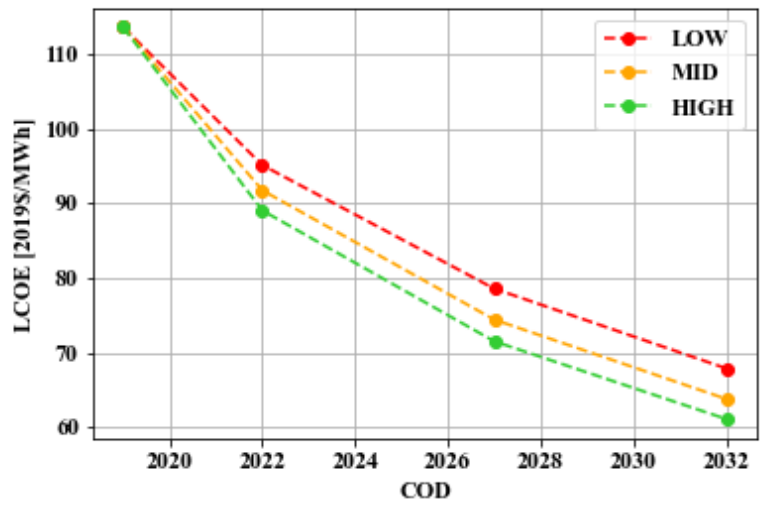

(b) Diablo Canyon

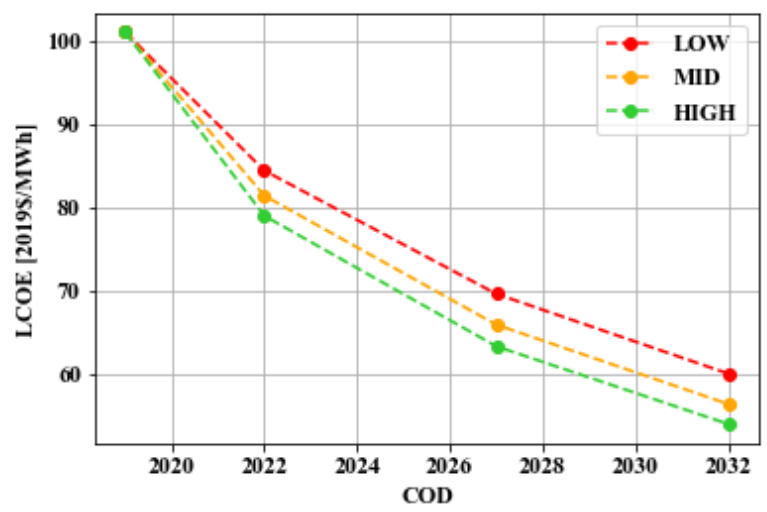

(c) Humboldt 


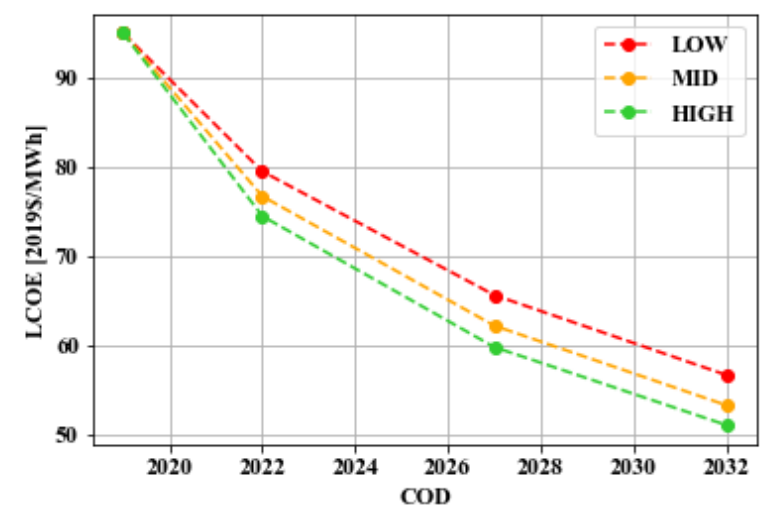

(d) Cape Mendocino

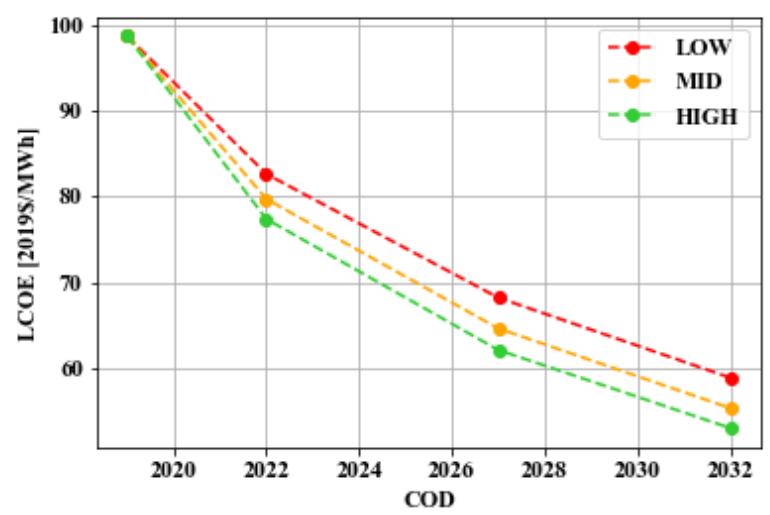

(e) Del Norte

Figure 40. (a)-(e) Cost scenario trajectories for the five study sites

\subsection{Sensitivity Analysis}

In this section, we illustrate the sensitivity of LCOE to changes in key cost components and spatial parameters. The sensitivity analysis presented here is not intended to be exhaustive; rather, it provides a sense for the magnitude by which LCOE changes when its key components and two spatial parameters of interest are varied. The modeled cost parameters are those captured in the LCOE equation in Eq. 3: CapEx, OpEx, NCF, and weighted average cost of capital (WACC). ${ }^{31}$ The two spatial parameters that are varied are export cable and port distance to site. These were included in this sensitivity analysis because of the uncertainty around offshore wind points of interconnection (and available bulk transmission lines) in California (see Sections 5.2 and 5.3). All these parameters were varied individually for the Morro Bay Call Area, holding all else constant. The baseline values are representative of Morro Bay with a 2019 COD, because this site is closest to the mean LCOE of all sites within the analysis domain. The resulting LCOE values are recorded in Table 16 and visualized in Figure 41. The estimated LCOE for Morro Bay in 2019 is $\$ 112 / \mathrm{MWh}$ under the CapEx mid-scenario. The weighted average cost of capital, CapEx, OpEx, and distance parameter values were varied to be $90 \%$ and $110 \%$ of their baseline

\footnotetext{
${ }^{31}$ WACC is part of the FCR calculation.
} 
value. The NCF was varied to be $99 \%$ and $101 \%$ of the baseline value, as this was thought to be a more realistic variation.

Table 16. LCOE Sensitivity Parameters and Results

\begin{tabular}{|l|l|l|l|}
\hline Parameter & $\begin{array}{l}\text { Baseline Value } \\
\text { (COD 2019) }\end{array}$ & $\begin{array}{l}\text { Variation Relative } \\
\text { to Baseline (Low, } \\
\text { High) }\end{array}$ & $\begin{array}{l}\text { Resulting LCOE } \\
\text { Values (Low, High) } \\
\text { [2019\$/MWh] }\end{array}$ \\
\hline WACC [\%] & 5.4 & $90 \%, 110 \%$ & $107 ; 117$ \\
\hline CapEx [2019\$/kW] & 4,637 & $90 \%, 110 \%$ & $104 ; 120$ \\
\hline OpEx [2019\$/kW-yr] & 122 & $90 \%, 110 \%$ & $109 ; 115$ \\
\hline NCF [\%] & 46.5 & $99 \%, 101 \%$ & $111 ; 113$ \\
\hline $\begin{array}{l}\text { Export Cable Distance } \\
\text { [km] }\end{array}$ & 43.5 & $90 \% ; 110 \%$ & $111 ; 112$ \\
\hline $\begin{array}{l}\text { Construction Port } \\
\text { Distance [km] }\end{array}$ & 317.7 & $90 \% ; 110 \%$ & $111 ; 112$ \\
\hline
\end{tabular}

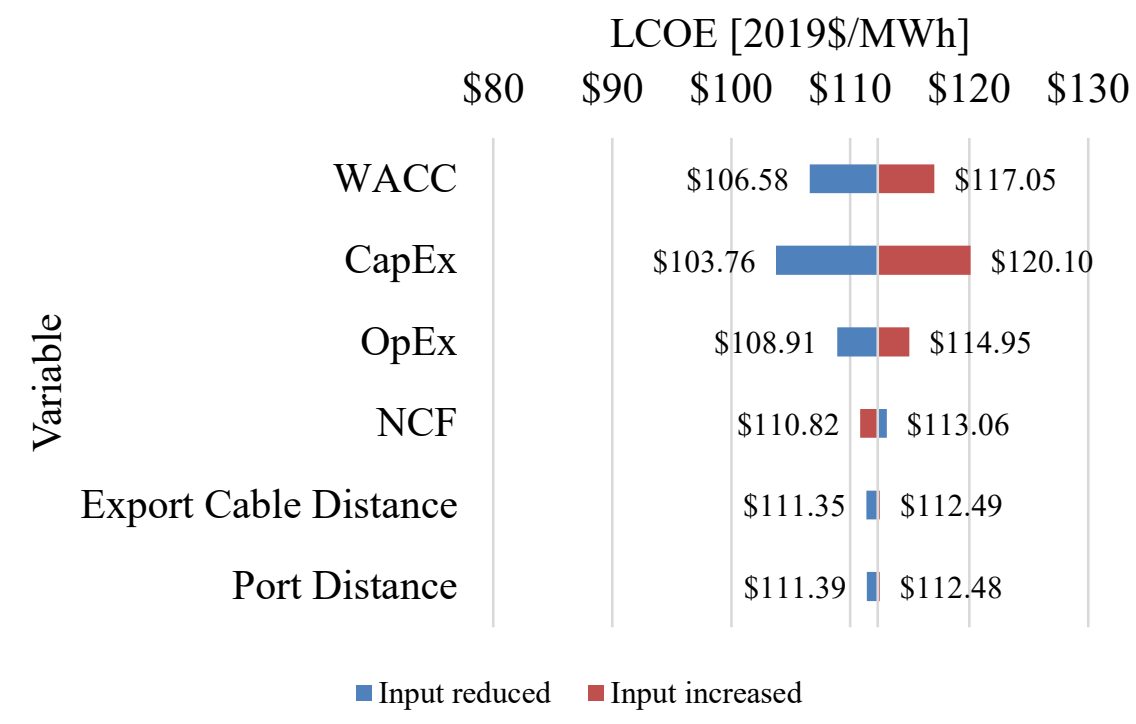

Figure 41. Results of LCOE sensitivity analysis case (2019 baseline)

Note: WACC, CapEx, OpEx and distance parameters were varied $+/-10 \%$ of their baseline values. NCF was varied $+/-1 \%$ of the baseline value. LCOE for the increased input value is shown in red; reduced input values are shown in blue.

We also explored the sensitivity of the LCOE results with respect to different plant sizes using NREL's ORBIT tool (NREL 2020). The size of power plants using fixed-bottom technology has increased (Musial et al. 2019b). We expect the per-unit cost of CapEx $(\$ / \mathrm{kW})$ and OpEx $(\$ / \mathrm{kW}$ year) to decrease as plant rating increases because of economies of scale. These economies of scale are induced by a fixed cost (e.g., export system, management costs, or port costs) that is distributed over a larger number of turbines (i.e., reducing the per-unit cost). Further, the purchasing power of an offshore wind developer might be greater as larger quantities of goods (e.g., turbines, cables) are procured, reducing the per-unit cost. 


\subsection{Comparison to Earlier Studies}

This analysis builds on an earlier study assessing the costs of floating offshore wind in California (Musial et al. 2016a). In the 2019-2020 IRP process, we used floating cost estimates from NREL's 2018 Annual Technology Baseline (NREL 2019a) and documented in Collier (2019). These assessments, all published in different years, reflect varying sets of key assumptions (Table 17). The floating (and fixed-bottom) offshore wind industry has progressed rapidly over the last few years in terms of commercial and technological status. Modeling assumptions are updated to reflect those advances.

Table 17. Key Modeling Assumptions of This Study Compared to Two Prior NREL Assessments

\begin{tabular}{|l|l|l|l|}
\hline & This Study & $\begin{array}{l}\text { Prior California Floating } \\
\text { Cost Assessment } \\
\text { (Musial et al. 2016a) }\end{array}$ & $\begin{array}{l}\text { 2018 Annual } \\
\text { Technology Baseline } \\
\text { (NREL 2019a) }\end{array}$ \\
\hline $\begin{array}{l}\text { Turbine size, 2019/2032 } \\
\text { (MW) }\end{array}$ & $8-15$ & $6-10$ & $3.4-10$ \\
\hline Plant size (MW) & 1,000 & 600 & 600 \\
\hline Fixed charge rate (\%) & $7.2 \%$ & $10.5 \%$ & $9.5 \%$ \\
\hline Wind speed data & $\begin{array}{l}\text { CA20 resource } \\
\text { data set }\end{array}$ & $\begin{array}{l}17-y r \text { AWS Truepower/ } \\
\text { MERRA32 data set }\end{array}$ & Wind Toolkit data 33 \\
\hline Aggregation & Site-specific & Site-specific & $\begin{array}{l}\text { Average (techno- } \\
\text { resource group) }\end{array}$ \\
\hline
\end{tabular}

These differences in modeling assumptions have a considerable impact on cost and performance results. For instance, on average across the study areas, the CapEx in this study is estimated approximately 15\% lower than the 2019-2020 IRP input for year 2030 (Table 18). Figure 42 shows a comparison of all three studies over time illustrated for the Diablo Canyon study area. This difference can be attributed to a higher turbine rating and larger plant size assumption in this study. In addition, the Annual Technology Baseline estimates (2019a) average costs and performance across a so-called "techno-resource group" (up to several gigawatts of capacity), which deviates from the site-specific estimates generated in this study. OpEx estimates for 2030 are estimated approximately 11\% lower in this study than the 2019-2020 IRP cost input. This difference exists primarily because of a different interpolation method used between Musial et al. (2016) (exponential fit) and this study (logarithmic fit) and because of differences in the represented spatial parameters. Figure 43 depicts a comparison of all three studies over time illustrated for the Diablo Canyon study area. Net capacity factors are assessed to be significantly higher in this study than the 2019-2020 IRP input with the exception of Morro Bay. In the 20192020 IRP, a considerably higher net capacity factor of 55\% was estimated for Morro Bay while modeling in this study suggests $49 \%$.

\footnotetext{
32 National Aeronautics and Space Administration's Modern-Era Retrospective Analysis (MERRA).

${ }^{33}$ Source: NREL (2020).
} 
Table 18. Comparison Between the 2019-2020 IRP and NREL Cost and Performance Values

\begin{tabular}{|c|c|c|c|c|c|c|c|c|}
\hline & \multicolumn{2}{|c|}{$\begin{array}{l}\text { Net Capacity } \\
\text { Factor }(\%)\end{array}$} & \multicolumn{2}{|c|}{ CapEx $(\$ / k W)$} & \multicolumn{2}{|c|}{ OpEx (\$/kW-yr) } & \multicolumn{2}{|c|}{ LCOE (\$/MWh) } \\
\hline & $\begin{array}{l}2019- \\
2020 \text { IRP }\end{array}$ & $\begin{array}{l}\text { NREL } \\
2020\end{array}$ & $\begin{array}{l}2019- \\
2020 \text { IRP }\end{array}$ & $\begin{array}{l}\text { NREL } \\
2020\end{array}$ & $\begin{array}{l}2019- \\
2020 \text { IRP }\end{array}$ & $\begin{array}{l}\text { NREL } \\
2020\end{array}$ & $\begin{array}{l}2019- \\
2020 \text { IRP }\end{array}$ & $\begin{array}{l}\text { NREL } \\
2020\end{array}$ \\
\hline COD & \multicolumn{8}{|c|}{2030} \\
\hline Morro Bay & 55 & 49 & 3,791 & 3,139 & 71 & 64 & 76 & 67 \\
\hline $\begin{array}{l}\text { Diablo } \\
\text { Canyon }\end{array}$ & 46 & 48 & 4,042 & 3,128 & 71 & 63 & 96 & 68 \\
\hline Humboldt & 52 & 53 & 3,791 & 3,064 & 71 & 62 & 81 & 61 \\
\hline $\begin{array}{l}\text { Cape } \\
\text { Mendocino }\end{array}$ & 53 & 55 & 3,791 & 2,976 & 71 & 64 & 79 & 57 \\
\hline Del Norte & 52 & 55 & 3,791 & 3,076 & 71 & 64 & 81 & 59 \\
\hline
\end{tabular}

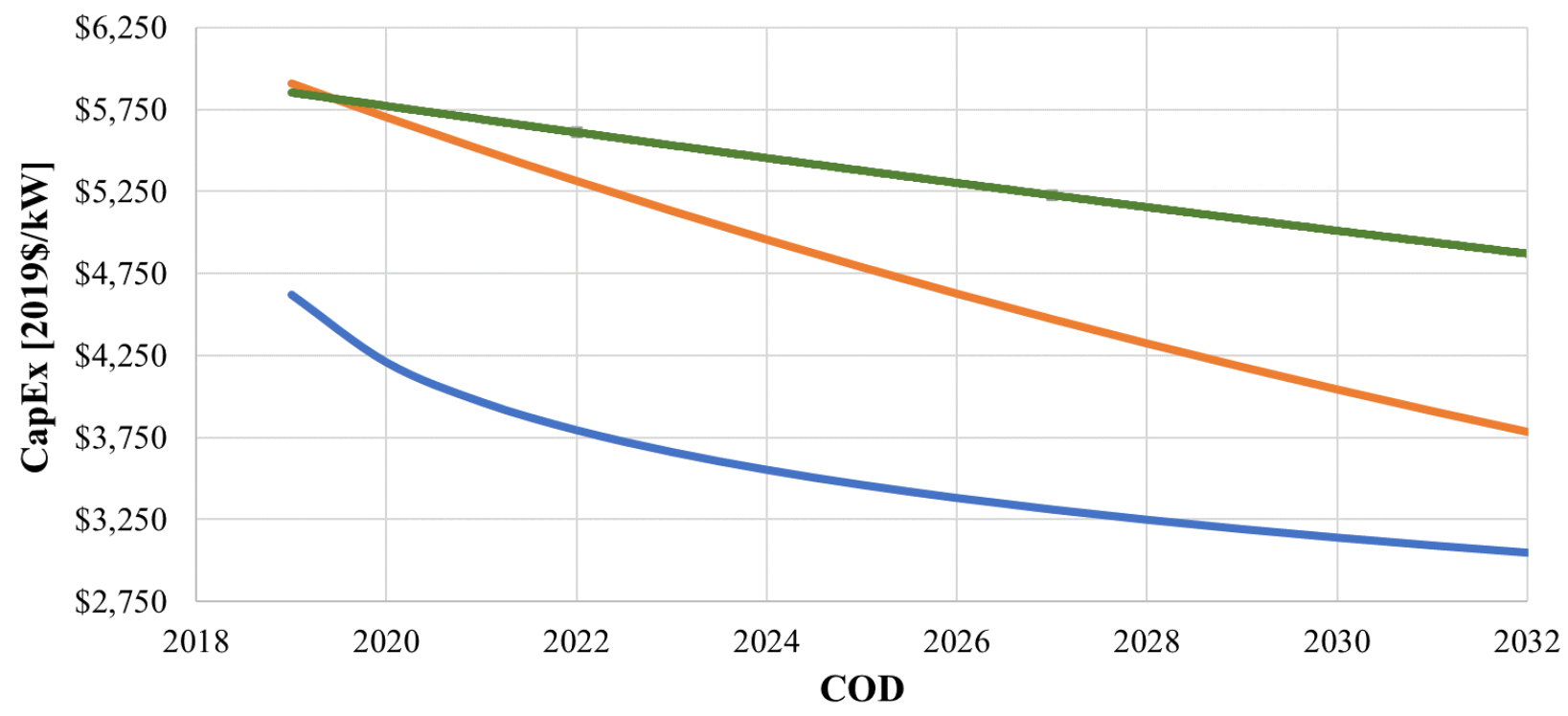

—This Study —2019-2020 IRP = Musial et al. (2016a)

Figure 42. CapEx estimated in this analysis in comparison to two prior California floating offshore wind studies illustrated for the Diablo Canyon study area 


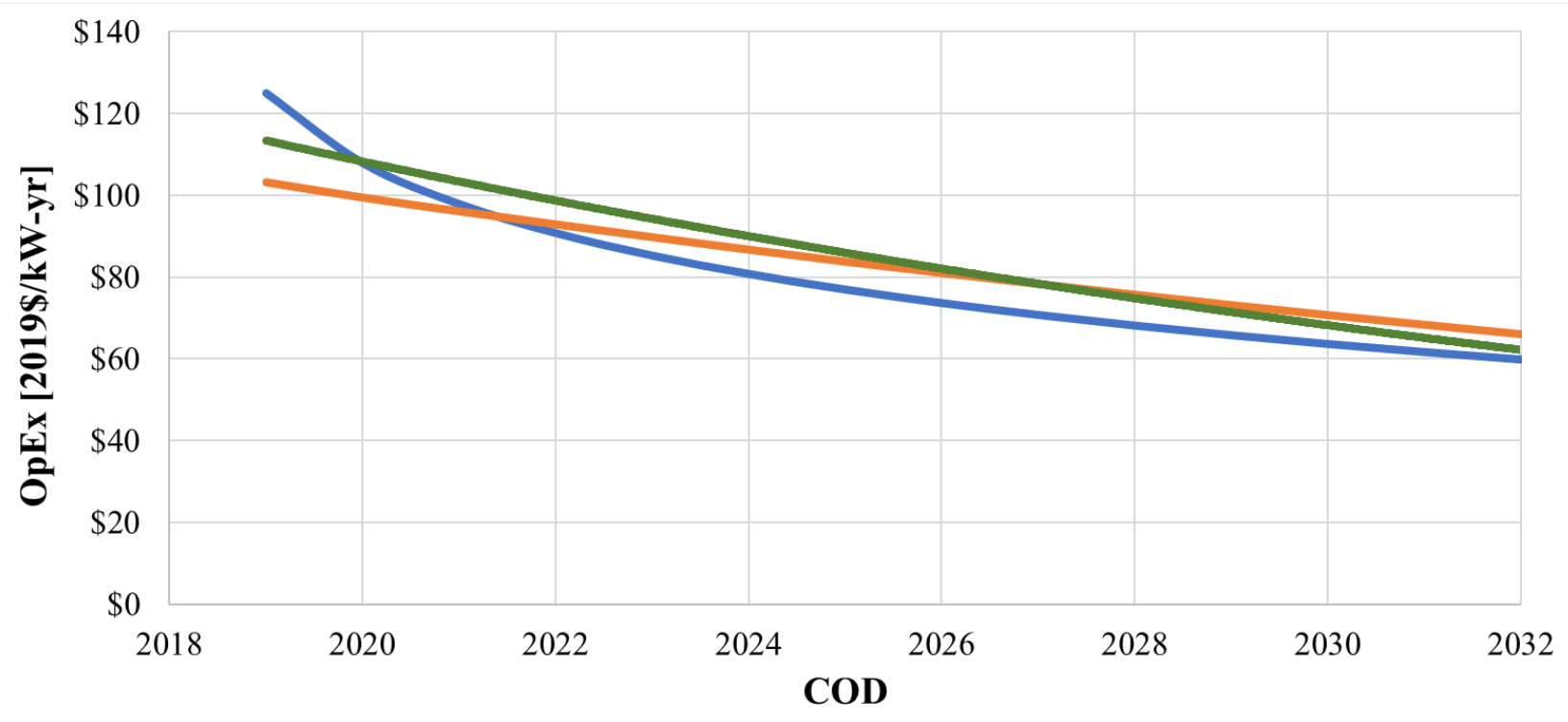

—This Study —2019-2020 IRP — Musial et al. (2016a)

Figure 43. OpEx estimated in this analysis in comparison to two prior California floating offshore wind studies illustrated for the Diablo Canyon study area 


\section{Summary and Conclusions}

In this study, we developed site-specific cost and performance estimates for floating offshore wind to inform California's long-term energy planning. NREL carried out the study with funding from BOEM and in coordination with the CPUC in relation to its IRP process. The analysis focuses on five study areas that represent regions where offshore wind has development potential. The selection of study areas is not the result of a marine spatial planning effort and does not reflect stakeholder engagement or BOEM's leasing process; the study areas were selected for cost and performance evaluation only. Key results for the five study areas include the following:

- Estimated LCOE for a 1,000 MW plant across the five California study areas ranges from \$95/MWh to \$114/MWh for a COD in 2019, declining to \$53-64/MWh by 2032.

- Cost reductions over the study period are driven by increasing turbine size, technology innovation, competition within the supply chain, and learning throughout the industry as experience is gained with floating wind technology and deployment.

- Variation in LCOE between study sites is related to spatial variables, including wind speed, export cable length, distance to port, and water depth. Of the five study sites, Morro Bay has the deepest water and the farthest distances to port and cable landfall, which results in the highest LCOE. The three northern study areas have relatively lower values for all of these parameters, whereas Diablo Canyon has relatively shallower water but greater distances to cable landfall than the northern sites. Higher average wind speeds at the northern sites also contribute significantly to lower LCOE.

This study does not examine the costs of upgrading or building new land-based infrastructure to support offshore wind in California. Gaining access to the strong resource potential on the north coast will require significant investments in the bulk transmission system. Developing a new floating wind industry in California will require port upgrades and new vessels capable of building and transporting the types of floating substructures and turbines at the scale being developed. This study does not include a consideration of the policy, market, and regulatory factors that may create demand for offshore wind energy within state or regional power markets. 


\section{Key Limitations and Future Work}

Key limitations and caveats associated with ORCA modeling are discussed in detail in Beiter et al. (2016). These limitations and caveats relate to the general uncertainties associated with the availability of cost data, the timing of expected innovation (and associated cost reduction) trajectories, and macroeconomic factors (e.g., commodity prices, exchange rates). Some additional caveats associated with this analysis and the California modeling assumptions include the following:

- Study areas were chosen only for the purpose of cost modeling. This study does not represent a stakeholder engagement or a marine spatial planning effort to create wind energy areas under BOEM's leasing process, and the hypothetical sites have not been vetted by ocean user communities. This study also does not consider environmental resources or related laws.

- Bulk transmission expansion and land-based substation upgrades (and their costs) are not considered in this analysis. It is expected that major transmission expansion is needed for commercial-scale offshore wind to interconnect with the grid in California, particularly in the northern part of the state. The central coast has better grid connection resources. Major upgrades to the bulk transmission systems will require significant investments but the allocation of those costs have not been determined. Conversely, some grid system costs may potentially be avoided by using offshore wind development to reduce congestion in some locations. Assessing the costs of major bulk transmission expansion is not trivial and the need to accurately capture development and permitting timelines is beyond the scope of this study.

- In this analysis, we modeled a commercial-scale, 1,000-MW floating offshore wind farm for projects with a COD between 2019 and 2032. Today, there are only pilot-scale floating offshore wind projects with up to $30 \mathrm{MW}$ of capacity. Continued upscaling of plant size and turbine rating in combination with an expansion of the supply chain are needed to obtain the costs modeled in this analysis.

- Local supply and logistical solutions along the Pacific Coast (e.g., port upgrades and vessel capabilities) are assumed to be available. The costs associated with incentivizing and developing such a supply chain are not reflected in the LCOE estimated in this study.

- This analysis is based on semisubmersible substructures, but other floating substructure technology types could be suitable over the modeled time frame.

- Some of the price and cost data used for this analysis are only approximations to project costs. For instance, the strike prices from U.S. and European offshore wind procurement auctions are for projects that have not yet started commercial operation (or reached their financial investment date). It is not known how many of these projects will commence operation and if they can be commissioned for costs lower than the reported bid prices.

- Common elements between floating and fixed-bottom offshore wind systems may not translate directly at the same cost (e.g., turbines may need some customization before installing them on a floating platform). Some costs may change from fixed-bottom to floating systems but are not accounted for in this analysis.

- Floating cost assumptions do not include an Atlantic-to-Pacific adjustment. The supply chains in the Pacific may have different constraints and advantages, such as better access to Asian markets, that have not been accounted for. 
- Turbine growth may be hindered by unforeseen technology issues. For example, the development of 15-MW wind turbines is technologically challenging, and although prototypes of this size are likely under development their timeline for commercialization is uncertain.

- Technology assumptions regarding turbine scaling and array spacing are conservative, which have likely resulted in lower capacity factors (gross and net) than what are possible. Optimization around these parameters as well as the possibility of larger turbines than those modeled could further lower the cost estimates herein.

Future research is needed to further validate assumptions of this study, particularly to evaluate the degree to which learning and supply chain expertise from the U.S. Atlantic coast and Asia (and the fixed-bottom industry) can be leveraged for building a robust floating offshore wind supply chain along the Pacific coast. As more data become available about the evolving technology and cost trajectory of the global and U.S. floating wind industry, costs will need to be further calibrated. Additionally, a comprehensive evaluation of offshore wind as a new generating resource in California will need to consider the costs and the complementarity of the technology's production profile with the future power system in CAISO. Some evidence exists (e.g., Douville et al. 2020; Energy and Environmental Economics 2019) that suggests offshore wind energy could be complementary to the existing solar and land-based energy supply because the resource has different diurnal characteristics. Another area to explore could be the contribution of offshore wind to system resiliency and reliability (e.g., by injecting power directly into coastal load centers while power lines further inland may need to be curtailed because of wildfire risks). Further work will have to assess these benefits to the energy system and evaluate the cost of bulk transmission at sites where offshore wind is considered.

Offshore wind may play a significant role in helping California reach its goal of $100 \%$ of electricity being from renewable and zero-carbon resources by 2045 . Future studies should be conducted to assess the integration of offshore wind in harmony with other renewable energy sources and to determine the optimal capacity of offshore wind in California's $100 \%$ renewable energy mix. 


\section{References}

4C Offshore. 2020. "4COffshore Monthly Reports (Accessed through Subscription Services)." https://www.4coffshore.com/.

Annoni, Jennifer, Paul Fleming, Andrew Scholbrock, Jason Roadman, Scott Dana, Christiane Adcock, Fernando Porte-Angel, Florian Haizmann, and David Schlipf. 2018. "Analysis of control-oriented wake modeling tools using lidar field results." Wind Energy Science, November. https://doi.org/10.5194/wes-3-819-2018.

Barter, Garrett E., Amy Robertson, and Walter Musial. 2020. "A Systems Engineering Vision for Floating Offshore Wind Cost Optimization.” Renewable Energy Focus 34 (September): 116. https://doi.org/10.1016/j.ref.2020.03.002.

Beiter, P., N. Vincent, and O. Ma. 2018. "2016 Renewable Energy Grid Integration Data Book." Data Book DOE/GO-102018-5081. U.S. Department of Energy Office of Energy Efficiency and Renewable Energy. https://www.nrel.gov/docs/fy18osti/71151.pdf.

Beiter, P., W. Musial, L. Kilcher, M. Maness, and A. Smith. 2017. An Assessment of the Economic Potential of Offshore Wind in the United States from 2015 to 2030 (Technical Report). NREL/TP-6A20-67675. National Renewable Energy Laboratory (NREL). https://www.nrel.gov/docs/fy17osti/67675.pdf.

Beiter, P., W. Musial, A. Smith, L. Kilcher, R. Damiani, M. Maness, S. Sirnivas, et al. 2016. A Spatial-Economic Cost-Reduction Pathway Analysis for U.S. Offshore Wind Energy Development from 2015-2030 (Technical Report). NREL/TP-6A20-66579. Golden, CO: National Renewable Energy Laboratory. https://www.nrel.gov/docs/fy16osti/66579.pdf.

Beiter, P., P. Spitsen, W. Musial, and E. Lantz. 2019. The Vineyard Wind Power Purchase Agreement: Insights for Estimating Costs of U.S. Offshore Wind Projects (Technical Report). NREL/TP-5000-72981. Golden, CO: National Renewable Energy Laboratory. https://www.nrel.gov/docs/fy19osti/72981.pdf.

Bleeg, James, Mark Purcell, Renzo Ruisi, and Elizabeth Traiger. 2018. Wind Farm Blockage and the Consequences of Neglecting Its Impact on Energy Production. Energies 11 (6): 1609. https://www.mdpi.com/1996-1073/11/6/1609.

Buchsbaum, L. 2018. "Floating Offshore Wind Farms Exploit a Great Energy Resource.” July 31, 2018. https://www.powermag.com/floating-offshore-wind-farms-exploit-a-great-energyresource/.

Bureau of Ocean Energy Management (BOEM). 2018. "California Offshore Renewable Energy.” BOEM California Intergovernmental Renewable Energy Task Force. https://www.boem.gov/sites/default/files/renewable-energy-program/StateActivities/CA/BOEM-Offshore-Renewables-Factsheet--02-22-17.pdf.

_. 2020a. "California Activities." https://www.boem.gov/california. . 2020b. "Nominations." https://www.boem.gov/renewable-energy/stateactivities/nominations- 0 .

—. 2020c. "Regional Proposals." https://www.boem.gov/renewable-energy/stateactivities/regional-proposals. 
California Energy Commission. 2020a. "Electric Generation Capacity and Energy." https://www.energy.ca.gov/data-reports/energy-almanac/california-electricity-data/electricgeneration-capacity-and-energy.

_. 2020b. "California Offshore Renewable Energy." 17-MISC-01. https://efiling.energy.ca.gov/GetDocument.aspx? $\mathrm{tn}=234009 \&$ DocumentContentId=66829.

California Public Utility Commission (CPUC). 2019a. "Inputs and Assumptions: 2019-2020 Integrated Resource Planning."

https://www.cpuc.ca.gov/uploadedFiles/CPUCWebsite/Content/UtilitiesIndustries/Energy/E nergyPrograms/ElectPowerProcurementGeneration/irp/2018/Inputs\%20\%20Assumptions\% 202019-2020\%20CPUC\%20IRP 20191106.pdf.

_. 2019b. "2019-20 IRP: Proposed Reference System Plan." https://www.cpuc.ca.gov/uploadedFiles/CPUCWebsite/Content/UtilitiesIndustries/Energy/E nergyPrograms/ElectPowerProcurementGeneration/irp/2018/2019\%20IRP\%20Proposed\%2 0Reference\%20System\%20Plan_20191106.pdf.

_ 2020. "Integrated Resource Plan and Long Term Procurement Plan (IRP-LTPP)." 2020. https://www.cpuc.ca.gov/irp/.

Cohen, S., J. Becker, D. Bielen, M. Brown, W. Cole, K. Eurek, W. Frazier, et al. 2019. Regional Energy Deployment System (ReEDS) Model Documentation: Version 2018 (Technical Report). NREL/TP-6A20-72023. National Renewable Energy Laboratory. https://www.nrel.gov/docs/fy19osti/72023.pdf.

Collier, R., S. Hull, O. Sawyerr, S. Li, M. Mogadali, D. Mullen, and A. Olson. 2019. California Offshore Wind: Workforce Impacts and Grid Integration. UC Berkeley Labor Center. http://laborcenter.berkeley.edu/pdf/2019/CA-Offshore-Wind-Workforce-Impacts-and-GridIntegration.pdf.

Damiani, R. 2016. JacketSE: An Offshore Wind Turbine Jacket Sizing Tool (Technical Report). NREL/TP-5000-65417. National Renewable Energy Laboratory (NREL). https://www.nrel.gov/docs/fy16osti/65417.pdf.

Daniel, John P, Shu Liu, Eduardo Ibanez, Ken Pennock, Gregory Reed, and Spencer Hanes. 2014. "National Offshore Wind Energy Grid Interconnection Study Final Technical Report." U.S. Department of Energy. https://www.energy.gov/sites/prod/files/2014/08/f18/NOWEGIS\%20Full\%20Report.pdf.

Department of the Interior. 2018. "Federal Register. Commercial Leasing for Wind Power Development on the Outer Continental Shelf (OCS) Offshore California - Call for Information and Nominations (Call)." https://www.boem.gov/sites/default/files/regulations/Federal-Register-Notices/2018/83-FR53096.pdf.

Douville, T., D. Bhatnagar, and R. O'Neil. 2020. Exploring the Grid Value Potential of Offshore Wind Energy in Oregon. OCS Study BOEM 2020-026 PNNL-29935. Pacific Northwest National Laboratory (PNNL). https://www.pnnl.gov/main/publications/external/technical reports/PNNL-29935.pdf. 
Draxl, Caroline, Andrew Clifton, Bri-Mathias Hodge, and Jim McCaa. 2015. "The Wind Integration National Dataset (WIND) Toolkit." Applied Energy 151 (1 August 2015): 35566. https://doi.org/10.1016/j.apenergy.2015.03.121.

Energy and Environmental Economics (E3). 2019. The Economic Value of Offshore Wind Power in California. https://www.ethree.com/wp-content/uploads/2019/09/2019-08-08 E3-CastleWind-Offshore-Wind-Value-Report-FINAL.pdf.

Feldman, D., M. Bolinger, and P. Schwabe. 2020. Current and Future Costs of Renewable Energy Project Finance Across Technologies (Technical Report). NREL/TP-6A20-76881. Golden, CO: National Renewable Energy Laboratory (NREL). https://www.nrel.gov/docs/fy20osti/76881.pdf.

Filippelli, Matthew. 2019. "IEC 61400-15 Standard - Progress Update and Call for Participation." Presented at the AWEA Wind Resource \& Project Energy Assessment Conference, Renton, Washington, September. https://zenodo.org/communities/iec 61400$15 /$ ?page $=1 \&$ size $=20$.

Gaertner, Evan, Jennifer Rinker, Latha Sethuraman, Frederik Zahle, Benjamin Anderson, Garrett Barter, Nikhar Abbas, et al. 2020. "Definition of the IEA 15 MW Offshore Reference Wind Turbine.” International Energy Agency. https://www.nrel.gov/docs/fy20osti/75698.pdf.

General Electric. 2018. "GE Announces Haliade-X, the World's Most Powerful Offshore Wind Turbine.” March 1, 2018. https://www.ge.com/news/press-releases/ge-announces-haliade-Xworlds-most-powerful-offshore-wind-turbine.

Gilman, P., B. Maurer, L. Feinberg, A. Duerr, L. Peterson, W. Musial, P. Beiter, et al. 2016. National Offshore Wind Strategy: Facilitating the Development of the Offshore Wind Industry in the United States. DOE/GO-102016-4866 7483. U.S. Department of Energy Office of Energy Efficiency and Renewable Energy. doi:10.2172/1325403.

Global Wind Energy Council. 2020. “GWEC Launches Task Force to Drive Global Growth of Floating Offshore Wind.” https://gwec.net/gwec-launches-task-force-to-drive-globalgrowth-of-floating-offshore-wind/.

Guillet, Jerome. 2018. "Who Will Fund U.S. Offshore Wind - and on What Terms?" Teaneck, New Jersey (U.S.). https://green-giraffe.eu/presentations/who-will-fund-us-offshore-wind$\% \mathrm{E} 2 \% 80 \% 93$-and-what-terms.

Hannon, M., E. Topham, J. Dixon, D. McMillan, and M. Collu. 2019. “Offshore Wind, Ready to Float? Global and UK Trends in the Floating Offshore Wind Market." University of Strathclyde and DNV GL. https://brandcentral.dnvgl.com/fr/gallery/10651/others/694b3feb674e460198df6db6ba0038 61/694b3feb674e460198df6db6ba003861_low.pdf?utm_campaign=EN_Publication_Autore sponder_V2_PDF\&utm_medium=email\&utm_source=Eloqua.

Hundleby, Giles, Kate Freeman, Andy Logan, and Ciaran Frost. 2017. "Floating Offshore: 55 Technology Innovations That Will Have Greater Impact on Reducing the Cost of Electricity from European Floating Offshore Wind Farms.” KiC InnoEnervy and BVG Associates. http://www.innoenergy.com/new-floating-offshore-wind-report-55-technology-innovationsthat-will-impact-the-lcoe-in-floating-offshore-wind-farms/. 
Jacobson, A., and M. Severy. 2020. "Electricity Transmission Challenges and Alternatives for Offshore Wind in Northern California." Presented at the Presentation to Western Electricity Coordinating Council, Environmental Data Task Force, July 24.

https://www.wecc.org/Administrative/Schatz\%20\%20NorthCoast_OffshoreWind_Transmission_July\%202020.pdf.

Junginger, Martin, Atse Louwen, Nilo Gomez Tuya, David de Jager, Ernst van Zuijlen, and Michael Taylor. 2019. "Offshore Wind Energy." In Technological Learning in the Transition to a Low-Carbon Energy System, 1st ed., 103-17. Academic Press.

King, Jennifer, Paul Fleming, Ryan King, Luis A. Martínez-Tossas, Christopher Bay, Rafael Mudafort, and Eric Simley. 2020. "Controls-Oriented Model for Secondary Effects of Wake Steering." Wind Energy Science Discussions, February. https://doi.org/10.5194/wes-2020-3.

Louwen, Atse, and Juliana Subtil Lacerda. 2019. "The Experience Curve: Concept, History, Methods, and Issues." In Technological Learning in the Transition to a Low-Carbon Energy System, 1st ed., 9-31. Academic Press.

Maness, M., B. Maples, and A. Smith. 2017. NREL Offshore Balance-of-System Model (Technical Report). National Renewable Energy Laboratory (NREL). NREL/TP-6A2066874. https://www.nrel.gov/docs/fy17osti/66874.pdf.

Manitoba Hydro International. 2020. "PSCAD."https://www.pscad.com/software/pscad/overview.

MHI Vestas. 2018. "Vineyard Wind Selects MHI Vestas as Preferred Supplier for First LargeScale Offshore Wind Project in the United States.” November 27, 2018. http://www.mhivestasoffshore.com/vineyard-wind-selects-mhi-vestas-as-preferred-supplier.

Musial, W., P. Beiter, and J. Nunemaker. 2020a. Cost of Floating Offshore Wind Energy Using New England Aqua Ventus Concrete Semisubmersible Technology (Technical Report). NREL/TP-5000-75618. National Renewable Energy Laboratory (NREL). https://www.nrel.gov/docs/fy20osti/75618.pdf.

Musial, Walter, Philipp Beiter, Paul Spitsen, Jake Nunemaker, Vahan Gevorgian, Aubryn Cooperman, Rob Hammond, and Matt Shields. 2020b. 2019 Offshore Wind Technology Data Update (Technical Report). National Renewable Energy Laboratory (NREL). NREL/TP-5000-77411. https://www.nrel.gov/docs/fy21osti/77411.pdf.

Musial, W., P. Beiter, J. Nunemaker, D. Heimiller, J. Ahmann, and J. Busch. 2019a. Oregon Offshore Wind Site Feasibility and Cost Study. NREL/TP-5000-74597. National Renewable Energy Laboratory (NREL). https://www.nrel.gov/docs/fy20osti/74597.pdf.

Musial, W., P. Beiter, P. Spitsen, and J. Nunemaker. 2019b. 2018 Offshore Wind Technologies Market Report (Technical Report). Golden, CO: National Renewable Energy Laboratory. https://www.energy.gov/eere/wind/downloads/2018-offshore-wind-market-report.

Musial, W., P. Beiter, S. Tegen, and A. Smith. 2016a. Potential Offshore Wind Energy Areas in California: An Assessment of Locations, Technology, and Costs (Technical Report). NREL/TP-5000-67414. National Renewable Energy Laboratory (NREL). https://www.boem.gov/sites/default/files/environmental-stewardship/EnvironmentalStudies/Pacific-Region/Studies/BOEM-2016-074.pdf. 
Musial, W., D. Heimiller, P. Beiter, G. Scott, and C. Draxl. 2016b. 2016 Offshore Wind Energy Resource Assessment for the United States (Technical Report).NREL/TP-5000-66599. Golden, CO: National Renewable Energy Laboratory. https://www.nrel.gov/docs/fy16osti/66599.pdf.

Musial, W., and B. Ram. 2010. Large-Scale Offshore Wind Power in the United States (Technical Report). National Renewable Energy Laboratory (NREL). NREL/TP-50040745. https://www.nrel.gov/docs/fy10osti/40745.pdf.

National Renewable Energy Laboratory (NREL). 2019a. "2018 Annual Technology Baseline.” Golden, CO: National Renewable Energy Laboratory (NREL). https://atb.nrel.gov/electricity/2018/index.html.

—. 2019b. "FLORIS. Version 1.1.7." https://github.com/wisdem/floris. 2020. "Wind Integration National Dataset Toolkit.” https://www.nrel.gov/grid/windtoolkit.html.

NREL. 2020. Offshore Renewable Balance-of-System Installation Tool (ORBIT) (version 0.5.0). National Renewable Energy Laboratory (NREL). https:/github.com/WISDEM/ORBIT.

Nunemaker, Jake, Matt Shields, Robert Hammond, and Patrick Duffy. 2020. ORBIT: Offshore Renewables Balance-of-System and Installation Tool. National Renewable Energy Laboratory. NREL/TP-5000-77081. https://www.nrel.gov/docs/fy20osti/77081.pdf.

Nygaard, Nicolai. "Systematic Quantification of Wake Model Uncertainty." Paper presented at the EWEA Offshore Conference, Copenhagen, Denmark, March 2015.

Optis, M., A. Rybchuk, N. Bodini, M. Rossol, and W. Musial. 2020. 2020 Offshore Wind Resource Assessment for the California Pacific Outer Continental Shelf (Technical Report). National Renewable Energy Laboratory. NREL/TP-5000-77642. https://www.nrel.gov/docs/fy21osti/77642.pdf.

Pietermen, R., H. Braam, T. Obdam, L. Rademakers, and T. van der Zee. 2011. "Optimization of Maintenance Strategies for Offshore Wind Farms." Energy Center of the Netherlands (ECN). http://www.ecn.nl/docs/library/report/2011/m11103.pdf.

Porter, Aaron, and Shane Phillips. 2016. "Determining the Infrastructure Needs to Support Offshore Floating Wind and Marine Hydrokinetic Facilities on the Pacific West Coast and Hawaii." OCS Study BOEM 2016-011. https://www.boem.gov/sites/default/files/environmental-stewardship/EnvironmentalStudies/Pacific-Region/Studies/BOEM-2016-011.pdf.

Shields, M., and J. Nunemaker. 2020. "Process-Based Balance-of-System Cost Modeling for Offshore Wind Power Plants in the United States." Preprint (Conference Paper, NAWEA/WindTech 2019) NREL/CP-5000-74933. National Renewable Energy Laboratory (NREL). https://www.nrel.gov/docs/fy20osti/74933.pdf.

Short, W., D. Packey, and T. Holt. 1995. A Manual for the Economic Evaluation of Energy Efficiency and Renewable Energy Technologies (Technical Report). NREL/TP-462-5173. National Renewable Energy Laboratory (NREL). https://www.nrel.gov/docs/legosti/old/5173.pdf. 
Shreve, D., and R. Kragelund. 2020. "Foresight 20/20: Onshore \& Offshore Wind." https://www.woodmac.com/our-expertise/focus/Power--Renewables/wind-foresight2020/?utm_source $=$ gtm\&utm medium $=$ article\&utm_campaign=wmpr_fs2020wind.

Siemens Gamesa. 2020. "Powered by Change: Siemens Gamesa Launches 14 MW Offshore Direct Drive Turbine with 222-Meter Rotor." May 19, 2020. https://www.siemensgamesa.com/newsroom/2020/05/200519-siemens-gamesa-turbine-14222-dd.

Smith, Aaron, Tyler Stehly, Walter Musial, and Jake Nunemaker. 2015. 2014-2015 Offshore Wind Technologies Market Report (Technical Report). Golden, CO: National Renewable Energy Laboratory. https://www.nrel.gov/docs/fy15osti/64283.pdf.

Stehly, T., and P. Beiter. 2019. 2018 Cost of Wind Energy Review (Technical Report). National Renewable Energy Laboratory (NREL). NREL/TP-5000-74598. https://www.nrel.gov/docs/fy20osti/74598.pdf.

U.S. Department of Transportation, Bureau of Transportation Statistics. 2020. "Tonnage of Top 50 U.S. Water Ports. Ranked by Total Tons.” January 30, 2020. https://www.bts.gov/content/tonnage-top-50-us-water-ports-ranked-total-tons.

U.S. Energy Information Administration (EIA). 2020. "State Electricity Profiles." https://www.eia.gov/electricity/state/.

Valpy, Bruce, and Philip English. 2014. Future Renewable Energy Costs: Offshore Wind. BVG Associates. https://eit.europa.eu/sites/default/files/KIC_IE_OffshoreWind_anticipated_innovations_imp act.pdf.

Valpy, Bruce, Giles Hundleby, Kate Freeman, Alun Roberts, and Andy Logan. 2017. Future Renewable Energy Costs: Offshore Wind. BVG Associates. https://bvgassociates.com/wpcontent/uploads/2017/11/InnoEnergy-Offshore-Wind-anticipated-innovations-impact2017_A4.pdf

Walker, Keith, Neil Adams, Brian Gribben, Breanne Gellatly, Nicolai Nygaard, Andrew Henderson, Miriam Marchante Jimémez, et al. 2015. "An Evaluation of the Predictive Accuracy of Wake Effects Models for Offshore Wind Farms." Wind Energy, July. https://onlinelibrary.wiley.com/doi/full/10.1002/we.1871.

Weber, C. 2020. "Making Floating Wind Bankable.” April 23, 2020. https://greengiraffe.eu/article/making-floating-wind-bankable.

Wiser, Ryan, Karen Jenni, Joachim Seel, Erin Baker, Maureen Hand, Eric Lantz, and Aaron Smith. 2016. "Expert Elicitation Survey on Future Wind Energy Costs." Nature Energy 1 (September). https://www.nature.com/articles/nenergy2016135.

Yang, Shimeng, Soeren Lassen, and Daniel Liu. 2019. Offshore Wind Operations and Maintenance Trends. Wood Mackenzie Power \& Renewables. https://www.woodmac.com/reports/power-markets-offshore-wind-operations-andmaintenance-trends-2019-301033. 


\section{Appendix A. Derivation of Experience Factors}

An experience curve takes the form:

$$
C_{Q}=C_{1} Q^{b}
$$

where $Q$ is the global cumulative production of the item, $C_{1}$ is the cost of the first unit, $C_{Q}$ is the cost of the $Q^{\text {th }}$ item, and $b$ is the experience parameter (Louwen and Subtil Lacerda 2019). This equation represents an exponentially decreasing curve that realizes more rapid cost reductions during early production stages; it can be expressed as a linear equation by taking the natural logarithm of each side:

$$
\log C_{Q}=\log C_{1}+b \log Q
$$

This formulation allows the experience parameter, $b$, to be estimated by a linear regression between costs and cumulative production.

This analysis considers the relationship between project capital expenditures (CapEx) and the cumulative installed capacity of fixed-bottom projects, which is reported in (Junginger et al.2019). These publicly available data are also controlled for a range of exogenous variables that have the potential to impact CapEx for individual projects but do not represent systematic, industrywide cost reductions. This is accomplished using a multivariate linear regression taking the form:

$$
\log C_{Q}=\log C_{1}+b \log Q+\beta_{1} X_{1}+\beta_{2} X_{2}+\cdots
$$

where $X_{1}, X_{2}$ are the control variables and $\beta_{1}, \beta_{2}$ are the corresponding regression coefficients. By controlling for these variables, the impact of increased global production on CapEx is assessed independently from additional project-specific variables such as turbine rating or plant capacity.

Several statistical checks are implemented in the regression analysis. First, the coefficient of determination, $\mathrm{R}^{2}$, is evaluated to quantify the goodness of fit for a particular set of explanatory variables. Second, the statistical significance of the individual $\beta$ coefficients is determined to evaluate the confidence in the estimation of that particular term; statistical significance of $\mathrm{P}<|\mathrm{t}|$ of 0.05 is desired. Finally, the variance inflation factor (VIF) of each input variable is evaluated to determine the collinearity, or dependence, between the variables; VIF $<4$ is a reasonable measure of independence between the variables.

With the experience parameter, $b$, estimated from the regression analysis, the learning rate, $L R$, is defined as:

$$
L R=1-2^{b}
$$

The learning rate may be interpreted as the percentage decrease in CapEx for each global doubling of cumulative installed capacity. 
The results of the regression analysis are provided in Table A-1 for projects with capacities above 150 megawatts (MW) installed between 2015 and 2019; as described in (Junginger et al. 2019). Although these filters limit the number of data points, they also ensure that only similar commercial-scale projects are being used to extract the learning rate. Control variables for the installation country, turbine rating, plant capacity, water depth, and distance to shore are successively introduced to eliminate these impacts on the derived learning rate. Additional exogenous variables, such as cable length or voltage, were considered but ultimately not included as they either were not reported for several projects or introduced undesirable collinearity into the experience factor. The final set of regression results, which include all of the aforementioned control variables, produce an $\mathrm{R}^{2}$ value of 0.854 (meaning that $85.4 \%$ of the variance in the data is explained by the given variables) with a statistically significant experience factor of $b=-0.182$ with a standard error of \pm 0.07 . This experience factor corresponds to a learning rate of $\mathrm{LR}=11.9 \%$, which is commensurate with reported values in the offshore wind literature.

Table A-1. Multivariate Regression Results for Different Control Variable Scenarios

\begin{tabular}{|c|c|c|c|c|c|c|c|}
\hline & $\begin{array}{l}\text { Cumulativ } \\
\text { e Capacity }\end{array}$ & Country & $\begin{array}{l}\text { Turbine } \\
\text { Rating }\end{array}$ & $\begin{array}{c}\text { Plant } \\
\text { Capacity }\end{array}$ & Depth & $\begin{array}{l}\text { Distance } \\
\text { to Shore }\end{array}$ & $\mathbf{R}^{2}$ \\
\hline$b$ & -0.38 & - & - & - & - & - & \multirow[t]{3}{*}{0.274} \\
\hline $\mathbf{P}>|\mathbf{t}|$ & 0.001 & - & - & - & - & - & \\
\hline VIF & $\mathrm{N} / \mathrm{A}$ & - & - & - & - & - & \\
\hline$b$ & -0.178 & $\begin{array}{l}-0.68- \\
0.153\end{array}$ & - & - & - & - & \multirow[t]{3}{*}{0.814} \\
\hline $\mathbf{P}>|\mathbf{t}|$ & 0.007 & $0-0.434$ & - & - & - & - & \\
\hline VIF & 1.3 & $1.1-1.7$ & - & - & - & - & \\
\hline$b$ & -0.128 & $-0.7-.07$ & -.03 & - & - & - & \multirow[t]{3}{*}{0.822} \\
\hline $\mathbf{P}>|\mathbf{t}|$ & 0.072 & $0-0.6$ & 0.14 & - & - & - & \\
\hline VIF & 1.7 & $1.1-2.1$ & 1.6 & - & - & - & \\
\hline$b$ & -0.126 & $-0.7-.08$ & -0.3 & $-2 e-5$ & - & - & \multirow[t]{3}{*}{0.816} \\
\hline $\mathbf{P}>|\mathbf{t}|$ & 0.076 & $0-0.6$ & 0.147 & 0.9 & - & - & \\
\hline VIF & 2 & $1.4-3.1$ & 1.6 & 2.2 & - & - & \\
\hline$b$ & -0.177 & $-0.6-0.08$ & -.02 & -.0002 & 0.009 & - & \multirow[t]{3}{*}{0.849} \\
\hline $\mathbf{P}>|\mathbf{t}|$ & 0.02 & $0-0.6$ & 0.339 & 0.528 & 0.01 & - & \\
\hline VIF & 2.1 & $1.3-4$ & 1.7 & 2.3 & 2.4 & - & \\
\hline$b$ & $\begin{array}{c}-0.182 \pm \\
.07\end{array}$ & $-0.6-0$ & -0.02 & -.0002 & 0.007 & 0.002 & \multirow[t]{3}{*}{0.854} \\
\hline$P>|t|$ & 0.016 & $0-1$ & 0.32 & 0.52 & 0.04 & 0.18 & \\
\hline VIF & 2.1 & $1.5-4$ & 1.7 & 2.3 & 2.6 & 2.4 & \\
\hline
\end{tabular}

As no commercial-scale floating offshore wind projects currently exist, the experience factors derived from fixed-bottom data are assumed to apply to floating technology. This implicitly assumes that, as the floating industry matures, developers, original equipment manufacturers, and service providers (the majority of whom will come from the fixed-bottom industry) will apply learning at the same rate that they have accumulated on fixed-bottom projects, and that the floating industry will be able to avoid the exogenous market drivers that led to costs increasing until 2014 (Smith et al. 2015). As this is a broad assumption about the experience curves of the 
floating industry, the most conservative bound of the fixed-bottom experience factor $(b=-0.182$ +0.07 ) is used to model the learning rate for the floating industry, resulting in a value of LR $=$ $7.5 \%$. Although subject to limitations, this approach provides a method for future cost reductions to be linked with anticipated deployment scenarios - as the global cumulative capacity of floating projects grows, additional cost savings will be realized.

The key caveats and limitations of this approach are:

- The filtered data include only 35 projects, an inherently small sample size for the regression analysis.

- CapEx costs come from public data and quoted values from developers, and likely contain bias. It may also be possible that different developers include various cost components in their quoted CapEx values.

- Learning rates (particularly with these small sample sizes) are adversely affected by modeling price instead of cost, fitting models to a limited number of cumulative doublings of a product, and several other methodological issues (Junginger et al. 2019).

- Learning curves are a top-down modeling approach and cannot explain the relative impact of technological innovation, supply chain maturity, changing input prices, or improved manufacturing on total CapEx reduction.

- The extension of fixed-bottom to floating technologies assumes the same learning rate for the industry in both cases without supporting data. For instance, the derived learning rate encompasses the development of both fixed-bottom foundations and turbines. The floating industry will need to develop experience and supply chains for new platform topologies but will not require the same amount of learning for the turbines, which will be closely related to fixed-bottom machines.

A learning curve incorporates the specific impact of a multitude of technological innovations in addition to the experiential learning and improved supply efficiencies. A comprehensive list of potentially impactful innovations has been developed by Valpy et al. (2017) and Valpy and English (2014). These are not explicitly modeled in the learning curve approach taken in this analysis but are listed in Table A-2 to provide context for the reader. 
Table A-2. Examples of Technological Innovations That Can Contribute to Capital Expenditure and Opertaional Expenditure (OpEx) Cost Reductions. Adapted from Valpy et al. (2017) and Valpy and English

(2014)

\begin{tabular}{|c|c|}
\hline Category & Innovation Examples \\
\hline \multirow[t]{5}{*}{ Improved site understanding and data } & Introduction of floating meteorological stations \\
\hline & $\begin{array}{l}\text { Greater level of data for geophysical and geotechnical } \\
\text { surveys }\end{array}$ \\
\hline & $\begin{array}{l}\text { Introduction of multivariable optimization of array } \\
\text { layout }\end{array}$ \\
\hline & $\begin{array}{l}\text { Introduction of reduced cable burial depth } \\
\text { requirements }\end{array}$ \\
\hline & Avian/wildlife surveys \\
\hline \multirow[t]{8}{*}{ Blade improvements } & Higher blade tip speed \\
\hline & Improvements in blade aerodynamics \\
\hline & Introduction of active flow control \\
\hline & $\begin{array}{l}\text { Improvements in blade design standards and } \\
\text { processes }\end{array}$ \\
\hline & Improvements in blade materials and manufacturing \\
\hline & Optimized floating turbines \\
\hline & Improvements in blade pitch control \\
\hline & Downwind rotors \\
\hline \multirow[t]{3}{*}{ Improved understanding of wind resource } & Improved atmospheric modeling \\
\hline & Introduction of on-site inflow wind measurements \\
\hline & Bankable resource characterization \\
\hline \multirow[t]{7}{*}{ Improved drivetrains } & $\begin{array}{l}\text { Improvements in mechanical geared high-speed } \\
\text { drivetrains }\end{array}$ \\
\hline & Introduction of midspeed drivetrains \\
\hline & Introduction of direct-drive drivetrains \\
\hline & Introduction of superconducting drivetrains \\
\hline & $\begin{array}{l}\text { Introduction of continuously variable transmission } \\
\text { drivetrains }\end{array}$ \\
\hline & Improved drivetrain testing \\
\hline & Light-weight generators \\
\hline \multirow{5}{*}{$\begin{array}{l}\text { Substructure and foundation } \\
\text { improvements }\end{array}$} & Holistic tower/substructure design \\
\hline & Improved materials (i.e., corrosion resistance) \\
\hline & Coupled transition piece/substructure design \\
\hline & Float-out systems \\
\hline & Improved design tools \\
\hline \multirow[t]{4}{*}{ Array cable system improvements } & Higher operating voltages \\
\hline & Improved array cable materials \\
\hline & DC collection systems \\
\hline & Dynamic cables \\
\hline \multirow[t]{4}{*}{ Export infrastructure improvements } & Improved materials in power electronics \\
\hline & $\begin{array}{l}\text { Design of holistic high-voltage direct current offshore } \\
\text { transmission system }\end{array}$ \\
\hline & Improved export cable materials \\
\hline & Dynamic cables \\
\hline \multirow[t]{3}{*}{ Assembly and installation efficiency } & $\begin{array}{l}\text { Improvements in the range of working conditions for } \\
\text { support structure installation }\end{array}$ \\
\hline & $\begin{array}{l}\text { Improvements in the range of lifting conditions for } \\
\text { blades }\end{array}$ \\
\hline & $\begin{array}{l}\text { Introduction of feeder arrangements in the installation } \\
\text { of turbines }\end{array}$ \\
\hline
\end{tabular}




\begin{tabular}{|c|c|}
\hline Category & Innovation Examples \\
\hline & Methods for reducing marine life disturbance \\
\hline \multirow[t]{3}{*}{ Improved OpEx strategies } & $\begin{array}{l}\text { Improvements in operation and maintenance strategy } \\
\text { for far-from-shore projects }\end{array}$ \\
\hline & $\begin{array}{l}\text { Improvements in personnel transfer from base to } \\
\text { turbine location }\end{array}$ \\
\hline & $\begin{array}{l}\text { Improvements in personnel access from transfer } \\
\text { vessel to turbine }\end{array}$ \\
\hline \multirow[t]{4}{*}{ Improved OpEx data and controls } & Improvements in weather forecasting \\
\hline & Introduction of turbine condition-based maintenance \\
\hline & Logistics improvements \\
\hline & Remote sensing and diagnostics \\
\hline \multirow[t]{5}{*}{ Advanced control strategies } & Introduction of turbine condition-based maintenance \\
\hline & Wake steering \\
\hline & Better load management during operation \\
\hline & Adaptive site control for optimization \\
\hline & Extreme load mitigation \\
\hline
\end{tabular}




\section{Appendix B. Additional Results}

Table B-1. Detailed Capital Expenditure Breakdown for the Five Study Areas (2019)

\begin{tabular}{|c|c|c|c|c|c|c|}
\hline Item & $\begin{array}{l}\text { Site 1: } \\
\text { Morro } \\
\text { Bay }\end{array}$ & $\begin{array}{l}\text { Site 2: } \\
\text { Diablo } \\
\text { Canyon }\end{array}$ & $\begin{array}{c}\text { Site } 3: \\
\text { Humboldt }\end{array}$ & $\begin{array}{c}\text { Site 4: } \\
\text { Cape } \\
\text { Mendocino }\end{array}$ & $\begin{array}{c}\text { Site 5: } \\
\text { Del } \\
\text { Norte }\end{array}$ & $\begin{array}{c}\text { Analysis } \\
\text { Domain } \\
\text { Mean }\end{array}$ \\
\hline Tower [\$/kilowatt (kW)] & 182 & 182 & 182 & 182 & 182 & 182 \\
\hline $\begin{array}{l}\text { Rotor nacelle assembly } \\
{[\$ / \mathrm{kW}]}\end{array}$ & 1,116 & 1,116 & 1,116 & 1,116 & 1,116 & 1,116 \\
\hline TURBINE SUPPLY [\$/kW] & 1,297 & 1, 297 & 1, 297 & 1, 297 & 1, 297 & 1, 297 \\
\hline Substructure $[\$ / k W]$ & 1,235 & 1,235 & 1,235 & 1,235 & 1,235 & 1,235 \\
\hline $\begin{array}{l}\text { SUPPORT STRUCTURE } \\
\text { [\$/kW] }\end{array}$ & 1,235 & 1,235 & 1,235 & 1,235 & 1,235 & 1,235 \\
\hline $\begin{array}{l}\text { Port, staging, logistics, and } \\
\text { fixed costs }[\$ / \mathrm{kW}]\end{array}$ & 44 & 44 & 44 & 44 & 44 & 44 \\
\hline Turbine install [\$/kW] & 197 & 182 & 147 & 149 & 160 & 157 \\
\hline Substructure install $[\$ / k W]$ & 92 & 80 & 77 & 74 & 79 & 71 \\
\hline $\begin{array}{l}\text { TOTAL INSTALLATION } \\
\text { [\$/kW] }\end{array}$ & 333 & 306 & 269 & 267 & 284 & 272 \\
\hline Array cabling $[\$ / k W]$ & 291 & 258 & 275 & 275 & 273 & 256 \\
\hline Export cable $[\$ / \mathrm{kW}]$ & 454 & 487 & 447 & 357 & 455 & 484 \\
\hline Onshore spur line $[\$ / k W]$ & 78 & 78 & 78 & 78 & 69 & 77 \\
\hline $\begin{array}{l}\text { TOTAL ELECTRIC } \\
\text { SYSTEM [\$/kW] }\end{array}$ & 823 & 823 & 800 & 710 & 797 & 817 \\
\hline Development [\$/kW] & 142 & 141 & 139 & 135 & 139 & 140 \\
\hline Lease price $[\$ / \mathrm{kW}]$ & 88 & 88 & 88 & 88 & 88 & 88 \\
\hline Project management $[\$ / k W]$ & 74 & 73 & 72 & 70 & 72 & 72 \\
\hline $\begin{array}{l}\text { BALANCE OF SYSTEM } \\
{[\$ / \mathrm{kW}]}\end{array}$ & 2,694 & 2,666 & 2,602 & 2,505 & 2,615 & 2,624 \\
\hline $\begin{array}{l}\text { Insurance during } \\
\text { construction }[\$ / \mathrm{kW}]\end{array}$ & 46 & 46 & 45 & 44 & 45 & 45 \\
\hline Project completion [\$/kW] & 46 & 46 & 45 & 44 & 45 & 45 \\
\hline Decommissioning $[\$ / k W]$ & 50 & 45 & 39 & 38 & 41 & 39 \\
\hline $\begin{array}{l}\text { Procurement contingency } \\
{[\$ / \mathrm{kW}]}\end{array}$ & 213 & 213 & 211 & 206 & 211 & 212 \\
\hline Install contingency $[\$ / \mathrm{kW}]$ & 100 & 90 & 78 & 77 & 83 & 79 \\
\hline $\begin{array}{l}\text { Construction financing } \\
{[\$ / k W]}\end{array}$ & 191 & 189 & 186 & 181 & 187 & 187 \\
\hline $\begin{array}{l}\text { TOTAL SOFT CAPEX } \\
\text { [\$/kW] }\end{array}$ & 645 & 629 & 603 & 590 & 612 & 607 \\
\hline TOTAL CAPEX & 4,637 & 4,592 & 4,502 & 4,392 & 4,524 & 4,529 \\
\hline
\end{tabular}

Note: Costs are rounded to the nearest dollar. 


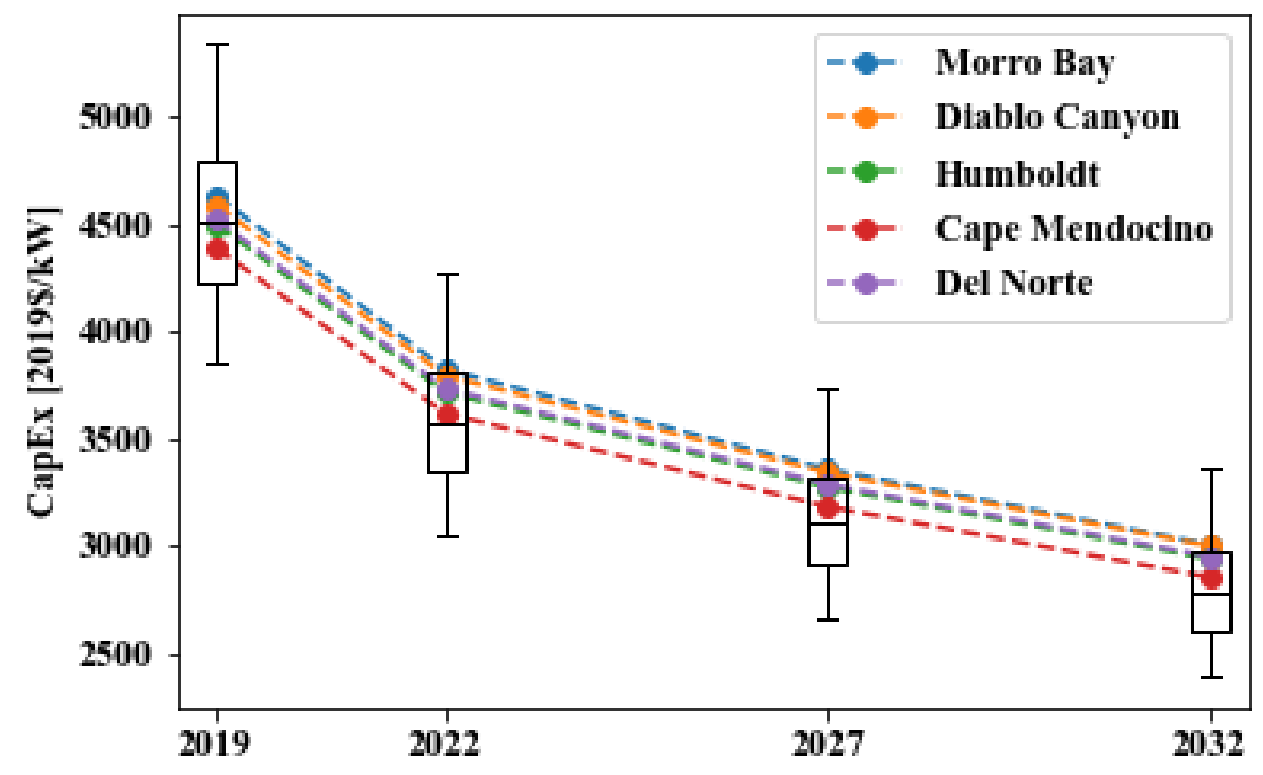

Figure B-1. CapEx results between 2019 and 2032

Note: Box plots indicate the distribution of CapEx across the entire analysis domain

Table B-2. Detailed OpEx Breakdown for the Five Study Areas (2019)

\begin{tabular}{|l|c|c|c|c|c|c|}
\cline { 2 - 7 } \multicolumn{1}{c|}{ Item } & $\begin{array}{c}\text { Site 1: } \\
\text { Morro Bay }\end{array}$ & $\begin{array}{c}\text { Site 2: } \\
\text { Diablo } \\
\text { Canyon }\end{array}$ & $\begin{array}{c}\text { Site 3: } \\
\text { Humboldt }\end{array}$ & $\begin{array}{c}\text { Site 4: Cape } \\
\text { Mendocino }\end{array}$ & $\begin{array}{c}\text { Site 5: } \\
\text { Del } \\
\text { Norte }\end{array}$ & $\begin{array}{c}\text { Analysis } \\
\text { Domain }\end{array}$ \\
\hline Operations $[\$ / \mathrm{kW}-\mathrm{yr}]$ & 30 & 30 & 30 & 30 & 30 & 30 \\
\hline Maintenance $[\$ / \mathrm{kW}-\mathrm{yr}]$ & 93 & 91 & 88 & 93 & 93 & 86 \\
\hline TOTAL OPEX & $\mathbf{1 2 3}$ & 121 & 118 & 122 & 123 & 115 \\
\hline
\end{tabular}

Note: Costs are rounded to the nearest dollar. 


\section{Appendix C. Wind Farm Layouts for COD Years}

The turbine nameplate capacity changes with the commercial operation date (COD) year as described in Section 3.2. This impacts the actual plant layouts for the specific COD years in two ways. First, the power plant is nominally 1,000 megawatts (MW), but this is not evenly divisible by corresponding nameplate capacities: $8,10,12$, and $15 \mathrm{MW}$. This results in cases where the actual plant capacity differs from the nominal plant capacity to maintain discrete numbers of turbines, shown in Table C-1.

Table C-1. Actual Plant Capacity by COD year

\begin{tabular}{|l|l|l|l|}
\hline COD Year & $\begin{array}{l}\text { Turbine Nameplate } \\
\text { Capacity [MW] }\end{array}$ & Number of Turbines & $\begin{array}{l}\text { Actual Plant } \\
\text { Capacity [MW] }\end{array}$ \\
\hline $\mathbf{2 0 1 9}$ & 8 & 125 & 1,000 \\
\hline $\mathbf{2 0 2 2}$ & 10 & 100 & 1,000 \\
\hline $\mathbf{2 0 2 7}$ & 12 & 84 & 1,008 \\
\hline $\mathbf{2 0 3 2}$ & 15 & 67 & 1,005 \\
\hline
\end{tabular}

The second impact appears in the absolute turbine spacing because of the assumption of constant relative spacing between turbines on the square grid described in Section 4.2.2. As the rotor diameter changes with the turbine capacity, the absolute spacing between turbines increases. Plots depicting the plant layouts for different COD years are presented in Figures C-1 through Figure C-4. The dots representing turbines are scaled to represent one turbine rotor diameter for their respective COD years. Note the partial rows where the total number of turbines is not a perfect square. The axes limits are constant to facilitate comparison.

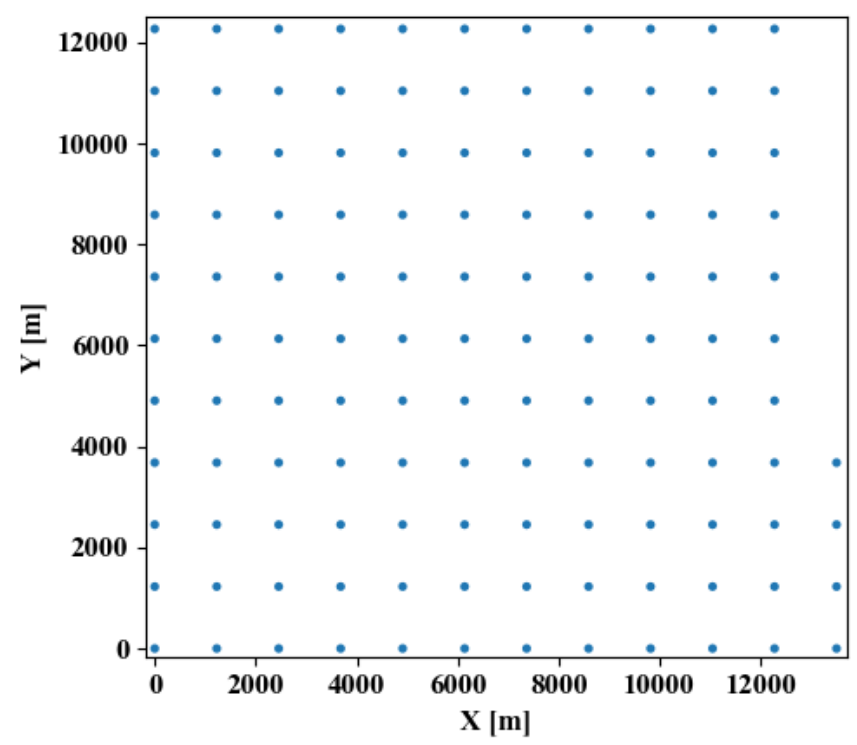

Figure C-1. Plant layout for 2019 COD

Note: Dots representing turbine positions scaled to represent 1 rotor diameter for COD year. 


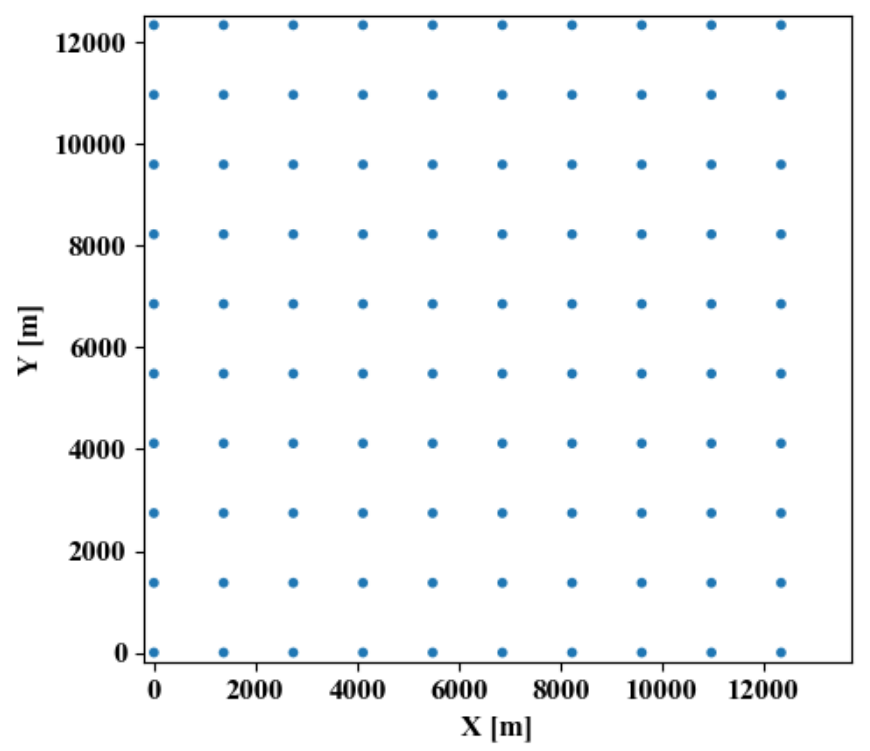

Figure C-2. Plant layout for 2022 COD

Note: Dots representing turbine positions scaled to represent 1 rotor diameter for COD year.

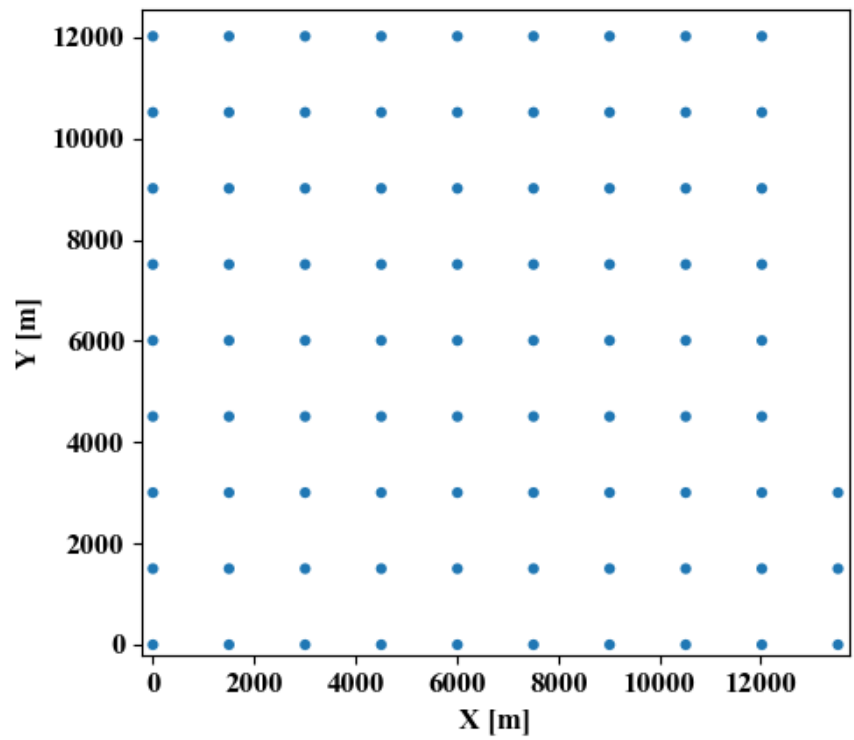

Figure C-3. Plant layout for 2027 COD

Note: Dots representing turbine positions scaled to represent 1 rotor diameter for COD year. 


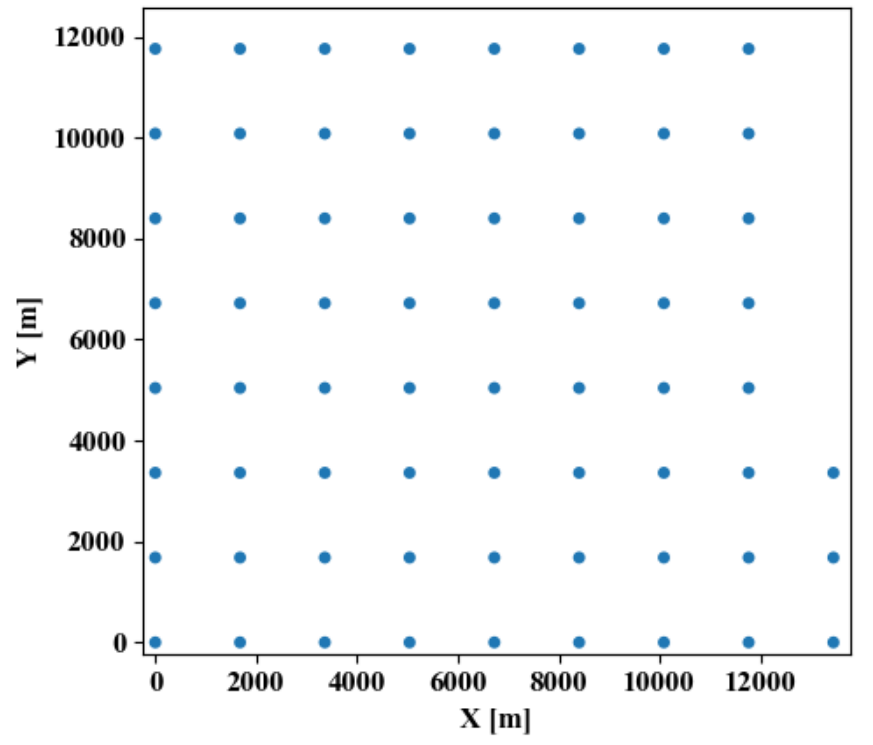

Figure C-4. Plant layout for 2032 COD

Note: Dots representing turbine positions scaled to represent 1 rotor diameter for COD year. 


\section{Appendix D. Wind Turbine Power Curve Tabular Data}

Power curves for the turbines used in this study are included below along with power and thrust coefficients. Note three are scaled versions of the 15-MW reference turbine mentioned above (Gaertner et al. 2020). Power curves have been extended to $30 \mathrm{~m} / \mathrm{s}$ cut-out wind speed.

Table D-1. Tabular Turbine Data

\begin{tabular}{|c|c|c|c|c|c|c|}
\hline $\begin{array}{l}\text { Wind } \\
\text { Speed } \\
{[\mathrm{m} / \mathrm{s}]}\end{array}$ & CP & CT & $\begin{array}{c}\text { 8-MW } \\
\text { (COD } \\
\text { 2019) } \\
\text { Power } \\
{[\mathrm{kW}]}\end{array}$ & $\begin{array}{c}\text { 10-MW } \\
\text { (COD } \\
2022 \text { ) } \\
\text { Power } \\
{[\mathrm{kW}]}\end{array}$ & $\begin{array}{c}\text { 12-MW } \\
\text { (COD } \\
\text { 2027) } \\
\text { Power } \\
{[\mathrm{kW}]}\end{array}$ & $\begin{array}{c}\text { 15-MW } \\
\text { (COD } \\
\text { 2032) } \\
\text { Power } \\
{[\mathrm{kW}]}\end{array}$ \\
\hline 3 & 0.100 & 0.820 & 37 & 47 & 56 & 70 \\
\hline 3.5 & 0.272 & 0.801 & 160 & 200 & 241 & 301 \\
\hline 4 & 0.359 & 0.808 & 316 & 395 & 474 & 593 \\
\hline 4.5 & 0.409 & 0.822 & 512 & 641 & 769 & 961 \\
\hline 4.75 & 0.427 & 0.823 & 629 & 787 & 944 & 1180 \\
\hline 5 & 0.442 & 0.823 & 759 & 949 & 1139 & 1423 \\
\hline 5.25 & 0.453 & 0.831 & 900 & 1125 & 1350 & 1688 \\
\hline 6 & 0.475 & 0.835 & 1411 & 1764 & 2116 & 2645 \\
\hline 6.2 & 0.479 & 0.834 & 1571 & 1963 & 2356 & 2945 \\
\hline 6.4 & 0.483 & 0.832 & 1740 & 2175 & 2610 & 3262 \\
\hline 6.5 & 0.484 & 0.829 & 1828 & 2286 & 2743 & 3428 \\
\hline 6.55 & 0.485 & 0.827 & 1874 & 2342 & 2811 & 3513 \\
\hline 6.6 & 0.486 & 0.825 & 1920 & 2400 & 2880 & 3600 \\
\hline 6.7 & 0.487 & 0.820 & 2014 & 2517 & 3020 & 3775 \\
\hline 6.8 & 0.488 & 0.816 & 2109 & 2637 & 3164 & 3955 \\
\hline 6.9 & 0.489 & 0.811 & 2207 & 2759 & 3311 & 4138 \\
\hline 6.92 & 0.489 & 0.810 & 2227 & 2784 & 3340 & 4176 \\
\hline 6.93 & 0.489 & 0.809 & 2237 & 2796 & 3355 & 4194 \\
\hline 6.94 & 0.489 & 0.808 & 2247 & 2809 & 3370 & 4213 \\
\hline 6.95 & 0.489 & 0.808 & 2257 & 2821 & 3385 & 4231 \\
\hline 6.96 & 0.489 & 0.807 & 2266 & 2833 & 3400 & 4250 \\
\hline 6.97 & 0.489 & 0.807 & 2276 & 2845 & 3415 & 4268 \\
\hline 6.98 & 0.489 & 0.806 & 2286 & 2858 & 3429 & 4287 \\
\hline 6.99 & 0.489 & 0.807 & 2296 & 2870 & 3444 & 4305 \\
\hline 7 & 0.489 & 0.807 & 2306 & 2882 & 3459 & 4324 \\
\hline 7.5 & 0.489 & 0.805 & 2837 & 3546 & 4255 & 5319 \\
\hline 8 & 0.489 & 0.805 & 3443 & 4304 & 5164 & 6455 \\
\hline 8.5 & 0.489 & 0.804 & 4130 & 5162 & 6195 & 7743 \\
\hline 9 & 0.489 & 0.804 & 4902 & 6128 & 7353 & 9192 \\
\hline 9.5 & 0.489 & 0.804 & 5766 & 7207 & 8649 & 10811 \\
\hline 10 & 0.489 & 0.803 & 6725 & 8406 & 10088 & 12609 \\
\hline 10.25 & 0.489 & 0.802 & 7243 & 9054 & 10865 & 13581 \\
\hline 10.5 & 0.489 & 0.802 & 7786 & 9732 & 11679 & 14599 \\
\hline
\end{tabular}




\begin{tabular}{|c|c|c|c|c|c|c|}
\hline $\begin{array}{l}\text { Wind } \\
\text { Speed } \\
{[\mathrm{m} / \mathrm{s}]}\end{array}$ & CP & CT & $\begin{array}{c}\text { 8-MW } \\
\text { (COD } \\
\text { 2019) } \\
\text { Power } \\
{[\mathrm{kW}]}\end{array}$ & $\begin{array}{c}\text { 10-MW } \\
\text { (COD } \\
2022 \text { ) } \\
\text { Power } \\
{[\mathrm{kW}]}\end{array}$ & $\begin{array}{c}\text { 12-MW } \\
\text { (COD } \\
\text { 2027) } \\
\text { Power } \\
{[\mathrm{kW}]}\end{array}$ & $\begin{array}{c}\text { 15-MW } \\
\text { (COD } \\
\text { 2032) } \\
\text { Power } \\
{[\mathrm{kW}]}\end{array}$ \\
\hline 10.6 & 0.487 & 0.769 & 7964 & 9954 & 11945 & 14932 \\
\hline 10.7 & 0.473 & 0.707 & 7964 & 9954 & 11945 & 14932 \\
\hline 10.72 & 0.470 & 0.699 & 7964 & 9954 & 11945 & 14932 \\
\hline 10.74 & 0.468 & 0.690 & 7963 & 9954 & 11945 & 14932 \\
\hline 10.76 & 0.465 & 0.682 & 7963 & 9954 & 11945 & 14931 \\
\hline 10.78 & 0.463 & 0.675 & 7963 & 9954 & 11945 & 14932 \\
\hline 10.784 & 0.462 & 0.673 & 7963 & 9954 & 11945 & 14932 \\
\hline 10.786 & 0.462 & 0.673 & 7963 & 9954 & 11945 & 14932 \\
\hline 10.787 & 0.462 & 0.672 & 7963 & 9954 & 11945 & 14932 \\
\hline 10.788 & 0.462 & 0.672 & 7963 & 9954 & 11945 & 14932 \\
\hline 10.789 & 0.461 & 0.672 & 7963 & 9954 & 11945 & 14932 \\
\hline 10.7895 & 0.461 & 0.671 & 7964 & 9954 & 11945 & 14932 \\
\hline 10.8 & 0.460 & 0.668 & 7963 & 9954 & 11945 & 14932 \\
\hline 10.9 & 0.449 & 0.635 & 8000 & 10000 & 12000 & 15000 \\
\hline 11 & 0.437 & 0.607 & 8000 & 10000 & 12000 & 15000 \\
\hline 12 & 0.337 & 0.426 & 8000 & 10000 & 12000 & 15000 \\
\hline 14 & 0.212 & 0.251 & 8000 & 10000 & 12000 & 15000 \\
\hline 16 & 0.142 & 0.171 & 8000 & 10000 & 12000 & 15000 \\
\hline 18 & 0.100 & 0.118 & 8000 & 10000 & 12000 & 15000 \\
\hline 20 & 0.073 & 0.085 & 8000 & 10000 & 12000 & 15000 \\
\hline 22 & 0.055 & 0.066 & 8000 & 10000 & 12000 & 15000 \\
\hline 24 & 0.042 & 0.052 & 8000 & 10000 & 12000 & 15000 \\
\hline 26 & 0.033 & 0.041 & 8000 & 10000 & 12000 & 15000 \\
\hline 28 & 0.027 & 0.030 & 8000 & 10000 & 12000 & 15000 \\
\hline 30 & 0.022 & 0.020 & 8000 & 10000 & 12000 & 15000 \\
\hline 30.001 & 0 & 0 & 0 & 0 & 0 & 0 \\
\hline
\end{tabular}

